\title{
O Problema de Corte de Estoque Inteiro*
}

\author{
Maria José Pinto
}

Orientador: Prof. Dr. Marcos Nereu Arenales

Dissertação apresentada ao Instituto de Ciências Matemáticas e de Computação da Universidade de São Paulo, como parte dos requisitos para a obtenção do título de Mestre na Área de

Ciências de Computação e Matemática Computacional.

USP - São Carlos

Abril de 1999

- Trabalho realizado com o apoio da Fapesp 
"Para tudo há um tempo, para cada coisa há um momento debaixo dos céus:

tempo para nascer e tempo para morrer;

tempo para plantar e tempo para colher o que foi plantado;

... tempo para chorar e tempo para rir;

... tempo para dar abraços e tempo para apartar-se;

tempo para procurar e tempo para perder;

tempo para guardar e tempo para jogar fora;

tempo para rasgar e tempo para costurar;

tempo para calar e tempo para falar;

tempo para amar e tempo para odiar;

tempo para a guerra e tempo para a paz.

... todas as coisas que Deus faz são boas a seu tempo.

... Assim, eu conclui que nada é melhor para o homem do que alegrar-se e procurar o bem-estar durante sua vida; e que comer, beber e gozar do fruto de seu trabalho é um dom de Deus."

(Eclesiastes 3, 1-8.11.12-13) 
Dedico este trabalho à minha

familia e à Deus. 


\section{Agradecimentos}

A Deus, por ter estado sempre ao meu lado, preenchendo minha vida com seu amor sem limites. Confesso que sem Ele nada disso seria possivel.

À minha familia por acreditar em mim e pelo incentivo em todos os momentos. Principalmente aos meus pais, José e Ordália, pelo amor e pelo 'colo' quando mais precisei.

Ao meu orientador, Prof. Dr. Marcos Nereu Arenales pois sua atenção, ajuda, amizade e apoio durante este tempo, foram vitais para o bom desenvolvimento deste nosso trabalho.

A todos os amigos aqui conquistados e que de formas diferentes, mas muito especiais, fizeram parte (e continuarão fazendo) da minha história. São eles: Fábio, Selma e Silvio, Carlos Eduardo, Thereza, Juliana, Alessandra, Vanessa, Luciane, Maristela, Lilian, Ricardo, Luciana, Luiz Fernando, Ana, Araxá, Sandra, Paulo, Aletéia, Cris e Gisele. Também não poderia deixar de citar aqui o nome de novos amigos: Andrezza, Flávia e Jorge. Em especial, gostaria de agradecer ao Emerson por tudo que vivemos juntos e pela grande amizade que ficou.

Ao Grupo de Oração Universitário Sal \& Luz pelo incentivo à minha fé e perseverança na caminhada com Deus. Agradeço o carinho de todos os integrantes do grupo, principalmente à Vivian, Kelly, Josélia, Rogério, Paulinho e Maria Helena.

Aos amigos que conheci em Viçosa, por estarem ainda hoje participando da minha caminhada e, mesmo de longe, torcendo por mim. Vocês são muito especiais e estarão sempre em meu coração.

A todos os funcionários pela disponibilidade e atenção com que me trataram. Em especial quero agradecer à Adriana e à Sandra pela paciência em tirar todas as minhas dúvidas e pelo sorriso sempre presente.

Aos professores Antonio Castelo Filho e Reinaldo Morabito Neto por contribuirem para minha formação acadêmica. À professora Regina, pelo incentivo e amizade. Agradeço também à Ivani, por proporcionar momentos agradáveis de conhecimento e descontração durante as aulas de inglês.

À Fapesp pelo apoio financeiro ao projeto.

Agradeço de maneira geral, à todas as pessoas que de alguma forma e até mesmo sem perceber, colaboraram para a realização deste trabalho através de gestos, palavras ou até mesmo de um sorriso. 


\section{RESUMO}

Neste trabalho estudamos o problema de corte de estoque inteiro. Para o caso unidimensional, apresentamos alguns métodos heurísticos selecionados por Wäscher e Gau (1996), os quais realizaram um estudo computacional. Tais métodos partem da solução ótima do problema relaxado por programação linear e buscam uma solução inteira em sua 'vizinhança'. Neste presente trabalho, estendemos um dos métodos para o caso bidimensional, que consiste em resolver o problema original relaxado, impondo padrões de corte 2-estágios e irrestritos e utilizando a geração de colunas proposta por Gilmore e Gomory (1965). Em seguida, um arredondamento para o inteiro inferior é feito, resultando em um problema residual. Para resolução deste problema, abandonamos novamente a condição de integralidade e utilizamos a técnica de geração de colunas impondo agora padrões de corte 2restágios e restritos. 0 arredondamento é realizado, resultando em um novo problema residụal, que será tratado da mesma forma. Este procedimento é repetido até que o arredondamento resulte somente em freqüências nulas. Por fim, padrões restritos são utilizados até toda a demanda restante ser atendida. Os resultados dos testes computacionais obtidos com a implementação deste método são apresentados, onde foram observadas fortes indicações da propriedade MIRUP ser também válida para problemas de corte bidimensional 2-estágios.

\section{ABSTRACT}

This work is concerned with the integer cutting stock problem. For the one-dimensional case, we present some heuristic methods selected by Wäscher and Gau (1996), who worked on a computational study. These methods start from an optimal solution for the relaxation problem by linear programming and search for an integer solution in its 'neighbourhood'. In the present work, we extend one of the methods to the two-dimensional case, which consists of solving the relaxation original problem, imposing unconstrained 2-stage cutting patterns and doing use of the column generation method proposed by Gilmore and Gomory (1965). Then a rounding down is made, resulting in a residual problem. To solve this problem, we abandon again the integer condition and utilize the column generation technique, imposing now constrained 2-stage cutting patterns. The rounding down is made, resulting in a new residual problem, that will be treated in the same way. This procedure is repeated until the rounding down only results in zero frequencies. Finally, constrained pattern are used until all the remaining demand be attended. The results of the computational tests obtained with the implementation of this method are presented, where we observed strong indication that the MIRUP property is also valid to 2-stage two-dimensional cutting problems. 


\section{Sumário}

Lista de Figuras. vii

Lista de Tabelas viii

Lista de Gráficos ix

Capítulo 1: Introdução. 1

1.1 Classificação dos problemas de corte quanto à dimensão. 2

1.2 Objetivo 3

1.3 Organização do texto. 4

Capitulo 2: Revisão Bibliográfica 6

Capítulo 3: O Problema de Corte de Estoque Inteiro Unidimensional 11

3.1 Definição e Formulação do Problema. 12

3.2 Método Simplex com Geração de Colunas aplicado ao Problema ...................................... 16

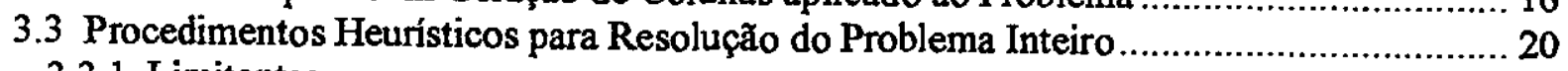

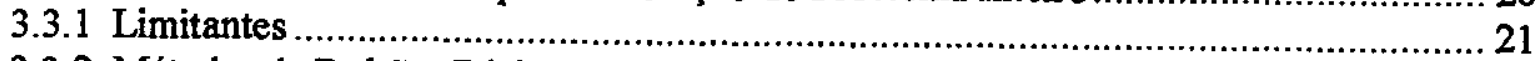

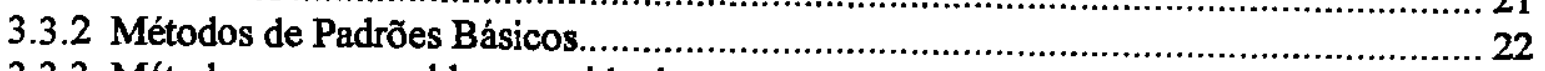

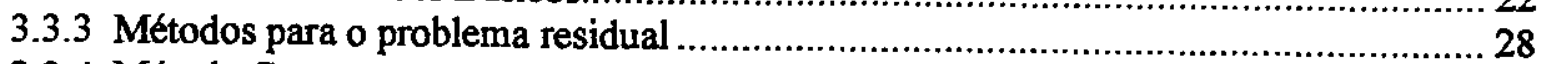

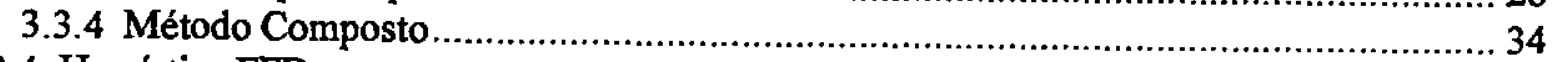

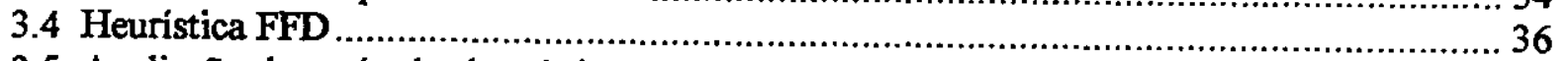

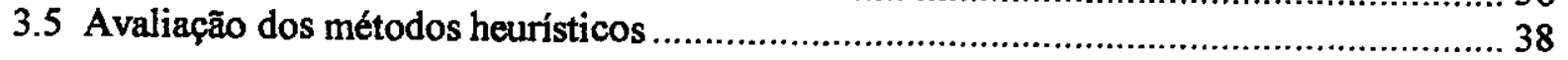

Capítulo 4: O Problema de Corte de Estoque Inteiro Bidimensional ...................................... 40

4.1 Definição e Formulação do Problema .................................................................... 41

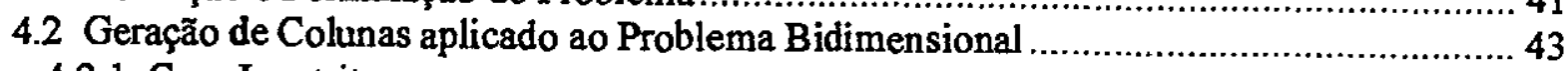

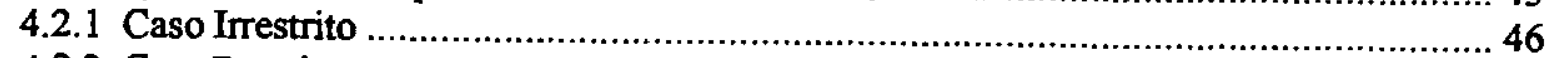

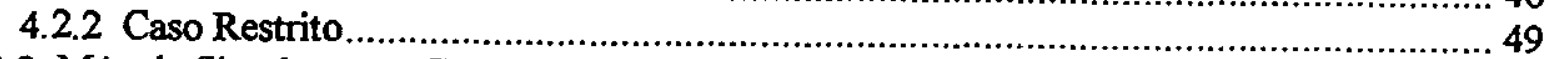

4.3 Método Simplex com Geração de Colunas para o Problema Bidimensional ....................... 53 
4.4 Método Heurístico para o Problema de Corte de Estoque Bidimensional Inteiro. 54

4.5 Limitantes

Capítulo 5: Resultados Computacionais. 58

5.1 Resultados. 62

Capítulo 6: Conclusões e Propostas Futuras 66

Anexo A: Alguns exemplos resolvidos em detalhes. 68

Anexo B: Solução Degenerada com Ciclagem. 81

Referências Bibliográficas 89

Apêndice: Métodos de Resolução da Mochila Unidimensional 93

Ap.1 Métodos de resolução. 93

Ap.1.1 Programação Dinâmica. 94

Ap. 1.2 Método de Enumeração Implícita (Branch and Bound) 95 


\section{Lista de Figuras}

Figura 2.1: Exemplo de padrão de corte unidimensional 13

Figura 4.1: Exemplo de padrão de corte bidimensional 41

Figura 4.2: Corte guilhotinado 2-estágios 43

Figura 4.3: Tipos de corte 44

Figura 4.4: Corte 2-estágios não-exato 45

Figura Ap.1: Maneira como o método de Programação Dinâmica percorre as possíveis soluçб́es do Problema da Mochila ............................................................ 95 


\section{Lista de Tabelas}

Tabela 5.1: Tempo médio de execução para exemplos pequenos .............................................63

Tabela 5.2: Tempo médio de execução para exemplos grandes.................................................. 64 


\section{Lista de Gráficos}

Gráfico 5.1: Qualidade da solução para exemplos pequenos............................................... 62

Gráfico 5.2: Qualidade da solução para exemplos grandes .............................................. 64

Gráfico 5.3: Qualidade da solução para exemplos pequenos com $\gamma=0,5 \ldots \ldots \ldots \ldots \ldots \ldots . . . \ldots . . . .65$

Gráfico 5.2: Qualidade da solução para exemplos grandes com $\gamma=0,5 \ldots \ldots \ldots \ldots \ldots \ldots \ldots . . . . . . . . .65$ 


\section{Capítulo 1}

\section{Introdução}

Problemas de corte de estoque são essenciais no planejamento da produção em várias indústrias, tais como indústrias de papel, de aço, têxtil, etc. Estes problemas consistem em produzir um conjunto de itens, para atender uma certa demanda, a partir da cortagem de peças em estoque, otimizando uma função objetivo, como por exemplo, minimizar o número total de peças em estoque cortadas ou as perdas. Em geral, estes problemas são formulados como problemas de Otimização Linear Inteira. Gilmore e Gomory (1961) relaxaram a condição de integralidade e propuseram um método eficiente de geração de colunas para a resolução do problema linear resultante. Entretanto, devido à sua complexidade e pela inexistência de algoritmos exatos, que resolvam problemas de tamanhos médios, várias heuristicas foram propostas para a solução do problema inteiro.

A importância econômica, aliada a esta complexidade, tem tornado o problema de corte de estoque objeto de grande estudo, aumentando com isto o número de publicações nesta área, como será mencionado no capítulo 2.

Para resolver otimamente um dado problema de corte, a utilização de códigos para resolução de problemas inteiros seria uma opção inicial. Utilizando esta idéia, Wäscher e Gau (1996) testaram vários exemplos da literatura. Entretanto, ao ser aplicada em problemas de tamanhos médios ou grandes, que normalmente resultam em modelos com vários milhões de variáveis, esta estratégia fracassa. Nestes casos, somente métodos heurísticos produziram soluções.

Woolsey (1972) também relata que, utilizando exemplos reais, muitos dos procedimentos heurísticos não obtém, na prática, soluções melhores do que aquelas obtidas manualmente, uma 
situação comum para problemas com poucos itens a serem produzidos. (Deve-se observar que a técnica de geração de colunas é bem adequada para problemas com alta demanda).

Com isto quando temos um problema de grande porte, uma opção é adotar métodos heurísticos que implementem estratégias de arredondamento da solução obtida para o problema relaxado de forma a não se distanciar muito do ótimo. Recentemente, Wäscher e Gau (1996) apresentaram um estudo computacional dessas heuristicas para o problema unidimensional, as quais serão revistas neste trabalho (capitulo 3).

\subsection{Classificaçåo dos problemas de corte quanto à dimensăo}

Dyckhoff e Finke (1992) apresentaram uma classificação dos problemas de corte considerando dimensão, forma de alocação, agrupamento de peças em estoque e agrupamento de itens. Nesta seção, apresentamos somente a classificação feita com relação à dimensão, ou seja, consideramos que um problema pode ser classificado em função de suas dimensões relevantes da seguinte forma:

\section{- Unidimensional:}

Apenas uma das dimensões é significativa no processo de cortagem. Este problema ocorre no corte de barras de aço, bobinas de papel, etc. Sua formulação e métodos de resolução, quando se trata do problema de corte inteiro, serão tratados neste trabalho, no capítulo 3 .

\section{- 1.5-dimensional:}

Duas dimensões são significativas para a solução do problema, porém uma delas é variável. Um exemplo deste tipo de problema é o de um rolo de tecido que tem largura fixa e comprimento suficientemente grande para produzir vários conjuntos de roupa.

\section{- Bidimensional:}

- Duas dimensões (por exemplo, comprimento e largura) são significativas no processo de cortagem. Resolver o problema bidimensional consiste em combinar geometricamente os itens ao longo do comprimento e da largura das peças em estoque. Este tipo de problema 
ocorre em indústrias de placas de vidro, de madeira, etc. Sua formulação e resolução com relação ao problema inteiro serão apresentados no capitulo 4.

\section{- 2.5-dimensional:}

Neste caso, três dimensões são relevantes na resolução do problema, porém uma delas é variável. Um exemplo seria um contêiner com largura e altura fixas e suficientemente comprido para acomodar um volume de carga.

\section{- Tridimensional:}

As três dimensões são significativas no processo de cortagem. As aplicações mais interessantes deste tipo de problema consistem no problema inverso do corte, isto é, no problema de empacotamento. Problemas de corte tridimensionais ocorrem em indústrias de espuma para produção de colchões, travesseiros, etc.

Neste trabalho, tratamos inicialmente dos problemas unidimensionais e, posteriormente, dos bidimensionais.

\subsection{Objetivo}

O objetivo principal deste trabalho é verificar a possibilidade de estender, para o caso bidimensional, os procedimentos heurísticos utilizados para obtenção da solução inteira para o problema de corte de estoque unidimensional. Uma avaliação do desempenho computacional necessário para verificar a qualidade da solução obtida, será realizada.

A referência principal será o trabalho de Wäscher e Gau (1996), que consideraram heurísticas para encontrar uma solução, na vizinhança da solução ótima relaxada, para problemas unidimensionais. Para fazer a extensão para o caso bidimensional, teremos de verificar se os conceitos adotados para o caso unidimensional continuam válidos também quando consideramos duas dimensões. Com isto nosso objetivo consistirá também em, quando necessário, encontrar alternativas equivalentes para os conceitos não-válidos. 
Uma outra análise que faremos será com relação à propriedade MIRUP (Modified Integer Rounding Up Property), onde procuramos observar qual a possibilidade do problema de corte bidimensional também possuir esta propriedade.

\subsection{Organização do texto}

O texto está estruturado da seguinte maneira:

O Capítulo 2 apresenta uma breve revisão bibliográfica, contendo a citação de algumas publicações relacionadas com o assunto do nosso trabalho, em ordem cronológica.

No Capítulo 3, um modelo básico para o problema de corte de estoque unidimensional é apresentado. Apresentamos também o processo de Geração de Colunas aplicado ao problema de corte de estoque unidimensional. Em seguida é feito uma breve introdução sobre limitantes para o valor ótimo da função objetivo, que poderão ser utilizados como referenciais para a avaliação da qualidade das soluções obtidas dos procedimentos heurísticos que são tratados em seguida. Neste capítulo, apresentamos também um algoritmo para a heuristica. FFD (First Fit Decreasing). Algumas análises feitas por Wäschere Gau (1996) sobre o desempenho computacional dos métodos, juntamente com algumas considerações observadas durante o nosso estudo, são feitas no final deste capitulo.

Como o objetivo principal do nosso trabalho é estender os métodos que serão vistos no capítulo 3, tratamos no Capítulo 4 do problema em sua forma bidimensional, onde apresentamos inicialmente sua definição e formulação. Neste caso, a resolução do Problema da Mochila não é trivial como no caso unidimensional, sendo necessário o estudo de métodos de resolução tanto para o caso irrestrito, quanto para o caso restrito deste problema. Este estudo é apresentado na seção 4.2. Em seguida, estudamos uma extensão para o Método Simplex, utilizando a Geração de Colunas agora para o problema bidimensional. Um método heurístico, juntamente com seu algoritmo, será tratado também neste capítulo, juntamente com um breve comentário sobre os limitantes, utilizados como referência com relação à qualidade da solução obtida heuristicamente. 
No Capítulo 5 analisamos os resultados dos testes computacionais obtidos pela implementação do método heurístico estendido para o caso bidimensional.

No Capítulo 6 são feitas as considerações finais, onde apresentamos a conclusão do trabalho juntamente com algumas propostas futuras.

A apresentação deste trabalho será complementada com dois anexos. No Anexo A mostramos alguns exemplos ilustrativos de maneira detalhada utilizando o método visto no capitulo 4 e no Anexo B tratamos de um exemplo obtido durante os testes computacionais, que possui solução degenerada com efeito de ciclagem. Apresentamos como o problema foi solucionado e as consequências ao utilizarmos esta solução.

Finalmente revisamos, no Apêndice, dois métodos de resolução para o Problema da Mochila: programação dinâmica e o método de enumeração implícita. 


\section{CAPÍtulo 2}

\section{Revisăo Bibliográfica}

Este capitulo relaciona e cita algumas publicações que são apresentadas na literatura sobre o problema de corte de estoque, em especial, o problema inteiro. Apresentamos esta breve revisão numa ordem cronológica.

O problema de corte tem sido pesquisado desde o ano de 1940, sendo que as principais publicações começaram a surgir por volta de 1960 . Um fato observado é que as pesquisas têm caminhado no sentido de desenvolver técnicas heurísticas adequadas, visto que o problema é NPcompleto e técnicas exatas, tais como enumeração implícita, não podem ser utilizadas para resolver exemplos grandes deste problema.

Entre os primeiros trabalhos publicados nesta área, podemos citar os pioneiros de Kantorovich (1939) e de Brooks et al. (1940) (cf. Dyckoff e Finke (1992)), relacionando o problema de corte com a programação linear.

$\mathrm{Na}$ década de 60 , vários trabalhos importantes surgiram, sendo que as modelagens matemáticas e métodos de resolução de maior repercussão na literatura foram publicados por Gilmore e Gomory $(1961,1963,1965)$. Em seus trabalhos de 1961 e 1963, estes autores trataram o problema de corte de estoque unidimensional como um problema de programação linear e mostraram a dificuldade em trabalhar com todas as colunas associadas aos padrões de corte, propondo um processo de geração de colunas para contornar esta dificuldade. Este processo será apresentado na seção 3.2 do próximo capítulo deste trabalho, quando tratamos do problema unidimensional. No trabalho de 1963, os autores aplicaram a formulação a uma indústria de papel. Em 1965, estudaram os problemas de corte de estoque bidimensional e multidimensional. Neste trabalho, com relação ao bidimensional, os autores abordaram o problema guilhotinado, 
estagiado e irrestrito e apresentaram um processo de decomposição para gerar os padrões de corte guilhotinados em 2-estágios. Apresentaremos este processo na seção 4.2.1, quando estivermos tratando do problema de corte inteiro bidimensional. Em um trabalho posterior, Gilmore e Gomory (1966) realizaram um estudo mais aprofundado sobre o Problema da Mochila quando este é aplicado ao problema unidimensional e ao bidimensional, procurando desenvolver técnicas mais rápidas de resolução. Foram apresentados métodos utilizando algoritmos de programação dinâmica.

No início da década de 70, Brown (1971) publicou o livro 'Optimum Packing and Depletion' que, de forma geral, trata do problema de corte/empacotamento, apresentando alguns problemas e técnicas de solução. Em 1972, Herz utilizou uma técnica recursiva para resolução de problemas de cortes guilhotinados multi-estágios. Este trabalho teve grande influência no trabalho de Morabito et al. $(1992,1996)$.

Woolsey (1972) publicou um artigo onde relata que as soluções feitas manualmente por funcionários experientes resultam, na prática, em soluções melhores do que aquelas geradas por métodos heurísticos, caracterizando uma situação comum para 'problemas pequenos'. Um exemplo citado no artigo foi o problema de cortes de barras, onde firmas de construção desejam encontrar a melhor maneira de cortar as barras em estoque, de forma a minimizar a perda. Um dos métodos utilizados para resolver o problema foi o processo de geração de colunas, aplicado ao problema de programação linear, que foi obtido ao relaxar as restrições de integralidade, seguido de algoritmos de arredondamento. Foram realizados testes para comparar os resultados deste método com os gerados pelos operadores da firma e, em nenhum caso, o algoritmo foi capaz de igualar com os resultados fornecidos por eles. Em seguida, pensou-se na possibilidade de resolver o problema inteiro utilizando códigos de linguagem apropriados, mas da mesma forma que anteriormente, os resultados do método utilizado não foram iguais aos dos operários.

Ainda na década de 70, Christofides e Whitlock (1977) sugeriram um algoritmo de busca em árvore para problemas bidimensionais guilhotinados restritos. Os autores obtiveram um bom resultado computacional na resolução de problemas de tamanho médio.

Iniciando a década de 80 , modificaçzes no algoritmo apresentado por Gilmore e Gomory em 1961 e 1963, foram propostas por Haessler (1980), onde o objetivo de minimizar a perda de material utilizado foi ampliado. $O$ autor propõe mudanças para os procedimentos que geram a solução inicial e os padrões subsequentes a entrar na base. Dyckhoff (1981) afirmando que o modelo de programação linear, com relação à técnica de Geração de Colunas, proposta por 
Gilmore e Gomory $(1961,1963)$, não funcionaria em algumas situações, apresentou outro modelo para o caso unidimensional, que possui vantagens, quando existem muitos itens a serem cortados. Este modelo também trata problemas quando a 'perda' que ocorre depois que o corte é feito, pode ser reutilizada. Em 1984, Coffman et al (cf Schwerin e Wäscher (1997)) relata que muitos métodos de solução heurística foram pesquisados para resolução do problema binpacking. Entretanto, segundo o autor, a heuristica FFD (revisada na seção 3.5 deste trabalho) consistiu de um dos mais atrativos, não somente por ser de fácil e rápida implementação, mas também por providenciar soluçðes de boa qualidade.

Ainda na década de 80 , um algoritmo exato para resolução do problema de corte bidimensional, não restrito à cortes guilhotinados, foi apresentado por Beasley (1985). O autor desenvolve uma relaxação lagrangiana de uma formulação inteira zero-um do problema, fornecendo um limitante que será usado em um procedimento de busca em árvore. Foi a primeira vez que um algoritmo exato para este problema foi apresentado. Em 1986, Marcotte (cf. Scheithauer e Terno (1995)) após provar que certas classes de problema de corte de estoque unidimensional possuem a propriedade IRUP (Integer Round-Up Property), mostra um exemplo onde a propriedade não é válida. Este trabalho motivou a realização do trabalho de Scheithauer e Terno (1995). Arcaro (1988) em sua dissertação propôs modificações para o problema unidimensional tratado por Gilmore e Gomory, considerando um outro tipo de função objetivo, ou seja, ao invés de minimizar a perda, considerou que a maximização dos lucros formularia melhor o objetivo para problemas reais. Modificações no conjunto de restrições também foram consideradas. Morabito (1989) introduz a abordagem em grafo E/OU para problemas bidimensionais guilhotinados.

Iniciando os anos 90, Stadtler (1990) realizou um estudo de caso em uma indústria de alumínio, onde o cálculo do número mínimo de peças em estoque de alumínio necessárias para atender os pedidos dos fregueses deveria ser determinado. Neste caso, os resultados fornecidos pela heurística FFD não foram satisfatórios, sendo apresentado um novo código baseado no processo de Geração de Colunas proposto por Gilmore e Gomory, acrescentado de um processo de arredondamento para obtenção de uma solução inteira. $O$ arredondamento é feito identificando a variável com maior valor fracionário onde, em seguida, o arredondamento desta variável para o inteiro superior e uma reotimização são feitos. $O$ processo é repetido até que a solução seja toda inteira. Em seguida, o excesso é reduzido sucessivamente. Depois, a heurística FFD é utilizada para atender a pequena demanda ainda não atendida. 
Considerando ainda os trabalhos da década de 90 , citamos a abordagem em grafo E/OU para solucionar o problema de corte bidimensional guilhotinado não-estagiado e irrestrito proposta por Morabito et al. (1992). Os autores Dyckoff e Finke (1992), em seu livro 'Cutting and Packing in Production and Distribution: Typology and Bibliografy', citaram e classificaram uma lista bastante abrangente de trabalhos publicados nas línguas inglesa e alemã dos trabalhos apresentados até o início de 1992, dedicado ao problema de corte e empacotamento. A maioria destas publicações trabalha com aplicações reais em várias indústrias. Wäscher e Gau (1995), em seu artigo, desenvolveram um problema gerador para o problema de corte de estoque unidimensional padrão. Também em 1995, Scheithauer e Terno publicaram um artigo conjecturando que o problema de corte de estoque unidimensional tem a propriedade MIRUP. Esta propriedade ocorre quando o valor ótimo do problema de corte de estoque inteiro unidimensional não é maior do que o valor ótimo do problema relaxado por programação linear correspondente, arredondado para o inteiro superior mais um, quando o número de peças em estoque define a função objetivo.

Em 1995, Morabito e Arenales analisaram a performance de duas heurísticas para resolver problemas de corte guilhotinado bidimensional maiores. Estes mesmos autores (Morabito e Arenales, 1996) estenderam a abordagem feita em Morabito et al. (1992), onde agora problemas restritos e estagiados são tratados, utilizando ainda a representação do problema em grafo E/OU. Também neste ano, Wäscher e Gau (1996) reuniram em um artigo vários métodos heurísticos para resolução do problema de corte de estoque inteiro unidimensional, onde um estudo computacional foi realizado. Estes métodos estão descritos no capítulo 3, pois o nosso trabalho tem como referência principal o trabalho desses autores.

Gramani (1997) trabalhou em sua dissertação com o problema de corte bidimensional guilhotinado e restrito em 2-estágios. A formulação matemática deste problema apresenta restrições não-lineares. A abordagem utilizada foi a relaxação lagrangiana, onde subproblemas irrestritos são obtidos, os quais são resolvidos pelo método proposto por Gilmore e Gomory (1965). Ao fazer a relaxação surge o problema dual lagrangiano que foi resolvido utilizando o Método do Subgradiente. Neste trabalho, também foram feitas implementações para obtenção de uma solução factivel inicial, onde métodos heurísticos foram propostos. Estes métodos serão aqui utilizados para estender a heuristica FFD para o problema bidimensional. Na seção 4.2.2 fazemos uma revisão deste trabalho. Também em 1997, Schwerin e Wäscher apresentaram um 
problema gerador para o problema bin packing sugerindo que este fosse utilizado para uma avaliação empírica de métodos heurísticos e exatos.

Finalizamos esta breve revisão, citando o trabalho de Scheithauer e Terno (1997). Os autores trabalharam com a possibilidade de caracterizar o poliedro para o problema de corte de estoque utilizando o conceito de desigualdades válidas. 


\section{Capítulo 3}

\section{O Problema de Corte de Estoque Inteiro Unidimensional}

Este capitulo trata do problema de corte de estoque em sua forma unidimensional, cuja formulação é apresentada na seção 3.1. A resolução do problema inteiro (isto é, com as restrições de integralidade) é inviável para problemas grandes, sendo necessária a utilização de métodos heurísticos. Com isto Wäscher e Gau (1996) realizaram um estudo computacional, onde reuniram alguns destes procedimentos heurísticos, que partem de uma solução ótima da relaxação por programação linear do problema original (a condição de integralidade é abandonada). A obtenção da solução relaxada é feita através do Método Simplex aplicado ao problema de corte, utilizando o processo de Geração de Colunas proposto por Gilmore e Gomory (1961). Este método é brevemente revisado na seção 3.2. A solução relaxada é geralmente nãointeira, sendo necessária a determinação de uma solução inteira em sua 'vizinhança'. Este passo é feito por métodos heuristicos que utilizam um processo de arredondamento. As heurísticas estudadas pelos autores são apresentadas na seção 3.3.

Em alguns procedimentos, a utilização da heurística FFD torna-se necessária na resolução do problema residual, que surge, quando as componentes da solução relaxada são arredondadas para o inteiro inferior. Com isto a idéia básica desta heurística e seu algoritmo serão revisados na seção 3.4. Finalizamos este capitulo com a seção 3.5 , onde será apresentado um breve comentário sobre os resultados computacionais obtidos por Wäscher e Gau (1996) em seu trabalho, seguido de algumas análises observadas durante nossos estudos com relação aos métodos apresentados. 


\subsection{Definição e Formulação do Problema}

O problema de corte de estoque inteiro unidimensional pode ser definido da seguinte forma:

Considere o estoque de um número suficientemente grande de barras de um certo comprimento $L$, que chamaremos de peças em estoque, e um conjunto de pedidos com demanda $d_{i}$ de barras menores de comprimentos $l_{i}, i=1, \cdots, m$, os quais chamaremos de itens. $\mathrm{O}$ problema então consiste em produzir os itens a partir da cortagem das peças em estoque de modo a atender a demanda, otimizando uma certa função, por exemplo, cortar o mínimo de peças em estoque.

Outros tipos de funções poderiam ser otimizadas neste caso, como por exemplo, a minimização da perda ou a maximização dos lucros. Observe que as peças que entram para serem cortadas (peças em estoque) e as que saem (itens) possuem todas as características idênticas, modificando somente o comprimento. Com isto todos os cortes necessários deverão ser feitos em uma única dimensão. Problemas de corte deste tipo particular podem ser encontrados em várias indústrias, como:

- na indústria de papel, onde grandes rolos têm que ser cortados em tamanhos encomendados por clientes. $O$ processo consiste em desenrolar o papel dos rolos maiores e enrolar novamente, mas agora nos carretéis apropriados, cortando o papel ao longo do comprimento para atender a demanda. Quando as perdas não são aproveitadas torna-se necessário uma operação de programação crítica, para que ela seja minima, depois de realizado o corte. Este caso foi citado no trabalho de Brown (1971). Arcaro (1988) tratou também deste problema, mas considerando o recorte de estoque, ou seja, o aproveitamento das sobras depois de realizado o primeiro corte. Neste trabalho não foi considerado o objetivo de minimizar as perdas e sim o de maximizar os lucros, pois foi considerado que este seria o objetivo real das empresas;

- na indústria de aço, onde barras de aço em estoque serão cortadas em barras menores (Brown, 1971); 
- na indústria de alumínio, onde um produtor de perfis de alumínio fornece aos fregueses o serviço de calcular o número mínimo de peças necessárias para atender os pedidos (Stadtler, 1990).

Conforme os tamanhos dos itens podemos cortar as peças em estoque de várias maneiras diferentes. A cada maneira de cortar chamaremos de padrão de corte. A figura abaixo ilustra um exemplo para o caso unidimensional:

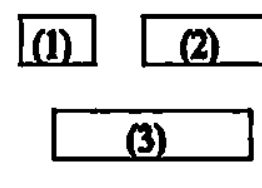

(a)

(b)
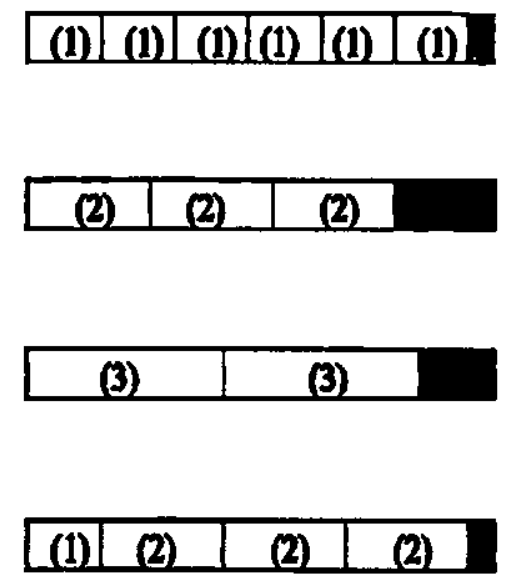

\begin{tabular}{|l|l|l|l|}
\hline (1) & $(1)$ & (2) & (3) \\
\hline
\end{tabular}

(c)

(a) Peça em estoque;

(b) Tipos de itens demandados;

(c) Exemplos de possiveis padrões de corte.

Figura 2. 1: Exemplo de padrão de corte unidimensional

Definição 3.1: Um padrão de corte, que produza apenas um tipo de item, é chamado de padrão de corte homogêneo. Este tipo de padrão está representado nos três primeiros padrões definidos na figura 2.1 . 
Após definirmos os padrões de corte, o próximo passo será determinar o número de vezes que cada padrão será utilizado para resolver o problema. Ou seja, a modelagem matemática de um problema de corte de estoque inteiro é feita em duas etapas:

Etapa 1: Definir todos os possíveis padrões de corte (supondo $n$ o número total de padrões obtidos);

Etapa 2: Decidir quantas vezes cada padrão de corte será utilizado para atender a demanda, que deverá ser um número não-negativo e inteiro.

A um padrão de corte associamos um vetor $m$-dimensional que contabiliza os itens produzidos, da seguinte forma:

$$
a_{j}=\left(a_{1 j}, a_{2 j}, \ldots, a_{m j}\right)
$$

onde: $a_{i j}$ é a quantidade de itens do tipo $i$, cortados segundo o padrão de corte $j$.

Para o caso unidimensional, as etapas citadas acima são formuladas da seguinte forma:

\section{- Etapa 1:}

$O$ vetor $m$-dimensional definido em (3.2) corresponderá a um padrão de corte, se e somente se, as restrições físicas do problema forem respeitadas, ou seja, o que está sendo alocado na barra não pode ultrapassar o seu comprimento. Esta condição pode ser formulada matematicamente como:

$$
\begin{aligned}
& \sum_{i=1}^{m} l_{i} a_{i j} \leq L \\
& a_{i j} \geq 0 \text { e inteiros, } i=1,2, \ldots, m .
\end{aligned}
$$

Desta forma, definir os padróes de corte consiste em determinar todas as soluções do sistema (3.3).

\section{- Etapa 2:}

Considere $x_{j}$ como sendo o número de vezes que a peça em estoque é cortada usando o padrão $j, j=1, \ldots, n$. 
Definidas as duas etapas, o modelo básico de otimização linear inteiro para o caso unidimensional é formulado como:

$$
\begin{aligned}
& \text { minimizar } f(\mathbf{x})=\sum_{j=1}^{n} x_{j} \\
& \text { sujeito a: } \sum_{j=1}^{n} a_{i j} x_{j} \geq d_{i}, i=1, \ldots, m, \\
& \qquad x_{j} \geq 0 \text { e inteiro, } j=1, \ldots n .
\end{aligned}
$$

A exigência de integralidade sobre as variáveis $x_{j}$ torna o problema (3.4) dificil, senão impossível, de ser resolvido computacionalmente. Em problemas práticos, $m$ (o número de tipos de itens) é da ordem de dezenas, enquanto que $n$ (o qual depende de $m, L$ e $l_{i} ; i=1, \ldots, m$ ) pode ser da ordem de vários milhões ou bilhões, inviabilizando a resolução direta do problema. Com isto a relaxação por programação linear, a utilização do processo de geração de colunas (seção 3.2), bem como o estudo de métodos heurísticos (seção 3.3) serão importantes na resolução do problema apresentado acima.

Observação 3.1: A função objetivo citada acima poderia ser definida de várias outras formas, dependendo da situação. Em seguida apresentamos algumas das alterações citadas no trabalho de Arenales et al. (1997).

1. Um outro objetivo a ser considerado é o de atender a demanda a um custo mínimo. Assim, se considerarmos $c_{j}$ como sendo o custo de cada peça cortada segundo o padrão $j$, a função custo é formulada como:

$$
\operatorname{minimizar} f(\mathbf{x})=\sum_{j=1}^{n} c_{j} x_{j}
$$

2. A função objetivo em (3.4) poderia também ser substituida pela função perda total, que é definida como:

$$
c_{j}=L-\left(a_{1 j} l_{1}+a_{2 j} l_{2}+\cdots+a_{m j} l_{m}\right)
$$

caracterizando a perda no padrão de corte $j$. 
3. Outra função objetivo a ser considerada é a função perda relativa:

$$
\begin{aligned}
\text { perda relativa } & =(\text { perda total }) /(\text { múmero de objetos cortados })= \\
& =\left[\sum_{j} L-\left(a_{l j} l_{l}+a{ }_{2 j} l_{2}+\cdots+a_{m j} l_{m}\right)\right] /\left(\sum_{j} x_{j}\right)
\end{aligned}
$$

Esta função, ao ser minimizada, busca ao mesmo tempo um numerador pequeno (perda total pequena) e um denominador grande (maior produção).

\subsection{Método Simplex com Geração de Colunas aplicado ao Problema}

Para resolver a relaxação contínua do problema (3.4) o Método Simplex é utilizado. Em problemas práticos o número de variáveis (colunas) $n$ é muito maior que o número de restrições (linhas) $m$. Entretanto, durante as iterações do Simplex, temos de determinar uma nova coluna para entrar na base. Este problema torna-se impraticável devido ao grande número de colunas que devem ser investigadas. Com isto o processo de geração de colunas proposto por Gilmore e Gomory (1961) é bastante eficiente para resolver o problema.

Este processo consiste em encontrar uma coluna útil resolvendo um problema de programação inteira, mas de um tipo especial, denominado Problema da Mochila, e que pode ser facilmente resolvido por vários métodos. No Apêndice apresentamos dois destes métodos de resolução da mochila: Programação Dinâmica (Gilmore e Gomory, 1961) e Método de Enumeração Implícita implementado pela busca em profundidade primeiro (Gilmore e Gomory, 1963). A formulação do problema é apresentada a seguir.

$O$ procedimento consiste em gerar a coluna $k$ (isto é, um padrão), utilizando uma heuristica gulosa, que procura a variável $\mathbf{x}_{k}$ com o menor custo relativo, $o$ que sugere o seguinte subproblema:

$$
\mathbf{c}_{k}-\pi^{T} \mathbf{a}_{k}=\min \left\{\mathbf{c}_{j}-\pi^{T} \mathbf{a}_{j}, j=1,2, \ldots\right\}
$$

onde o vetor $\pi$ é o multiplicador simplex.

Da teoria de otimização linear sabemos que, se $\mathbf{c}_{k}-\pi^{T} \mathbf{a}_{k} \geq 0$, então a solução básica é 6tima. No problema de corte, que estamos trabalhando, os custos das peças em estoque são constantes e iguais a um, ou seja, $c_{j}=c t e=1, j=1,2, \ldots, m$. Este fato resulta em: 


$$
\min \left\{\mathbf{c}_{j}-\pi^{T} \mathrm{a}_{j}\right\}=1-\max \left\{\pi^{T} \mathrm{a}_{j}\right\}
$$

Com isto encontrar a coluna não-básica, que substituirá a coluna básica, corresponde a resolver o seguinte problema:

$$
\begin{aligned}
& \text { maximizar } \pi_{l} y_{1}+\pi_{2} y_{2}+\ldots+\pi_{m} y_{m} \\
& \text { sujeito a : }\left(y_{1}, y_{2}, \ldots, y_{m}\right)^{T}-\text { corresponda a um padrão de corte }
\end{aligned}
$$

Para que a coluna $a_{j}=\left(y_{1}, y_{2}, \ldots, y_{m}\right)^{T}$ corresponda a um padrão de corte basta que satisfaça as restrições físicas do problema, ou seja:

$$
\begin{aligned}
& l_{J} y_{1}+l_{2} y_{2}+\ldots+l_{m} y_{m} \leq L \\
& y_{1} \geq 0, y_{2} \geq 0, \ldots, y_{m} \geq 0 \text { einteiros }
\end{aligned}
$$

Assim, o problema (3.5) poderá ser reescrito da seguinte forma:

$$
\begin{aligned}
& \text { maximizar } \pi_{1} y_{l}+\pi_{2} y_{2}+\ldots+\pi_{m} y_{m} \\
& \text { sujeito a: } l_{J} y_{1}+l_{2} y_{2}+\ldots+l_{m} y_{m} \leq L \\
& y_{1} \geq 0, y_{2} \geq 0, \ldots, y_{m} \geq 0 \text { einteiros, }
\end{aligned}
$$

que é conhecido, na literatura, como Problema da Mochila. Desta forma, se $1-\sum_{i=1}^{m} \pi_{i} y_{i} \geq 0$ podemos garantir que a solução do problema (3.4) relaxado é ótima.

A formulação (3.7a) corresponde, na realidade, ao Problema da Mochila Irrestrito, ou seja, não está sendo levada em consideração a limitação da demanda de cada item. Em alguns casos como, por exemplo, quando temos uma demanda pequena, considerar o Problema da Mochila Restrito torna-se mais viável, como será comentado na seção 3.5. A formulação deste problema é:

$$
\begin{aligned}
& \max \sum_{i=1}^{m} \pi_{i} y_{i} \\
& \text { sujeito a }: \sum_{i=1}^{m} l_{i} y_{i} \leq L \\
& \quad 0 \leq y_{i} \leq d_{i} \text { einteiro }
\end{aligned}
$$


Para resolver o Problema da Mochila utilizamos o método de Enumeração Implícita tanto para o caso restrito quanto para o irrestrito, utilizando modificações necessárias quando trabalhamos com o restrito. Estas modificações também são mencionadas no Apêndice.

Quanto à matriz básica inicial, no caso do problema de corte de estoque, consideramos os padrões de corte homogêneo, conforme definição dada na seção 3.1. Apresentamos em seguida o algoritmo do Método Simplex aplicado ao problema de corte de estoque unidimensional:

\section{Algoritmo}

Passol:

- Gere a matriz inicial das variáveis básicas $B$, utilizando a solução homogênea, da seguinte forma:

$$
B=\left(\begin{array}{cccccc}
\left\lfloor\frac{L}{l_{1}}\right\rfloor & 0 & 0 & 0 & \cdots & 0 \\
0 & \left\lfloor\frac{L}{l_{2}}\right\rfloor & 0 & 0 & \cdots & 0 \\
\vdots & & \vdots & & \ddots & \vdots \\
0 & 0 & 0 & 0 & \cdots & \left.\frac{L}{l_{m}}\right\rfloor
\end{array}\right)
$$

Este passo corresponde à fase I do Método Simplex.

- Faça $P A R E=$ Falso, $I T=1$

(A variável lógica $P A R E$ terá valor Falso até que a condição de otimalidade seja verificada e $I T$ indica o número da iteração atual\}

Passo2:

Enquanto $P A R E=$ Falso, faca:

\{Início da Iteração Simplex\}

2.1. Determine a solução básica corrente: $\mathbf{B x}=\mathbf{d}$.

2.2. Determine a solução básica dual: $\mathbf{B}^{T} \pi=1$. 
2.3. Resolva o Problema da Mochila

\section{Irrestrita:}

$$
\begin{aligned}
& \max \pi_{1} y_{1}+\pi_{2} y_{2}+\ldots+\pi_{m} y_{m} \\
& \text { sujeito a : } l_{1} y_{1}+l_{2} y_{2}+\ldots+l_{m} y_{m} \leq L \\
& y_{i} \geq 0, \text { e inteiros } i=1,2, \ldots, m
\end{aligned}
$$

ou Restrita:

$$
\begin{aligned}
\max & \pi_{1} y_{1}+\pi_{2} y_{2}+\ldots+\pi_{m} y_{m} \\
\text { sujeito a: } & l_{1} y_{1}+l_{2} y_{2}+\ldots+l_{m} y_{m} \leq L \\
& 0 \leq y_{i} \leq d_{i} \text { e inteiros } i=1,2, \ldots, m
\end{aligned}
$$

2.4. \{Teste a otimalidade\}

$$
\text { Fen } T_{0} \text { resici, ', }
$$

Se ${ }^{\succ} 1-\sum_{i=1}^{\tilde{m}} \pi_{i} y_{i} \geq 0$ então $P A R E=V e r d a d e i r o$ \{solução atual é ótima, obtida em $I T$ iteraçōes\}

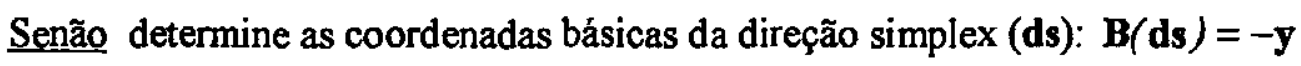

2.5. \{Determinação do passo\}

Encontre $l$ tal que:

$$
\frac{-x_{l}}{d s_{l}}=\min \left\{\frac{-x_{i}}{d s_{i}} / d s_{i}<0\right\}
$$

\section{6. \{Atualização\}}

Atualize a base, colocando a coluna y na posição da l-ésima coluna da matriz B

Faça: $I T=I T+1$.

\{Fim da Iteração Simplex\} 


\subsection{Procedimentos Heurísticos para Resolução do Problema Inteiro}

A utilização de heurísticas para se obter uma solução inteira a partir da solução relaxada do problema (3.4) ocorre com freqüência na literatura. Com isto Wäscher e Gau (1996) reúnem estas heurísticas e as dividem em: Métodos de Padrões Básicos, Métodos para o Problema Residual e Métodos Compostos.

Uma breve idéia do uso de limitantes, utilizados pelos autores como referência na avaliação da qualidade da solução obtida heuristicamente e o algoritmo da heurística FFD, utilizado na resolução do problema residual, também serão apresentados nesta seção.

Para um melhor entendimento de como as heurísticas e os limitantes funcionam faremos uso de um exemplo numérico, cujos dados serão dados a seguir:

\section{EXEMPLO 3.1:}

\section{Dados:}

\begin{tabular}{|lll|}
$L=100 \mathrm{~cm}$ & & \\
$l_{1}=45 \mathrm{~cm}$ & $\mapsto$ & $d_{1}=97$ \\
$l_{2}=36 \mathrm{~cm}$ & $\mapsto$ & $d_{2}=610$ \\
$l_{3}=31 \mathrm{~cm}$ & $\mapsto$ & $d_{3}=395$ \\
$l_{4}=14 \mathrm{~cm}$ & $\mapsto$ & $d_{4}=211$ \\
\hline
\end{tabular}

Solução do problema relaxado: $\left\{\begin{array}{l}\tilde{x}_{1}^{*}=48,5 \\ \tilde{x}_{2}^{*}=100,75 \\ \tilde{x}_{3}^{*}=197,5 \\ \tilde{x}_{4}^{*}=105,5\end{array}\right.$

Relacionada com os seguintes padrões: $\left(\begin{array}{l}2 \\ 0 \\ 0 \\ 0\end{array}\right),\left(\begin{array}{l}0 \\ 2 \\ 0 \\ 0\end{array}\right),\left(\begin{array}{l}0 \\ 1 \\ 2 \\ 0\end{array}\right),\left(\begin{array}{l}0 \\ 2 \\ 0 \\ 2\end{array}\right)$ 


\subsubsection{Limitantes}

A obtenção de bons limitantes para o valor ótimo da função objetivo é essencial para a resolução do problema em um tempo computacional razoável. Quanto à avaliação da qualidade das heurísticas, que serão apresentadas a seguir, estes limitantes poderão ser considerados como bons pontos de referência.

Assim, considere o vetor abaixo como sendo a solução ótima obtida pela relaxação do problema (3.4):

$$
\widetilde{\mathbf{x}}^{*}=\left(\tilde{x}_{1}^{*}, \tilde{x}_{2}^{*}, \cdots, \tilde{x}_{n}^{*}\right)
$$

Obs.: No exemplo 3.1 , esta solução é dada por: $\widetilde{x}^{*}=(48,5 ; 100,75 ; 197,5 ; 105,5 ; 0 ; 0 ; \ldots)$.

Com isto o valor correspondente da função objetivo será:

$$
f\left(\widetilde{x}^{*}\right)=\sum_{j=1}^{n} \widetilde{x}_{j}^{*} \stackrel{\text { no exemplo1 }}{\longrightarrow} \sum_{j=1}^{n} \widetilde{x}_{j}^{*}=452,25
$$

Como alguns, ou todos os elementos do vetor (3.9) geralmente são não-inteiros, do mesmo modo o valor para a função objetivo também não será. Com isto podemos considerar um limitante inferior $(L D)$ para $f\left(\mathbf{x}^{*}\right)$, definido como:

$$
L I\left(f\left(\mathbf{x}^{*}\right)\right)=\left[f\left(\tilde{\mathbf{x}}^{*}\right)\right]
$$

onde $\left[f\left(\widetilde{\mathbf{x}}^{*}\right)\right]$ é o menor inteiro maior ou igual a $f\left(\widetilde{\mathbf{x}}^{*}\right)$.

Obs.: Para o exemplo 3.1, temos: $\left[\sum_{j=1}^{n} \widetilde{x}_{j}^{*}\right\rceil=453$. Ou seja, não conseguiremos resolver este problema proposto utilizando menos do que 453 barras.

Como um arredondamento para o inteiro superior dos componentes não-inteiros de (3.9) resulta em uma solução factível para o problema original, pois satisfaz a demanda, um limitante superior $(L S)$ pode ser definido da seguinte forma:

$$
L S\left(f\left(\mathbf{x}^{*}\right)\right)=\sum_{j=1}^{n}\left[\tilde{\mathbf{x}}_{j}^{*}\right]
$$


que no exemplo 3.1, é igual a 454 barrạs.

Segundo Wäsher e Gau (1996), experiências têm mostrado que este limitante superior pode estar bem distante da solução ótima do problema. Ainda argumentam que, em alguns problemas práticos, a solução ótima procurada fornece o limitante inferior (3.10), ou seja:

$$
f\left(\mathbf{x}^{*}\right)=\left[f\left(\widetilde{\mathbf{x}}^{*}\right)\right]
$$

que equivalentemente pode ser reformulado como: $f\left(\mathbf{x}^{*}\right)-f\left(\widetilde{\mathbf{x}}^{*}\right)<1$.

A expressão $f\left(x^{*}\right)-f\left(\widetilde{x}^{*}\right)$ representa o gop de integralidade. A relação (3.12) define a propriedade IRUP (Integer Round-Up Property). Para exemplos testados em problemas reais, verificou-se que o maior valor encontrado para o gap de integralidade foi aproximadamente 1,066... . Com isto caracterizou-se uma modificação na relação (3.12), definindo a propriedade MIRUP (Modified Integer Round-Up Property) da seguinte forma:

$$
f\left(\mathbf{x}^{*}\right)-\left[f\left(\tilde{\mathbf{x}}^{*}\right)\right] \leq l
$$

Scheithauer e Terno (1995) consideram estas propriedades em seu artigo e conjecturam que o problema de corte unidimensional possui a MIRUP. Assim podemos considerar que o valor dado pelo limitante inferior (3.10) providencia um excelente ponto de referência para a avaliação da qualidade das soluq̧ões obtidas pelas heurísticas apresentadas na próxima subseção.

\subsubsection{Métodos de Padrōes Básicos}

Nestes métodos, os padrões de corte que correspondem às variáveis básicas da solução ótima do problema relaxado são identificados. Segundo o Método Simplex, o número destes padrões básicos corresponde a $\boldsymbol{m}$, ou seja, é igual ao número de pedidos. Isto ocorre porque a solução de (3.9) possui $m$ variáveis básicas $x_{B_{\jmath}}, x_{B_{2}}, \ldots, x_{B_{m}}$ devido à existência de $m$ restrições. Para relacionarmos com a notação utilizada na apresentação do Método Simplex, denotaremos estas variáveis $x_{B}$ representando o vetor das variáveis básicas. Por simplicidade de notação, escrevemos: $\mathbf{x}_{B}=\left(x_{1}, x_{2}, \ldots, x_{m}\right)^{T}$. Com isto somente os padrões básicos serão considerados para 
a geração de uma solução inteira. As variáveis não-básicas, denotadas por $\mathbf{x}_{N}$, serão fixadas em zero, ou seja: $\mathbf{x}_{N}^{*}=\widetilde{\mathbf{x}}_{N}^{*}=0$, enquanto que as freqüências $\left(\widetilde{x}_{1}^{*}, \widetilde{x}_{2}^{*}, \ldots, \widetilde{x}_{m}^{*}\right)$ serão ajustadas de forma a se tornarem inteiras, satisfazendo ainda as restrições de demanda, ou seja:

$$
\sum_{j} a_{i j} x_{j}^{\mathrm{H}} \geq d_{i}, i=1, \ldots, m
$$

onde: $\mathbf{I}^{\mathrm{H}}$ corresponde à solução obtida pela heurística $\mathrm{H}, \mathrm{H}=\mathrm{B1}, \mathrm{B} 2, \ldots$

Para fazer o ajuste mencionado são sugeridos os seguintes métodos:

\section{Heurística B1}

Este método consiste no mais simples processo de arredondamento de soluções fracionárias, ou seja, todas as componentes não-inteiras de (3.9) são arredondadas para o inteiro superior, ou seja:

$$
\mathbf{x}_{j}^{\mathrm{BI}}=\left\lceil\tilde{\mathbf{x}}_{j}^{*}\right\rceil j=1, \ldots, m,
$$

Este procedimento é bastante rápido e resultará, sem dúvida, em uma solução factível para o problema original pois com o arredondamento para o inteiro superior, as restrições de demanda nunca serão violadas. Mas, por outro lado, este procedimento poderá resultar em uma solução inteira distante do valor ótimo para o problema original.

Utilizando este método teremos a seguinte solução para o exemplo 3.1:

$$
\left\{\begin{array} { l } 
{ x _ { 1 } ^ { \mathrm { B } 1 } = 4 9 } \\
{ x _ { 2 } ^ { \mathrm { B } 1 } = 1 0 1 } \\
{ x _ { 3 } ^ { \mathrm { B } 1 } = 1 9 8 } \\
{ x _ { 4 } ^ { \mathrm { B } 1 } = 1 0 6 }
\end{array} \Rightarrow \text { estaremos utilizando } 4 5 4 \text { barras e produzindo } \left\{\begin{array}{l}
98 \\
612 \\
396 \\
212
\end{array}\right.\right. \text { itens de cada tipo, }
$$

resultando em um excesso de produção. 


\section{$\rightarrow$ Heurística B2}

Como foi visto, ao utilizarmos o procedimento anterior, a obtenção não desejada de um suprimento maior do que o necessário poderá ocorrer com freqüência. Para diminuir este problema, pode-se reduzir a quantidade de vezes que certos padrões de corte serão utilizados para valores inteiros menores, de maneira a não ocorrer violação das restrições de demanda, ou seja, de forma que ainda se tenha uma solução inteira factivel. Na literatura é sugerido que a redução destes padrões de corte seja de uma unidade. Tão logo uma variável $x_{k}^{\mathrm{B1}}$, da heuristica anterior, dentro das variáveis básicas seja identificada, ou seja, uma variável tal que a restrição

$$
a_{i k}\left(x_{k}^{\mathrm{B} 1}-1\right)+\sum_{\substack{j \neq k \\ j \neq k}} a_{i j} x_{j}^{\mathrm{B} 1} \geq d_{i}, \quad i=1,2, \ldots, m
$$

seja válida, $x_{k}^{\mathrm{B1}}$ é reduzida de uma unidade.

Como foi observado, ao aplicarmos a heurística B1, em nosso exemplo, obtivemos um excesso de produção indesejável. Utilizando a idéia da heurística B2 para reduzir este excesso temos que identificar uma variável $x_{k}^{B 1}$, que possa ser reduzida de uma unidade, sem que a demanda seja afetada.

Façamos uma análise:

Se $x_{1}^{\mathrm{Bl}}=48 \Rightarrow \widetilde{d}_{1}=96<d_{1}$

Se $x_{2}^{\mathrm{B} 1}=100 \Rightarrow \widetilde{d}_{2}=610 \geq d_{2}$

Se $x_{3}^{\mathrm{B} 1}=197 \Rightarrow \tilde{d}_{2}=611>d_{2}, \operatorname{mas} \tilde{d}_{3}=394<\mathrm{d}_{3} \Rightarrow x_{k}^{\mathrm{B} 1}=\widetilde{x}_{2}^{*}$

Se $x_{4}^{\mathrm{B} 1}=105 \Rightarrow \tilde{d}_{2}=610 \geq d_{2}, \operatorname{mas} \tilde{d}_{4}=210<d_{4}$

Resultando em: $\mathrm{x}^{\mathrm{B} 2}=(49 ; 100 ; 198 ; 106)$, o que corresponde a cortar 453 peças em estoque. Neste caso, o método heuristico obteve solução ótima. 
Observação 3.2: Utilizaremos $\tilde{d}_{i}$ para denotar a produção do item $i$ depois de realizado o arredondamento das freqüências para o inteiro superior ou para o inteiro inferior .

\section{$\rightarrow$ Heurística B3}

Este método consiste em, após terem sido determinadas as variáveis básicas, de acordo com a solução ótima do problema relaxado, encontrar a solução ótima do seguinte problema de programação linear:

$$
\begin{aligned}
\operatorname{minimize} & \sum_{j=1}^{m} \widetilde{x}_{j} \\
\text { sujeito a }: & \sum_{j=1}^{m} a_{i j} \widetilde{x}_{j} \geq d_{i}, \quad i=1, \ldots, m \\
& \widetilde{x}_{j} \geq 0
\end{aligned}
$$

onde:

- todas as variáveis básicas da solução ótima do problema relaxado que já corresponderem a valores inteiros serão fixados como:

$$
x_{j}^{\mathrm{B} 3}=\widetilde{x}_{j}^{*}, \quad \widetilde{x}_{j}^{*} \text { inteiro }
$$

- A variável $\widetilde{x}_{k}^{*}$, dentro das variáveis básicas, com o maior valor não-inteiro é arredondada para o inteiro superior da seguinte forma:

$$
x_{k}^{\mathrm{B} 3}=\left\lceil\tilde{x}_{k}^{*}\right\rceil
$$

Ao resolver o problema de otimização linear (3.16), juntamente com as duas restrições acima, não se pode garantir que teremos todas as variáveis inteiras. Neste caso o processo poderá ser repetido, fixando outras variáveis de acordo com (3.17) e (3.18). Como ao menos uma variável a mais será fixada em cada iteração, pode-se observar que para chegar à solução inteira do problema original serão feitas no máximo $m$ iterações. Observe que ao aplicarmos as relações (3.17) e (3.18) ao problema (3.16), estas variáveis deixarão de ser incógnitas e passarão 
para o lado direito da restrição de demanda na formulação do novo problema de programação linear que será resolvido.

Para o exemplo 3.1, voltemos à solução do problema original relaxado em (3.8) e veremos que, inicialmente, não temos nenhum valor já inteiro que possamos fixar segundo (3.17). E, como a maior freqüência é a terceira, teremos que $k=3$ e, pela relação (3.18):

$$
x_{k}^{\mathrm{B} 3}=\left\lceil\tilde{x}_{3}^{*}\right\rceil=198
$$

Como esta frequêencia está relacionada com o padrão $\left(\begin{array}{l}0 \\ 1 \\ 2 \\ 0\end{array}\right)$, estaremos produzindo 198 itens do tipo 2 e 396 itens do tipo 3. Com isto a demanda do tipo 3 foi atendida e os dados do novo problema de programação linear a ser resolvido serão:

\begin{tabular}{|lll|}
\hline$=100 \mathrm{~cm}$ & & \\
$l_{1}=45 \mathrm{~cm}$ & $\mapsto$ & $d_{1}=97$ \\
$l_{2}=36 \mathrm{~cm}$ & $\mapsto$ & $d_{2}=412$ \\
$l_{3}=14 \mathrm{~cm}$ & $\mapsto$ & $d_{3}=211$
\end{tabular}$\quad$ cuja solução é: $\left\{\begin{array}{l}\widetilde{x}_{1}^{*}=48,5 \\
\tilde{x}_{2}^{*}=100,5 \\
\tilde{x}_{3}^{*}=105,5\end{array}\right.$

$\therefore k=3 \Rightarrow x_{k}^{\mathrm{B} 3}=\left\lceil\tilde{x}_{3}^{*}\right\rceil=106$

A solução acima está relacionada com os seguintes padrões: $\left(\begin{array}{l}2 \\ 0 \\ 0\end{array}\right),\left(\begin{array}{l}0 \\ 2 \\ 0\end{array}\right),\left(\begin{array}{l}0 \\ 2 \\ 2\end{array}\right)$

Como a freqüência $x_{k}^{\mathrm{B} 3}$ está relacionada com o padrão $\left(\begin{array}{l}0 \\ 2 \\ 2\end{array}\right)$, estaremos produzindo 212 itens do tipo 2 e 212 itens do tipo 4 (do problema original). Com isto a demanda do tipo 4 foi atendida e os dados do novo problema de programação linear a ser resolvido será: 


$$
\begin{array}{lll}
L=100 \mathrm{~cm} & & \\
l_{1}=45 \mathrm{~cm} & \mapsto & d_{1}=97 \\
l_{2}=36 \mathrm{~cm} & \mapsto & d_{2}=200
\end{array}
$$

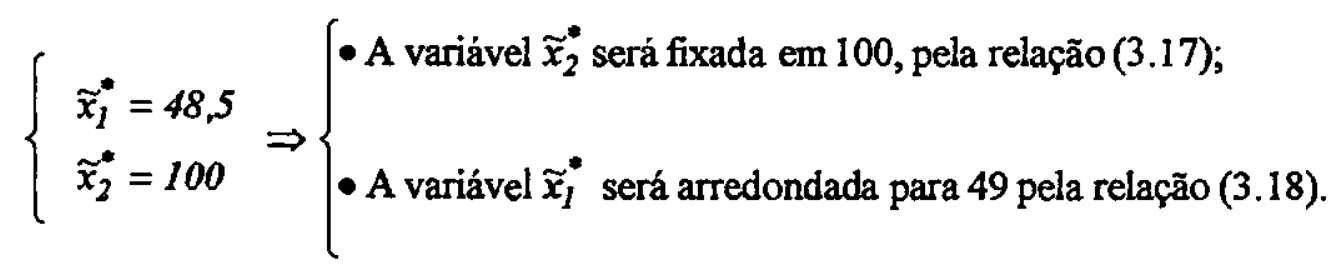

A solução acima está relacionada com os seguintes padrões: $\left(\begin{array}{l}2 \\ 0\end{array}\right),\left(\begin{array}{l}0 \\ 2\end{array}\right)$

Assim estaremos produzindo 98 itens do tipo 1 e 200 itens do tipo 2. Com isto a solução obtida é inteira e todas as demandas foram atendidas, o que resulta no término do processo. Neste caso, utilizamos: $198+106+100+49=453$ barras, que também é ótima mas com um excesso de produção.

Neste método as variáveis são arredondadas para o inteiro superior sucessivamente, utilizando (3.18). Note que, em cada iteração, somente problemas lineares terão que ser resolvidos. Porém, a solução inteira obtida ao final do processo descrito acima, poderá não ser uma solução inteira ótima para o problema.

Observação 3.3 : O problema de otimização linear apresentado em B3, formado apenas pelos padrões básicos, poderia ser resolvido como um problema de programação inteira de forma ótima, utilizando algum método de resolução conhecido na literatura, como por exemplo, métodos de plano de corte ou enumeração implícita. Isto é razoável, já que o número de variáveis para este problema é relativamente pequeno, sendo igual a $m$, o tamanho do pedido. Entretanto, observe que esta solução ótima encontrada somente resultaria em um ótimo local para o problema original, já que o espaço de solução para o problema de programação linear apresentado acima está artificialmente restrito aos padrões básicos da solução ótima para o problema relaxado. 


\subsubsection{Métodos para o problema residual}

Estes métodos consistem em arredondarmos para o inteiro inferior todas as componentes não-inteiras de (3.9). Ao fazermos isto, o seguinte vetor é obtido:

$$
\left(\left\lfloor\tilde{x}_{1}^{*}\right\rfloor,\left\lfloor\tilde{x}_{2}^{*}\right\rfloor, \ldots,\left\lfloor\tilde{x}_{n}^{*}\right\rfloor\right)
$$

onde: $\left\lfloor\widetilde{x}_{j}^{*}\right\rfloor=$ maior inteiro menor ou igual a $\widetilde{x}_{j}^{*}$. O que corresponde ao seguinte valor para a função objetivo: $\sum_{j=1}^{n}\left\lfloor\tilde{x}_{j}^{*}\right\rfloor$.

Para o exemplo 3.1, teremos que a relação (3.19) será: $(48,100,197,105,0,0, \ldots)$.

Observe que o vetor (3.19) não representa uma solução factível para o problema original, pois providenciará $\sum_{j=1}^{n} a_{i j}\left\lfloor\tilde{x}_{j}^{*}\right\rfloor$ unidades de comprimento $l_{i}$, onde nem sempre toda a demanda será atendida. Desta forma faltarão $\left.d_{i}-\sum_{j=1}^{m} a_{i j} \mid \tilde{x}_{j}^{*}\right\rfloor$ unidades de comprimento $l_{i}$ a serem atendidas, resultando em um problema residual, que é representado da seguinte forma:

$$
\begin{aligned}
\text { minimizar } & \sum_{j=1}^{n} y_{j} \\
\text { sujeito a : } & \sum_{j=l}^{n} a_{i j} y_{j} \geq d_{i}-\sum_{j=1}^{m} a_{i j}\left\lfloor\widetilde{x}_{j}^{*}\right\rfloor \quad i=1, \ldots, m \\
& y_{j} \geq 0 \text { e inteiro, } j=1, \ldots, n .
\end{aligned}
$$

A idéia básica do método, que será apresentado agora, consiste em resolver o problema residual acima separadamente e combinar sua solução com a solução inteira obtida pelo arredondamento para o inteiro inferior da solução do problema relaxado para o problema original, isto é: $x^{H}=\left\lfloor\widetilde{x}_{j}^{*}\right\rfloor+y_{j}$ 
Desta forma, o valor correspondente da função objetivo para esta solução combinada será dada por. $\sum_{j=1}^{n}\left(\left\lfloor\tilde{x}_{j}^{*}\right\rfloor+y_{j}\right)$.

Como pode ser observado, o problema residual (3.21) difere do problema original somente em relação às restrições de demanda, com respeito ao lado direito. Com relação ao lado esquerdo são idênticos, porque tanto 0 problema original quanto $o$ residual contêm os mesmos pedidos dos fregueses. Façamos então um paralelo com o problema original: levando em consideração a idéia de fazer a combinação das soluções segundo a relação (3.23), vemos que a restrição de demanda será reescrita, em sua forma matricial, para o problema residual da seguinte maneira:

$$
A \mathbf{A} \geq \mathbf{d} \Rightarrow \mathbf{A}[\tilde{\mathbf{x}}\rfloor+\mathbf{A y} \geq \mathbf{d} \Rightarrow \mathbf{A y} \geq \underbrace{\mathbf{d}-\mathbf{A}\lfloor\tilde{\mathbf{x}}\rfloor}_{r=\text { residio }}
$$

Isto resultará em uma formulação do problema residual, também na forma matricial, como segue:

\section{Problema Residual:}

$$
\begin{aligned}
& \operatorname{minimizar} f(\mathbf{y})=\mathbf{c}^{\mathbf{T}} \mathbf{y} \\
& \text { sujeito a }: \mathbf{A y} \geq \mathbf{r} \\
& \mathbf{y} \geq \mathbf{0} \text { e inteiro }
\end{aligned}
$$

Para o exemplo 3.1, vimos que ao fazermos o arredondamento para o inteiro inferior, estaremos deixando de produzir um pouco de cada item, pois estaremos produzindo:

$\widetilde{\mathbf{d}}^{T}=(96,607,394,210)$. Fazendo a diferença do que necessitamos produzir e o que já produzimos, teremos:

$\mathbf{d}-\tilde{\mathbf{d}} \Rightarrow$ demanda residual, ou seja: $\mathbf{r}^{T}=(1,3,1,1)$. 
Outra diferença, também importante, entre os problemas (3.4) e (3.24) é com relação ao número total de itens demandados que no residual é muito menor quando comparado à demanda do original. Com isto parece ser melhor tratar o problema residual como um bin-packing, que poderá ser resolvido tanto por algoritmos exatos quanto heuristicos. Entretanto, resolvê-lo otimamente pode não ser um caminho viável por dois motivos. $O$ primeiro deles está relacionado com a solução do problema original consistir de uma combinação da solução residual com a obtida utilizando o arredondamento para o inteiro inferior da solução do problema relaxado. Isto não garante que ao final do processo, teremos uma solução ótima para o original. $O$ segundo motivo a ser considerado é que o múmero de itens a ser produzido pelo problema residual pode ser grande (em particular, quando o número de pedidos é grande) resultando num esforço computacional não aconselhável para a resolução do problema como um bin-packing.

Vejamos então os métodos:

\section{$\rightarrow$ Heurística R1}

Com a intenção de reduzir o esforço computacional mencionado acima, pode-se resolver o problema residual através de um algoritmo heuristico. Wäsher e Gau (1996) optaram pela heurística FFD, cujo funcionamento apresentamos na seção 3.4. Entretanto, outros procedimentos simples poderiam ser utilizados neste caso, como por exemplo, a heurística BFD (Best-Fit-Decreasing).

Para ilustrar o método, consideremos novamente o exemplo 3.1 onde, ao aplicar a heuristica FFD, para atender o resíduo obtido ao fazermos o arredondamento indicado em (3.19), obtivemos os seguintes padrōes:

$$
\left(\begin{array}{l}
1 \\
1 \\
0 \\
1
\end{array}\right),\left(\begin{array}{l}
0 \\
2 \\
0 \\
0
\end{array}\right),\left(\begin{array}{l}
0 \\
0 \\
1 \\
0
\end{array}\right)
$$

(que serão utilizados uma única vez)

Observe que o segundo padrão gerado já havia sido obtido quando resolvemos o problema original relaxado. Portanto, a solução do problema residual combinada com a relaxação do 
problema original resulta nas freqüências $\left\{\begin{array}{c}x_{1}^{\mathrm{R} 1}=48 \\ x_{2}^{\mathrm{R} 1}=101 \\ x_{3}^{\mathrm{RI}}=197 \\ x_{4}^{\mathrm{RI}}=105 \\ x_{5}^{\mathrm{RI}}=1 \\ x_{6}^{\mathrm{R} 1}=1\end{array}\right.$, que estão relacionadas com os

seguintes padrões:

$$
a_{1}=\left(\begin{array}{l}
2 \\
0 \\
0 \\
0
\end{array}\right) \quad a_{2}=\left(\begin{array}{l}
0 \\
2 \\
0 \\
0
\end{array}\right) \quad a_{3}=\left(\begin{array}{l}
0 \\
1 \\
2 \\
0
\end{array}\right) \quad a_{4}=\left(\begin{array}{l}
0 \\
2 \\
0 \\
2
\end{array}\right) \quad a_{5}=\left(\begin{array}{l}
1 \\
1 \\
0 \\
1
\end{array}\right) a_{6}=\left(\begin{array}{l}
0 \\
0 \\
1 \\
0
\end{array}\right)
$$

Somando as freqüências teremos: $48+101+197+105+1+1=453$ barras. Ou seja, neste exemplo pequeno, conseguimos também com este procedimento encontrar a solução ótima.

\section{$\rightarrow$ Heurística $\mathbf{R 2}$}

Neste método (3.24), que é um problema de programação inteira, será relaxado com respeito à integralidade, sendo resolvido utilizando a técnica de geração de colunas apresentada na seção 3.2 deste capitulo. Ao chegar à uma solução com variáveis não-inteiras, tornamos a fazer um arredondamento para o inteiro inferior destas variáveis, resultando em outro problema residual que será tratado da mesma forma, e assim por diante. Este processo termina quando o arredondamento para o inteiro inferior resultar somente em freqüências nulas. Mas, com este procedimento algumas demandas, para somente alguns itens, ainda terão que ser satisfeitas, resultando assim num problema residual pequeno e que poderá ser resolvido por um algoritmo bin-packing.

Para ficar mais claro, escreveremos o algoritmo deste procedimento da seguinte forma:

\section{\{início do algoritmo\}}

1. Resolver o problema residual utilizando a técnica de geração de colunas (integralidade relaxada), obtendo a solução $\widetilde{\mathbf{y}}$. Neste caso, consideramos que o Problema da Mochila 
deve ser resolvido como sendo restrito, conforme será mencionado na seção 3.5. (No artigo, os autores não deixaram claro que, para o problema residual, a mochila deveria ser considerada desta forma);

2. Se $\lfloor\tilde{\mathbf{y}}\rfloor=0$ Então: utilize outra heurística para determinar $\tilde{\mathbf{y}}$.

Por exemplo, FFD: construa padrōes colocando-se primeiramente os itens de comprimentos maiores.

Señ̃o, faça:

$$
\begin{aligned}
& \mathbf{x}\lfloor\tilde{\mathbf{x}}\rfloor+\lfloor\tilde{\mathbf{y}}\rfloor \\
& \mathbf{r} \leftarrow \mathbf{r}-\mathbf{A}\lfloor\tilde{\mathbf{y}}\rfloor \\
& \text { Repita passo } 1 .
\end{aligned}
$$

\section{\{fim do algoritmo\}}

Seguindo os passos do algoritmo para o exemplo 3.1, relaxamos o problema residual e o resolvemos também utilizando o Método Simplex com geração de colunas. Agora, quando consideramos o caso restrito, temos que a demanda a ser atendida é: $\mathbf{d}^{T}=\mathbf{r}^{T}=(1,3,1,1)$. Com isto a quantidade de vezes que o item $i$ aparece no padrão $j$ terá que ser o mínimo entre o que ainda cabe na peça em estoque e a demanda residual, ou seja: $a_{i j}=\min \left\{\left\lfloor\frac{L}{l_{i}}\right\rfloor, r_{i}\right\}$.

Levando isto em consideração, obtemos a seguinte solução:

$$
\left\{\begin{array}{l}
\tilde{x}_{1}^{*}=0,5 \\
\tilde{x}_{2}^{*}=0,5 \\
\tilde{x}_{3}^{*} \cong 0,33333 \\
\tilde{x}_{4}^{*}=1
\end{array} \text {, onde: } a_{1}=\left(\begin{array}{l}
2 \\
0 \\
0 \\
0
\end{array}\right) a_{2}=\left(\begin{array}{l}
0 \\
2 \\
0 \\
0
\end{array}\right) a_{3}=\left(\begin{array}{l}
0 \\
0 \\
3 \\
0
\end{array}\right) a_{4}=\left(\begin{array}{l}
0 \\
2 \\
0 \\
1
\end{array}\right)\right.
$$

Observe que, ao considerarmos a mochila restrita, novos padrões foram gerados. Realizando $o$ arredondamento para o inteiro inferior, teremos:

$$
\left\lfloor\tilde{x}^{*}\right\rfloor=(0,0,0,1) \Rightarrow \mathbf{r}^{T}=(1,1,1,0) .
$$


Como ainda temos demanda a ser atendida, voltamos ao passo 1 do algoritmo e resolvemos novamente o problema residual, onde obtemos:

$$
\left\{\begin{array}{l}
\tilde{x}_{1}^{*}=0,5 \\
\tilde{x}_{2}^{*}=0,5 \\
\tilde{x}_{3}^{*} \cong 0,33333 \\
\tilde{x}_{4}^{*}=0
\end{array}, \text { onde: } a_{1}=\left(\begin{array}{l}
2 \\
0 \\
0 \\
0
\end{array}\right) \quad a_{2}=\left(\begin{array}{l}
0 \\
2 \\
0 \\
0
\end{array}\right) a_{3}=\left(\begin{array}{l}
0 \\
0 \\
3 \\
0
\end{array}\right) \quad a_{4}=\left(\begin{array}{l}
0 \\
0 \\
0 \\
7
\end{array}\right)\right.
$$

Realizando o arredondamento para o inteiro inferior:

$\left\lfloor\tilde{x}^{*}\right\rfloor=(0,0,0,0) \Rightarrow$ freqüência nula.

Agora, conforme descrito no algoritmo, utilizamos a heurística FFD para atender a demanda residual, onde obtemos os dois últimos padrões: $\left(\begin{array}{l}I \\ I \\ 0 \\ 0\end{array}\right)$ e $\left(\begin{array}{l}0 \\ 0 \\ 1 \\ 0\end{array}\right)$, que são utilizados uma única vez.

Com isto a solução final do procedimento, depois de feitas as combinações, resulta em:

$$
\left\{\begin{array}{rl}
x_{1}^{\mathrm{R} 2} & =48 \\
x_{2}^{\mathrm{R} 2} & =100 \\
x_{3}^{\mathrm{R} 2} & =197 \\
x_{4}^{\mathrm{R} 2} & =105 \\
x_{5}^{\mathrm{R} 2} & =1 \\
x_{6}^{\mathrm{R} 2} & =1 \\
x_{7}^{\mathrm{R} 2} & =1
\end{array} \Rightarrow \sum_{i=1}^{7} x_{i}^{\mathrm{R} 2}=453\right. \text { barras }
$$

Estas freqüências estão relacionadas com os respectivos padrões:

$$
a_{1}=\left(\begin{array}{l}
2 \\
0 \\
0 \\
0
\end{array}\right) \quad a_{2}=\left(\begin{array}{l}
0 \\
2 \\
0 \\
0
\end{array}\right) \quad a_{3}=\left(\begin{array}{l}
0 \\
I \\
2 \\
0
\end{array}\right) \quad a_{4}=\left(\begin{array}{l}
0 \\
2 \\
0 \\
2
\end{array}\right) \quad a_{5}=\left(\begin{array}{l}
0 \\
2 \\
0 \\
1
\end{array}\right) \quad a_{6}=\left(\begin{array}{l}
I \\
1 \\
0 \\
0
\end{array}\right) a_{7}=\left(\begin{array}{l}
0 \\
0 \\
I \\
0
\end{array}\right)
$$




\subsubsection{Método Composto}

Como o nome sugere, este método consiste em combinar as idéias dos métodos de padrões básicos com as dos métodos para o problema residual, podendo ser representado pela seguinte heurística:

\section{$m$ Heurística C1}

Para gerar uma solução factivel para o problema original a heurística B3 é utilizada. Com isto um excesso de produção ocorre, o qual será reduzido iterativamente. Para fazer isto, o padrão de corte, que contém o maior número de peças demandadas em excesso, é identificado. A quantidade de vezes que este padrão será cortado, será reduzida de uma unidade. A partir daí, este passo será repetido até que não haja mais excesso.

Mas, agora pode estar faltando atender a demanda de alguns itens resultando, desta forma, em um problema residual como o apresentado anteriormente. Este problema poderá ser resolvido utilizando a heuristica $\mathrm{FFD}$, sendo que algum outro algoritmo bin-packing poderia ser utilizado.

Observação 3.4: Neste caso, poderiamos também resolver o problema residual utilizando um algoritmo exato, como mencionado nos Métodos para o Problema Residual, da subseção anterior.

Para o exemplo 3.1, quando utilizamos anteriormente a heuristica B3, obtivemos um excesso de produção, que será descrito a seguir.

Produzimos: $\left\{\begin{array}{l}\bullet 98 \text { itens do tipo 1; } \\ \bullet 610 \text { itens do tipo 2; } \\ \bullet 396 \text { itens do tipo 3; } \\ \bullet 212 \text { itens do tipo 4; }\end{array}\right.$ sendo que precisávamos de: $\left\{\begin{array}{l}\bullet 97 \text { itens do tipo 1; } \\ \bullet 610 \text { itens do tipo 2; } \\ \bullet 395 \text { itens do tipo 3; } \\ \bullet 211 \text { itens do tipo 4; }\end{array}\right.$

As frequiências que resultaram o excesso estão relacionadas aos seguintes padrões de corte: 


$$
a_{1}=\left(\begin{array}{l}
2 \\
0 \\
0 \\
0
\end{array}\right) \quad a_{2}=\left(\begin{array}{l}
0 \\
2 \\
0 \\
0
\end{array}\right) \quad a_{3}=\left(\begin{array}{l}
0 \\
1 \\
2 \\
0
\end{array}\right) \quad a_{4}=\left(\begin{array}{l}
0 \\
2 \\
0 \\
2
\end{array}\right) \text { e suas freqüências : }\left\{\begin{array}{c}
x_{1}^{\mathrm{B} 3}=49 \\
x_{2}^{\mathrm{B} 3}=100 \\
x_{3}^{\mathrm{B} 3}=198 \\
x_{4}^{\mathrm{B} 3}=106
\end{array}\right.
$$

Comecemos pelo primeiro item em excesso, que é o tipo 1. Observe que somente o primeiro padrão de corte possui este item. Com isto pela heuristica $\mathrm{C} 1$, devemos reduzir 49 de uma unidade, ou seja, estaremos cortando 48 barras segundo o padrão 1. Entretanto, se tivéssemos mais de um padrão escolheríamos aquele com a maior quantidade do item que está sendo analisado. Com esta primeira decisão tomada, já não existe excesso de produção do primeiro item e sim um resíduo que será resolvido depois. Como o padrão 1 possui apenas itens do tipo 1, esta redução não afetará a produção dos demais itens.

Passemos então para o segundo item, que não está sendo produzido em excesso, pois estamos obtendo 610 itens, o que corresponde exatamente a quantidade pedida. Passemos assim para 0 item 3, onde ocorre o excesso de um item. Novamente como o único padrão que possui este item é o terceiro, reduziremos sua frequiência para 197. Esta redução faz com que para o item 3, já não exista mais excesso e sim um resíduo de uma unidade, o qual será resolvido depois. Observe neste ponto, que ao fazermos esta redução, a produção do item 2 fica comprometida de um item. Ou seja, agora temos um resíduo a ser resolvido também para o item 2. Passemos então para o último item, que possui também um excesso de uma unidade. Como o único padrão que possui este item é o quarto, este terá sua freqüência diminuída de um, fazendo com que o excesso desapareça e um residuo de um item apareça. Observe que, novamente, esta redução afetou a produção do item 3 , sendo que agora seu residuo aumentou para 3 unidades.

Finalizando a primeira parte da heurística, temos até agora o seguinte resultado:

$$
\left\{\begin{array}{l}
x_{1}^{\mathrm{C}}=48 \\
x_{2}^{\mathrm{C}}=100 \\
x_{3}^{\mathrm{C}}=197 \\
x_{4}^{\mathrm{C} 1}=105
\end{array} \text {, relacionado com os padrōes: } a_{1}=\left(\begin{array}{l}
2 \\
0 \\
0 \\
0
\end{array}\right) a_{2}=\left(\begin{array}{l}
0 \\
2 \\
0 \\
0
\end{array}\right) a_{3}=\left(\begin{array}{l}
0 \\
1 \\
2 \\
0
\end{array}\right) a_{4}=\left(\begin{array}{l}
0 \\
2 \\
0 \\
2
\end{array}\right)\right.
$$


$\Rightarrow \mathbf{r}=\left(\begin{array}{l}1 \\ 3 \\ l \\ l\end{array}\right)$, que representa a demanda residual.

Utilizando a heuristica FFD, obtivemos os seguintes padrões: $\left(\begin{array}{l}I \\ I \\ 0 \\ I\end{array}\right),\left(\begin{array}{l}0 \\ 2 \\ 0 \\ 0\end{array}\right),\left(\begin{array}{l}0 \\ 0 \\ 1 \\ 0\end{array}\right)$

O segundo padrão é novamente gerado, fazendo com que ao invés de utilizá-lo 100 vezes, o mesmo seja utilizado 101 vezes. Com isto o problema está resolvido e utilizamos com esta heuristica: $48+101+197+105+1+1=453$ peças em estoque.

Um fato a ser considerado é que a cada decisão tomada, ou seja, a cada frequiência diminuída para um determinado item, é necessário que uma análise seja feita para verificar em que esta decisão influenciou na freqüência dos demais itens e, somente depois, aplicar a heuristica para o próximo item.

\subsection{Heurística FFD}

Nesta seção, apresentaremos um algoritmo para a heurística FFD usado para resolver o problema residual que, de forma geral, consiste em colocar a peça maior, ou mais valiosa, num padrão tantas vezes quanto possível, ou seja, até que não se consiga mais colocar esta peça ou até que sua demanda já tenha sido atendida. E, quando não for mais possível, passar para a próxima peça. Para ficar mais claro como esta heuristica funciona, apresentamos seu algoritmo:

\section{\{início do algoritmo\}}

\section{Passo 1:}

Ordene as peças a serem demandadas, segundo o tamanho. Por simplicidade de notação, suponha que: $l_{1} \geq l_{2} \geq \ldots \geq l_{m}$. 
Passo 2 :

Considere $k=m+1$, como sendo o primeiro padrão para o problema residual. (Supondo que $m$ padrões já foram definidos na resolução do problema original relaxado.)

Considere a demanda residual total como sendo: $D=\sum_{i=1}^{m} r_{i}$, onde $r_{i}$ representa a demanda residual de $l_{i}$.

\section{Passo 3 :}

Enquanto $D>0$ (enquanto existir demanda a ser satisfeita) faça:

\{inicio enquanto 1 \}

Faça: $\operatorname{RESTO}=\mathrm{L} ; i=1 ; \alpha_{j}=0, j=1, \ldots, m$.

(aqui, RESTO representa o espaço restante para alocação dos itens que, inicialmete, será igual ao comprimento total da barra.)

Enquanto $i \leq m$ e RESTO $\geq l_{m}$

(enquanto não tiver tentado colocar todos os itens para a construção do padrão ou enquanto couber algum item), faça:

\{início enquanto 2 \}

$-\alpha_{i}=\min \left\{\left[\frac{\mathrm{RESTO}}{l_{i}}\right\rfloor, r_{i}\right\}$

(o vetor $\alpha$ determinará quantas vezes cada item será utilizado para a construção de cada padrão de corte, que deverá ser igual ao mínimo entre o quanto este item pode ser alocado na barra e a quantidade que ainda falta para atender sua demanda.)

(atualização)

$$
\begin{aligned}
& \text { - RESTO = RESTO }-\alpha_{\mathrm{i}} * l_{i} \\
& \text { - } r_{i}=r_{i}-\alpha_{i} \\
& \text { - } D=D-\alpha_{i} \\
& \text { - } i=i+1
\end{aligned}
$$

\{fim enquanto 2$\}$ 
Faça: $a_{i k}=\alpha_{i} \quad i=1, \ldots, m$

(ou seja, o padrão de corte será montado com o auxílio do vetor $\alpha$ já obtido)

Faça: $k=k+1$ (Passa para a construção do próximo padrão)

\{fim enquanto 1\}

\section{\{fim do algoritmo\}}

Segundo Chvátal (1980), este procedimento produz soluções inteiras razoavelmente boas para problemas bin-packing , no caso unidimensional.

\subsection{Avaliação dos métodos heurísticos}

Depois da realização de vários testes, Wäscher e Gau (1996) chegaram à conclusão de que dois dos métodos apresentados na seção 3.3 são claramente superiores aos outros: a heurística R2 e a heurística $\mathrm{Cl}$. Estes métodos resolveram todos os exemplos rodados com diferença de uma unidade do valor ótimo da função objetivo. E ainda, para $98 \%$ e $92,7 \%$ dos exemplos, respectivamente, foi mostrado que uma solução ótima foi encontrada. Quanto ao tempo computacional, em média, foi pequeno para exemplos grandes.

Para aqueles problemas, que consumiram um maior tempo computacional de resolução foi verificado, que a geração de colunas foi o processo que exigiu maior tempo para ser feito (por volta de $76,6 \%$ para a heurística $\mathrm{R} 2$ e $90,3 \%$ para a heurística $\mathrm{C1}$ ).

Durante nossos estudos, fizemos algumas análises que serão consideradas abaixo:

1. Quando o arredondamento ocorre para o inteiro superior, a geraf̧ão de novos padrões além daqueles obtidos durante a geração de colunas, não é permitida, limitando a procura da solução inteira;

2. O arredondamento para o inteiro inferior permite a geração de padrões de corte diferentes daqueles gerados na resolução do problema original relaxado, o que amplia o espaço de busca; 
3. Ainda com relação ao arredondamento para o inteiro inferior, observamos que na resolução do problema residual, existe a necessidade de resolver os problemas da mochila necessários durante as iterações simplex como problemas restritos, evitando-se que a solução retorne ao ponto obtido anteriormente. Estes problemas possuem a formulação segundo (3.7b), onde agora a demanda residual deverá ser considerada no lugar da demanda original, ou seja, o vetor deverá ser substituído pelo vetor $\mathbf{r}$.

A desconsideração dos limitantes superiores, para a geração de colunas, produz padrões cuja freqüência é menor que um, ou seja, padrões que, uma vez utilizados, geram excesso de produção. Scheithauer e Terno (1997) chamam estes padrões de impróprios. 


\section{CAPÍtulO 4}

iif . O Problema de Corte de Estoque Inteiro Bidimensional

I : O objetivo principal deste trabalho, como mencionado no capitulo 1, consiste em verificar a

ii. : : possibilidade de estender o estudo realizado por Wäscher e Gau (1996), ou seja, trabalhar com

$\because$. métodos heurísticos de arredondamento para buscar uma solução inteira na 'vizinhança' de uma

a $\mathrm{m}$ solução relaxado contínua, considerando agora o caso bidimensional. Com isto neste capitulo,

$: 0 ₹$ a apresentamos o estudo realizado sobre este caso, onde consideramos agora duas dimensões relevantes no processo de corte.

:L:= Iniciamos este capítulo com a seção 4.1 , na qual definimos e formulamos o problema $\therefore$. . bidimensional. Será visto que o modelo básico (3.4) continua sendo válido, exceto pelo fato de

it . que o Problema da Mochila não mais modela um padrão de corte e, neste caso, optamos por .ก considerar o problema estagiado. Neste trabalho em particular estaremos restringindo o problema

.ri de forma a considerá-lo guilhotinado 2-estágios não-exato. A resolução do Problema da Mochila bidimensional será apresentada na seção 4.2.

.ंe: - Na seção 4.3 faremos um breve comentário de como, o Método Simplex com Geração de * Colunas pode ser estendido, ou seja, vamos utilizar o mesmo método apresentado na seção 3.2 r. do capítulo anterior, fazendo apenas as modificações necessárias quando tratamos de problemas

- bidimensionais. Em seguida, o método heurístico que implementamos para resolução do

1. . : problema de corte de estoque inteiro bidimensional é apresentado na seção 4.4. Este método é uma extensão da heurística $R 2$ do capítulo 3.

A seção 4.5 trata dos limitantes, utilizados como pontos de referência na avaliação da qualidade da solução obtida heuristicamente. 


\subsection{Definição e Formulação do Problema}

O problema de corte de estoque bidimensional pode ser definido da seguinte forma:

Considere um estoque de placas retangulares de largura $W$, comprimento $L$ e uma demanda $d_{i}$ de retângulos menores de largura $w_{i}$ e comprimento $l_{i}, i=1, \ldots, m$. Estes retângulos menores serão chamados itens. 0 problema bidimensional consiste em cortar as placas retangulares em estoque para obtenção dos itens, de maneira a utilizar uma quantidade mínima destas placas.

Este tipo de problema ocorre, por exemplo, em indústrias de placas de vidro. Aqui também existe uma variedade de tipos de funçס̃es alternativas a serem otimizadas, como por exemplo, a minimização das perdas e a maximização dos lucros ou da produtividade.

Como no problema unidimensional, a cada maneira diferente de cortar as peças em estoque utlizando as peças menores, chamamos de padrão de corte, como ilustrado na figura abaixo:

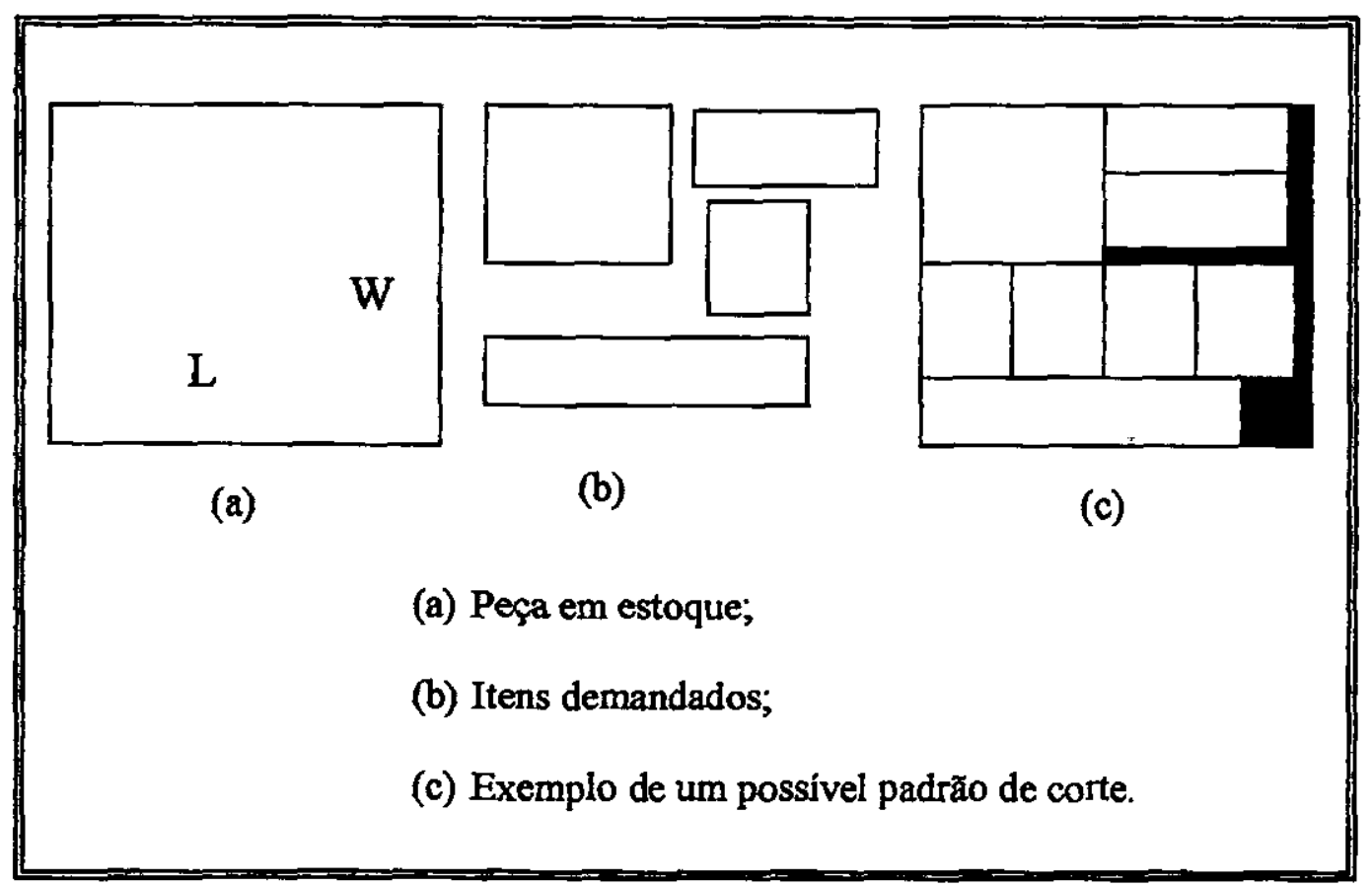

Figura 4.1: Exemplo de padrão de corte bidimensional 
Também associamos a cada padrão de corte um vetor $m$-dimensional que contabiliza os itens produzidos:

$$
a_{j}=\left(a_{1 j}, a_{2 j}, \ldots, a_{m j}\right) \quad j=1,2, \ldots, n
$$

onde: $a_{i j}$ é a quantidade de itens do tipo i, cortados segundo o padrão de corte $j$.

$n$ é o número total de padrões obtidos.

Observação 4.1: Para o caso bidimensional, que estamos tratando, este vetor não é obtido apenas resolvendo o Problema da Mochila, isto é, não basta que satisfaça as restrições fisicas do problema como para o caso unidimensional em (3.7a) e (3.7b). Neste caso, torna-se necessário outras considerações, relativas às regras de cortagem, que serão feitas mais adiante.

Temos que considerar também para o caso bidimensional, as duas etapas citadas quando definimos o problema unidimensional em (3.1a) e (3.1b). Ou seja, depois de definir os padrões de corte, devemos determinar o número de vezes que cada padrão será utilizado para atender a demanda. Portanto, considerando $x_{j}$ como sendo o número de vezes que a peça em estoque é cortada usando o padrão $j, j=1, \ldots, n$, obtemos o seguinte problema de otimização linear inteiro:

$$
\begin{aligned}
& \text { minimizar } f(\mathrm{x})=\sum_{j=1}^{n} x_{j} \\
& \text { sujeito a: } \sum_{j=1}^{n} a_{i j} x_{j} \geq d_{i}, i=1, \ldots, m, \\
& x_{j} \geq 0 \text { e inteiro, } j=1, \ldots . n .
\end{aligned}
$$

Observe que o modelo (4.2) é o mesmo modelo básico apresentado em (3.4), para o caso unidimensional. A diferença, como já observado, está na construção dos padrões de corte.

Também no caso bidimensional, resolver este problema otimamente para exemplos grandes torna-se inviável. Com isto o estudo de procedimentos heurísticos é importante. 


\subsection{Geração de Colunas aplicado ao Problema Bidimensional}

Da mesma forma que para o unidimensional, o Método Simplex com o processo de Geração de Colunas é utilizado. Entretanto, para o caso bidimensional, a escolha da coluna a entrar na base corresponde a resolver um problema de corte, formulado como:

$\operatorname{maximizar} \sum_{i} \pi_{i} y_{i}$

sujeito a: $\left(y_{1}, y_{2}, \ldots, y_{m}\right)^{T}$-corresponda a um padrão de corte para a placa $L \times W$

onde uma coluna $a=\left(y_{1}, y_{2}, \ldots, y_{m}\right)^{T}$ significa que $y_{i}$ itens foram produzidos no padrão de corte correspondente e $\pi_{i}$ é o multiplicador simplex.

Neste caso, um fator importante tem de ser considerado: o vetor associado ao padrão de corte que constitui as restriçðes do problema (4.3) não é mais trivialmente modelado como no caso unidimensional. Agora regras adicionais de cortagem, definidas pelos tipos de corte, são estabelecidas, as quais definem a disposição dos itens sobre a placa retangular em estoque.

Consideramos neste trabalho, restrições do tipo 2-estágios não-exato para o problema. $O$ corte do tipo 2-estágios está representado na figura (4.2). Tais restrições ocorrem, por exemplo, na indústria de móveis e consistem em produzir um dos mais simples padrões de cortes bidimensionais.

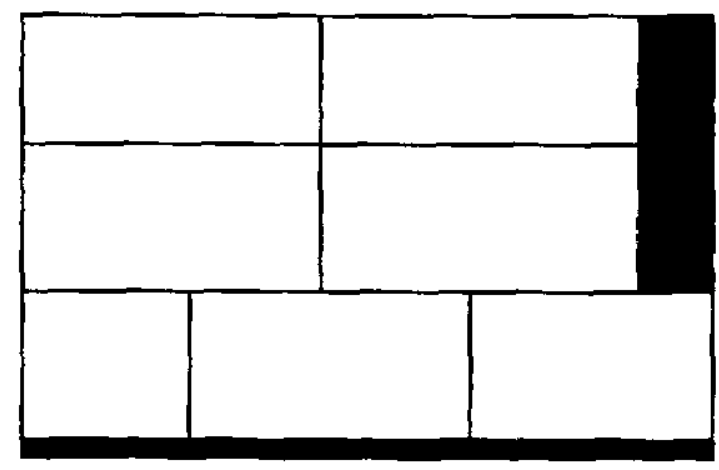

Figura 4.2: Corte guilhotinado 2-estágios

Definiremos mais formalmente os padrōes de corte guilhotinados e estagiados: 
Definição 4.1: Um corte é dito guilhotinado se, quando aplicado a um retângulo, produzir dois novos retângulos. Uma sequiência de cortes guilhotinados produz o que chamamos de corte guilhotinado (veja fig. 4.3a).

Padrões de corte não-guilhotinados (fig. 4.3b) ocorrem no problema de carregamento de paletes (segundo Morabito, 1992).

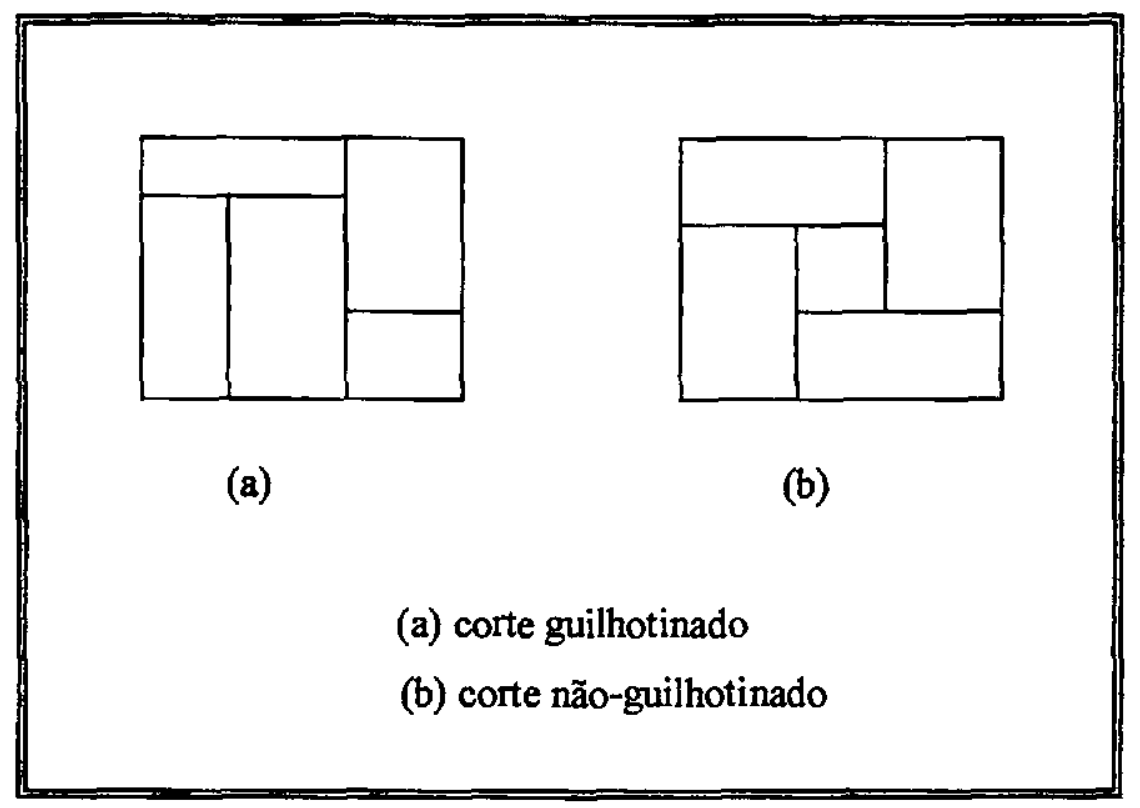

Figura 4.3: Tipos de corte

Os cortes guilhotinados são classificados em estagiados e não-estagiados. Um estágio é definido através da produção de um certo número de cortes guilhotinados numa mesma direção sobre a placa ou sobre partes dela, resultantes do estágio anterior. Os estágios sucessivos alternam a direção dos cortes, isto é, os cortes produzidos em um estágio subseqüiente são ortogonais ao corte produzido no estágio antecedente.

Definição 4.2: Um padrão de corte guilhotinado é dito ser em 2-estágios quando apenas uma mudança no sentido dos cortes guilhotinados é permitida, como na figura 4.2. Tais padrões são referidos simplesmente por padrões 2-estágios.

Um padrão 2-estágios é obtido em duas etapas: 
Etapa 1: Considerando que o primeiro corte feito na placa seja horizontal, primeiramente devese definir faixas de dimensão $L \times w_{j}$ e descrever padrões de corte para cada uma delas. Neste caso, temos vários problemas unidimensionais.

Etapa 2: Determinar quantas vezes cada faixa, com seu respectivo padrão, é utilizada na placa de dimensão $L \times W$.

Quando utilizamos o corte 2-estágios estamos sujeitos ao surgimento de 'rebarba', ou seja, pedaços da placa em estoque, que sobram depois de realizado o corte, mas, que não são utilizados para obtenção de um novo item (veja fig. 4.4).

Definição 4.3: Um padrão 2-estágios é dito não-exato quando é permitido a 'rebarba', caso contrário, é dito exato.

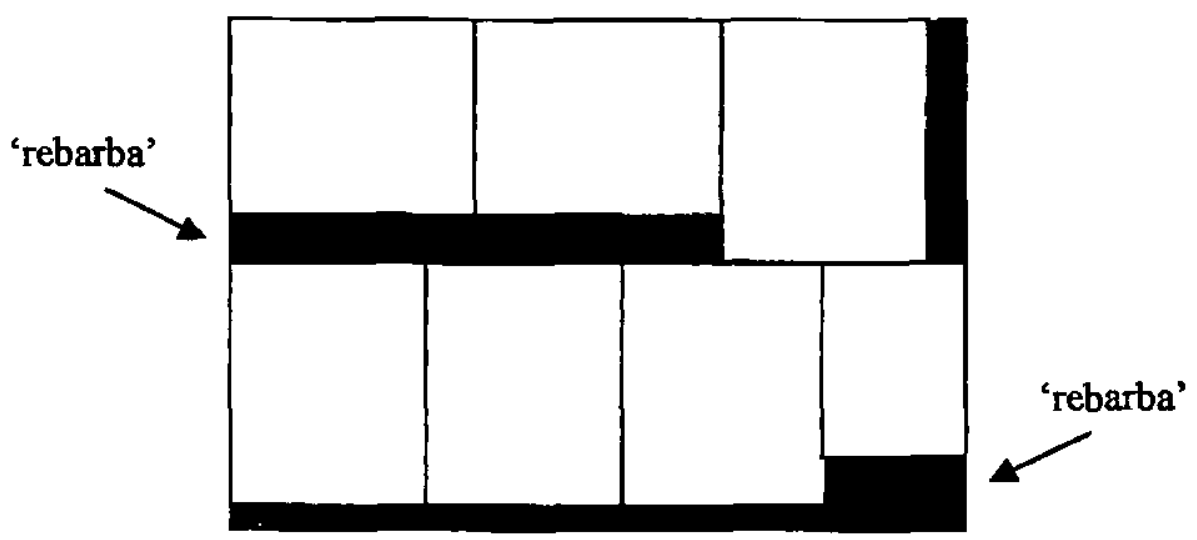

Figura 4.4: Corte 2-estágios não-exato

Os padrões de corte podem ainda ser classificados em restritos e irrestritos.

Definição 4.4: Um padrão de corte é irrestrito quando não há limitação na quantidade de itens por padrão de corte, caso contrário, o padrão é restrito.

Temos então os dois casos a serem considerados: o caso restrito e o caso irrestrito. Para o caso irrestrito, devido a inexistência da limitação no número de peças por padrão de corte, não teremos problemas com relação à Etapa 2, ou seja, bastará descobrir quais os melhores padrões de corte para as faixas $L \times w_{j}$ e utilizá-los de maneira que o objetivo em (4.3) seja 
maximizado. Já no caso restrito, a limitação na quantidade de peças a serem cortadas é relevante para a construção do padrão e a Etapa 2 não é independente da Etapa I. Este fato é o que complica a determinação do padrão restrito. Assim, apresentaremos em seguida o estudo feito para ambos os casos.

\subsubsection{Caso Irrestrito}

\section{Modelagem Matemática}

Para o caso irrestrito, podemos associar somente o melhor padrão de corte para cada faixa, isto é, o mais valioso. Neste caso, a Etapa 1 consistirá em gerar somente este padrão de corte ótimo para cada faixa $L \times w_{j}$. Observe que neste problema, estaremos considerando somente uma dimensão, ou seja, teremos um problema unidimensional, para o qual já sabemos como gerar padrões de corte.

Inicialmente, considere o conjunto que chamaremos de $W_{j}$ definido da seguinte forma:

$$
W_{j}=\left\{i / w_{i} \leq w_{j}\right\}
$$

Este conjunto denota os itens que podem compor a faixa de largura $w_{j}$. Denotamos por $r o$ número de diferentes faixas.

Com posse destes dados os padrões para cada faixa $j$ são trivialmente modelados por um vetor $m$-dimensional $\alpha$, que satisfaça as restrições fisicas do problema, como em (3.6), ou seja:

$$
\begin{aligned}
\sum_{i \in W_{j}} l_{i} \alpha_{i j} & \leq L \\
& \alpha_{i j} \geq 0 \text { e inteiros, } j=1,2, \ldots, r
\end{aligned}
$$

Considere agora, $\beta_{j}$ como sendo o número de vezes que cada um destes padrões será utilizado dentro da placa em estoque. Para determiná-lo basta resolver um Problema da Mochila com a seguinte formulação:

$$
\begin{aligned}
\sum_{j=1}^{r} w_{j} \beta_{j} & \leq W \\
\beta_{j} & \geq 0 \text { e inteiros }
\end{aligned}
$$


Desta forma, o número total de peças do tipo $i$ no padrão, será dado por:

$$
y_{i}=\sum_{j=1}^{r} \alpha_{i j} \beta_{j} \quad i=1, \ldots, m
$$

Portanto, o problema (4.3) com as restrições no processo de cortagem, guilhotinado em 2estágios é dada por:

$$
\begin{gathered}
\max \sum_{j=1}^{r} \sum_{i \in W_{j}} \pi_{i} \alpha_{i j} \beta_{j} \\
\text { sujeito a: } \sum_{i \in W_{j}} l_{i} \alpha_{i j} \leq L \quad j=1,2, \ldots, r \\
\sum_{j=1}^{r} w_{j} \beta_{j} \leq W \\
\alpha_{i j} \geq 0, \beta_{j} \geq 0 \text { e inteiros }
\end{gathered}
$$

\section{Método de resolução: Decomposição/Irrestrita}

O método utilizado para resolução do problema (4.8) consiste do método de decomposição proposto por Gilmore e Gomory (1965). Esta decomposição é feita por reescrever o problema da seguinte forma:

$$
\begin{aligned}
& \max \sum_{j=1}^{r}\left\{\max \sum_{i \in W_{j}} \pi_{i} \alpha_{i j}, \text { sujeito a: } \sum_{i \in W_{j}} l_{j} \alpha_{i j} \leq L, \alpha_{i j} \geq 0 \text { e inteiro }\right\} \beta_{j} \\
& \text { sujeito a: } \sum_{j=1}^{r} w_{j} \beta_{j} \leq W \\
& \qquad \beta_{j} \geq 0 \text { e inteiros }
\end{aligned}
$$

O problema (4.9) pode ser decomposto em dois níveis independentes, que correspondem às duas etapas relacionadas anteriormente: 
Etapa 1: Primeiro determina-se valores de $\alpha_{i j}$ : a solução ótima ou o padrão de corte mais valioso para cada faixa $j, j=1, \ldots, r$. Para isto, basta resolver os seguintes $r$ problemas:

$$
\begin{gathered}
V_{j}=\max \sum_{i \in W_{j}} \pi_{i} \alpha_{i j} \\
\text { sujeito a }: \sum_{i \in W_{j}} l_{i} \alpha_{i j} \leq L \quad j=1, \ldots, r \\
\alpha_{i j} \geq 0 \text { e inteiro }
\end{gathered}
$$

que consistem de problemas da mochila unidimensionais irrestritos.

Etapa 2: Agora temos que decidir quantas vezes cada faixa obtida anteriormente será repetida na placa $L \times W$, ou seja, temos que determinar $\beta_{j}$. Para isto, devemos resolver o seguinte problema irrestrito:

$$
\begin{gathered}
\max \sum_{j=I}^{r} V_{j} \beta_{j} \\
\text { sujeito a : } \sum_{j=I}^{r} w_{j} \beta_{j} \leq W \\
\beta_{j} \geq 0 \text { e inteiro }
\end{gathered}
$$

que consiste em um único Problema da Mochila unidimensional.

Ao resolvermos (4.10) e (4.11), ou seja, os ( $r+1)$ Problemas da Mochila, temos o vetor que caracteriza o número total de peças do tipo $i$ no padrão, dado por (4.7), que fornecerá uma coluna para o modelo (4.2).

Esta formulação consiste em um método eficiente de resolução. 


\subsubsection{Caso Restrito}

\section{Modelagem Matemática}

Neste caso, temos que determinar o padrão de corte ótimo, alocando os itens na placa sem violar as restrições de limitação de demanda para cada item. Aqui, o método de decomposição de Gilmore e Gomory será estendido de forma heurística, a qual é denominada heuristica de decomposição.

Da mesma forma que no caso irrestrito, a resolução do problema restrito consistirá das duas etapas abaixo:

Etapa 1: Descrever padrões de corte para faixas de dimensão $L \times w_{j}$.

Etapa 2: Determinar quantas vezes cada padrão para esta faixa será repetido na placa de dimensão $L \times W$.

A formulação do modelo restrito será semelhante à formulação apresentada para o caso irrestrito em (4.8). Entretanto, para o caso restrito, não serão considerados somente os padrões mais valiosos para cada faixa $j$. Agora temos de considerar um conjunto de padrões para cada uma delas. Este conjunto (veja Gramani, 1997) pode ser limitado por: $K_{j}=\left\lfloor\frac{W}{w_{j}}\right\rfloor$.

Com isto o $k$-ésimo padrão de corte unidimensional para a faixa $w_{j}, j=1, \ldots, m$ pode ser modelado pelo vetor $\left(\alpha_{k j}^{1}, \alpha_{k j}^{2}, \ldots, \alpha_{k j}^{m}\right)$ sujeito às seguintes restrições:

$$
\sum_{i \in W_{j}} l_{i} \alpha_{k j}^{i} \leq L, \quad \alpha_{k j}^{i} \geq 0 \text { e inteiros, } k=1, \ldots, K_{j}
$$

Agora, se considerarmos $\beta_{k j}$ como o número de vezes que o $k$-ésimo padrão é repetido na placa de dimensões $L \times W$, então:

$$
\sum_{j=1}^{m} w_{j} \sum_{k=1}^{K_{j}} \beta_{k j} \leq W
$$


Finalmente, o número de itens do tipo $i$, que estão sendo produzidos no padrão para a placa $L \times W$, será dado pela seguinte relação:

$$
y_{i}=\sum_{j=1}^{m} \sum_{k=1}^{K_{j}} \alpha_{k j}^{i} \beta_{k j}, i=1, \ldots, m
$$

Levando em consideração a limitação deste número, temos que:

$$
y_{i}=\sum_{j=1}^{m} \sum_{k=1}^{K_{j}} \alpha_{k j}^{i} \beta_{k j} \leq d_{i}, i=1, \ldots, m
$$

Considerando (4.12a), (4.12b), (4.12c), obtemos o seguinte modelo matemático para o caso restrito:

$$
\begin{aligned}
\max & \sum_{i=1}^{m} \sum_{j=1}^{m} \sum_{k=1}^{K_{j}} \alpha_{k j}^{i} \beta_{k j} \pi_{i} \\
\text { sujeito a : } & \sum_{i \in W_{j}} l_{j} \alpha_{k j}^{i} \leq L \quad j=1,2, \ldots, m \\
& \sum_{j=1}^{m} w_{j} \sum_{k=1}^{K_{j}} \beta_{k j} \leq W \quad k=1, \ldots K_{j} \\
& \sum_{j=1}^{m} \sum_{k=1}^{K_{j}} \alpha_{k j}^{i} \beta_{k j} \leq d_{i} \\
& \alpha_{k j}^{i} \geq 0, \beta_{k j} \geq 0 \text { e inteiros }
\end{aligned}
$$

Observação 4.2: O problema (4.13) foi estudado por Gramani (1997) que desenvolveu um conjunto de heurísticas e um algoritmo baseado em relaxação lagrangiana e no método do subgradiente para solucioná-lo. Descrevemos a seguir um dos procedimentos heurísticos propostos por Gramani, que será utilizado em nosso estudo.

\section{Método de resolução: Decomposiçăo/Restrito}

O procedimento com relação à Etapa 1 é análogo ao caso irrestrito, entretanto os $r$ problemas da mochila unidimensionais a serem resolvidos serão problemas restritos. 
Etapa 1: Para $j=1,2, \ldots, r$ resolva:

$$
V_{J}=\max \sum_{i \in W_{j}} \pi_{i} \alpha_{i j}
$$

$$
\begin{gathered}
\text { sujeito a : } \sum_{i \in W_{j}} l_{i} \alpha_{i j} \leq L \quad j=1, \ldots, r \\
0 \leq \alpha_{i j} \leq d_{i} \text { einteiro, } i \in W_{j}
\end{gathered}
$$

Resolvendo este problema para cada faixa, o padrão de corte ótimo para cada uma delas é encontrado.

Etapa 2: Resolva o problema de otimização inteiro:

$$
\begin{aligned}
\max & \sum_{j=1}^{r} V_{j} \beta_{j} \\
\text { sujeito a : } & \sum_{j=1}^{r} w_{j} \beta_{j} \leq W \\
& \sum_{j=1}^{r} \alpha_{i j} \beta_{j} \leq d_{i} \quad, j=1, \ldots, m \\
& \beta_{j} \geq 0 \text { einteiro } \quad, j=1, \ldots, r .
\end{aligned}
$$

Neste caso, a segunda restrição do conjunto de restrições acima é necessária devido à limitação do problema com relação à demanda. Esta etapa não consiste em um problema de fácil resolução, sendo necessário códigos mais avançados. Desta forma, ao invés de resolver o problema acima, usamos uma relaxação para determinar qual a faixa mais valiosa dentre as obtidas na Etapa 1, ou seja, vamos relaxar a condição de integralidade e reescrever as duas primeiras restrições acima como sendo a soma da primeira restrição multiplicada por um fator $\gamma$ com a segunda restrição multiplicada por $(1-\gamma)$. Este procedimento resulta no seguinte Problema da Mochila contínuo: 


$$
\begin{aligned}
& \max \quad \sum_{j=1}^{r} V_{j} \beta_{j} \\
& \text { sujeito a: } \sum_{j=1}^{r}\left[\gamma w_{j}+(1-\gamma) \sum_{i=1}^{m} \alpha_{i j}\right] \beta_{j} \leq \gamma W+(1-\gamma) \sum_{i=1}^{m} d_{i} \\
& \beta_{j} \geq 0 \quad, j=1, \ldots, r .
\end{aligned}
$$

Este é um problema de programação linear e o índice da variável básica btima é $k$, tal que:

$$
\frac{V_{k}}{\gamma w_{k}+(1-\gamma) \sum_{i=1}^{m} \alpha_{i k}}=\max \left\{\frac{V_{j}}{\gamma w_{j}+(1-\gamma) \sum_{i=1}^{m} \alpha_{i j}}, j=l, \ldots, r\right\}
$$

Com isto a obtenção de $\boldsymbol{\beta}_{j}$ consistirá no seguinte procedimento:

1. Determinar a faixa $k$ mais valiosa, conforme a relação (4.14), assumindo valores para $\gamma$. Seguindo sugestão de Gramani (1997), utilizamos $\gamma=1$;

2. Alocar a faixa $k$, com o padrão de corte obtido na Etapa 1, uma única vez na placa $\Rightarrow \beta_{k}=1$.

3. Fazer: $\bullet W \leftarrow W-w_{k}$

$$
\bullet d_{i} \leftarrow d_{i}-\alpha_{i k} \text {. }
$$

4. Se $W>w_{0}=\min \left\{w_{i} / d_{i}>0\right\}$, ou seja, enquanto a largura da placa permitir, que pelo menos, uma das faixas seja alocada, repetir a Etapa 1.

Observação 4.3: A utilização do melhor padrão obtido na Etapa 1, poderia também ter sido feita da seguinte forma: este padrão escolhido seria utilizado quantas vezes fosse possível, ou seja, enquanto não ultrapassasse a menor das condições abaixo:

$$
\text { Condiçăo 1: }\left\lfloor\frac{W}{w_{k}}\right\rfloor \quad \text { Condição } 2:\left\lfloor\frac{d_{i}}{\alpha_{i k}}\right\rfloor, i=1, \ldots, m
$$

$\mathrm{e}$, somente quando esta faixa $k$ não pudesse mais ser colocada, retomaria à Etapa 1 . 


\subsection{Método Simplex com Geração de Colunas para o Problema Bidimensional}

Para o problema bidimensional, o Método Simplex com Geração de Colunas, que utilizamos para resolver, quando necessário, problemas relaxados com relação à integralidade, é análogo ao método apresentado no capitulo anterior, para o problema unidimensional. Desta forma, será feito aqui somente um breve comentário sobre quais modificações deverão ser consideradas quando trabalhamos com duas dimensões.

Modificação 1: \{Geração da matriz básica inicial\}

Neste caso, consideramos também os padrões de corte homogêneos. Entretanto, como o problema é bidimensional, os $m$ padrões serão gerados da seguinte forma:

$$
B=\left(\begin{array}{cccccc}
\left\lfloor\frac{L}{l_{1}}\right\rfloor \times\left\lfloor\frac{W}{w_{1}}\right\rfloor & 0 & 0 & 0 & \ldots & 0 \\
0 & \left\lfloor\frac{L}{l_{2}}\right\rfloor \times\left\lfloor\frac{W}{w_{2}}\right\rfloor & 0 & 0 & \ldots & 0 \\
\vdots & \vdots & \vdots & \ddots & \vdots \\
0 & 0 & 0 & 0 & \ldots & \left.\frac{L}{l_{m}}\right\rfloor \times\left\lfloor\frac{W}{w_{m}}\right\rfloor
\end{array}\right)
$$

Modificação 2: \{Geração de colunas\}

Caso Irrestrito: Determine a nova coluna y para entrar na base conforme (4.8), utilizando o método de decomposição/irrestrito, descrito na seção 4.2.1.

Caso Restrito: Determine a nova coluna y conforme (4.13), utilizando o método de decomposição/restrito, descrito na seção 4.2.2. 


\subsection{Método Heurístico para o Problema de Corte de Estoque Bidimensional Inteiro}

Primeiramente, considere a forma matricial do problema (4.2):

$$
\begin{array}{ll}
\operatorname{minimizar} & f(\mathbf{x})=\mathbf{c}^{\mathrm{T}} \mathbf{x} \\
\text { sujeito a : } & \mathbf{A x} \geq \mathbf{d} \\
\mathbf{x} & \geq \mathbf{0} \text { e inteiro }
\end{array}
$$

Como foi dito anteriormente, resolver o problema (4.15) otimamente é uma tarefa inviável para problemas de grande porte, tornando-se necessária a utilização de heurísticas, que relaxem a condição de integralidade. Com isto o método heurístico, que apresentamos a seguir, encontra inicialmente uma solução ótima para esta relaxação por programação linear do problema inteiro em questão, utilizando o Método Simplex com Geração de Colunas (supomos a demanda alta, de modo que usamos o método da seção 4.2.1). Este passo gera uma solução geralmente não-inteira $\widetilde{\mathbf{x}}$. O procedimento heurístico consistirá em determinar uma solução inteira, na 'vizinhança' desta solução não-inteira obtida, da seguinte forma:

1. Faça o arredondamento: $[\tilde{\mathbf{x}}]$. Isto resulta numa falta, ou seja, nem toda a demanda será atendida, restando ainda o resíduo de $\mathbf{r}=\mathbf{d}-\mathbf{A}[\tilde{\mathbf{x}}]$ unidades a serem produzidas. Este procedimento produz um novo problema inteiro, denominado problema residual e que possui a formulação:

$$
\begin{aligned}
\text { minimizar } & \mathrm{f}(\mathrm{y})=\mathbf{c}^{T} \mathbf{y} \\
\text { sujeito a : } & \mathbf{A y} \geq \mathbf{r} \\
\mathbf{y} & \geq \mathbf{0} \text { e inteiro }
\end{aligned}
$$

(A denominação de problema residual para este problema já foi apresentada quando tratávamos do problema unidimensional, a qual mantemos aqui para o caso bidimensional).

2. Resolva o problema residual utilizando também a técnica de Geração de Colunas (integralidade relaxada) apresentada anteriormente. Entretanto, no caso do problema residual, o método de decomposição/restrito da seção 4.2.2 é que deverá ser utilizado para determinar 
a coluna a entrar na base. Ou seja, estaremos resolvendo o problema residual como um problema restrito. Com isto $\tilde{\mathbf{y}}$ é obtido.

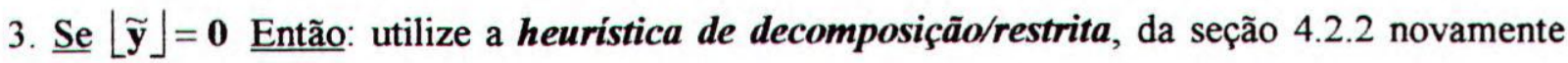
para terminar de atender a pequena demanda residual e pare o processo (em substituição à heurística FFD para o problema unidimensional).

Senão, faça as atualizações:

$$
\begin{aligned}
& \mathbf{x} \leftarrow\lfloor\tilde{\mathbf{x}}\rfloor+\lfloor\tilde{\mathbf{y}}\rfloor \\
& \mathbf{r} \leftarrow \mathbf{r}-\mathbf{A}\lfloor\tilde{\mathbf{y}}\rfloor
\end{aligned}
$$

Repita o passo 2.

Os resultados obtidos com a implementação desta heurística serão apresentados no capítulo 5 , onde mostraremos o desempenho computacional e verificaremos a qualidade das soluções obtidas pelo método, utilizando os limitantes a seguir.

\subsection{Limitantes}

Como no caso unidimensional, aqui também necessitamos saber qual a posição da solução encontrada heuristicamente com relação à solução ótima do problema original. Um caminho é a utilização de limitantes inferiores e superiores para a solução, que consideramos análogos ao problema unidimensional, ou seja:

1. Limitante inferior $\equiv \mathrm{LI}=\lceil f(\widetilde{\mathbf{x}})\rceil$

onde $\lceil f(\widetilde{\mathbf{x}})\rceil$ é o menor inteiro maior ou igual a $f(\widetilde{\mathbf{x}})$.

2. Limitante superior $\equiv \mathrm{LS}=\sum_{j=1}^{m}\left\lceil\widetilde{\mathbf{x}}_{j}\right\rceil$

O limitante superior é considerado desta forma, porque o arredondamento para o inteiro superior dos componentes não inteiros da solução obtida da relaxação do problema original, resulta em uma solução factível para o problema original, pois satisfaz a demanda. 


\section{Exemplo 4.1:}

Suponha um problema de corte bidimensional, com os seguintes dados:

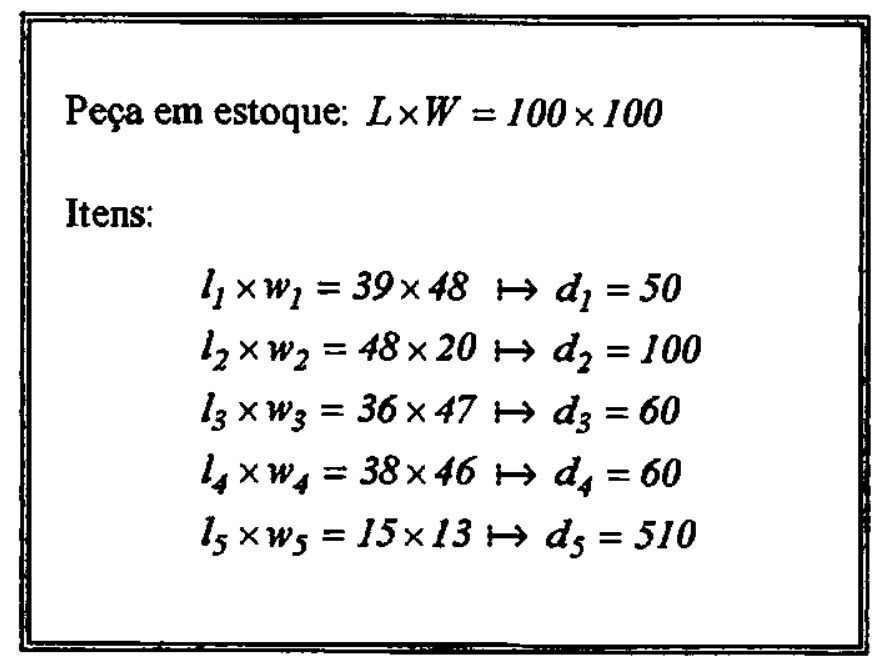

Solução do problema relaxado: $\left\{\begin{array}{l}\widetilde{x}_{1}^{*}=12,5 \\ \tilde{x}_{2}^{*}=25 \\ \widetilde{x}_{3}^{*}=2,5 \\ \widetilde{x}_{4}^{*} \cong 9,270833 \\ \widetilde{x}_{5}^{*} \cong 11,45833\end{array}\right.$

Então:

- como: $f(\tilde{\mathbf{x}})=\sum_{j=1}^{5} \widetilde{\mathbf{x}}_{j} \cong 60,729167 \Rightarrow L I=\lceil f(\tilde{\mathbf{x}})\rceil=61 \Rightarrow$ teremos que utilizar pelo menos 61 placas para atender toda a demanda.

- como: $\lceil\tilde{\mathbf{x}}\rceil=(13,25,3,10,12) \Rightarrow \mathrm{LS}=\sum_{j=1}^{5}\lceil\tilde{\mathbf{x}}\rceil=63 \Rightarrow$ poderemos utilizar no máximo 63 placas para atender a demanda.

Desta forma, se aplicarmos um método heurístico para resolução de um problema e obtivermos uma solução que utilize 61 placas em estoque, podemos afirmar que esta solução é ótima. 
Procuramos observar também como o algoritmo, que implementamos, se comporta com relação às propriedades (3.12) e (3.13), definidas na seção 3.3.1, considerando agora o problema bidimensional 2-estágios não-exato. 


\section{Capitulo 5}

\section{Resultados Computacionais}

Neste capítulo apresentamos os resultados computacionais obtidos com a implementação do método proposto na seção 4.4. A implementação foi feita em linguagem PASCAL, utilizando TURBO PASCAL 7.0. Os exemplos foram rodados em um microcomputador PENTIUM 200, com 16 Mbytes de RAM.

0 tamanho das peças em estoque foram fixadas em $L \times W=100 \times 100$. Alguns detalhes com relação à implementação e aos testes computacionais realizados são dados abaixo:

\section{(i) Quantidade de itens a serem produzidos}

Para realização da análise do método, os diferentes valores de $m$ utilizados em nossos testes foram: $m=5,10,20$ e 40 .

\section{(ii) Tamanho dos itens}

Para cada exemplo rodado, os tamanhos $l_{i} \times w_{i}, i=1, \ldots, m$ foram gerados de forma aleatória. Conforme Morabito (1992), dividimos os problemas em classes, com relação ao tamanho dos itens, da seguinte maneira:

- 'exemplos pequenos' $\Rightarrow\left\{\begin{array}{l}l_{i} \in[0.25 L, 0.75 \mathrm{~L}] \\ w_{i} \in[0.25 \mathrm{~W}, 0.75 \mathrm{~W}]\end{array}, i=1, \ldots, m\right.$. 
- ‘exemplos grandes' $\Rightarrow\left\{\begin{array}{l}l_{i} \in[0.10 \mathrm{~L}, 0.50 \mathrm{~L}] \\ w_{i} \in[0.10 \mathrm{~W}, 0.50 \mathrm{~W}]\end{array}, i=I, \ldots, m\right.$.

Para avaliarmos a eficiência do método quanto à qualidade da solução e ao tempo computacional, foram gerados 800 exemplos para cada diferente valor de $m$. Este processo foi repetido para cada uma das classes acima, onde a análise foi realizada separadamente para cada classe.

(iii) Demanda

As coordenadas do vetor de demanda foram determinadas de forma a estarem diretamente relacionadas ao tamanho da peça em estoque e dos itens a serem produzidos, ou seja:

$$
d_{i}=\left\lfloor\frac{L * W}{l_{i} * w_{i}}\right\rfloor * 30, \quad i=1, \ldots, m
$$

\section{(iv) Geração de Colunas}

Quanto ao processo de Geração de Colunas utilizado na resolução de problemas contínuos apresentado na seção 4.2 do capítulo anterior, algumas considerações quanto à sua implementação devem ser feitas:

- Da maneira como foi definido, o modelo (4.2) considera a hipótese de resolver o problema com folga, permitindo a produção de itens em excesso. Para isto, o algoritmo do Método Simplex com Geração de Colunas apresentado será alterado para considerar, implicitamente, as variáveis de folga, da seguinte forma: quando surgir alguma componente do vetor $\pi$ (multiplicador simplex) negativa, não resolveremos o Problema da Mochila, para determinar a coluna a entrar na base, simplesmente a definiremos como uma coluna $y$, contendo $m$ coordenadas, $\operatorname{com}(-1)$ somente na posição negativa do vetor $\pi$ e 0 nas demais posições (i. e., coluna correspondente à variável de folga). Ou seja:

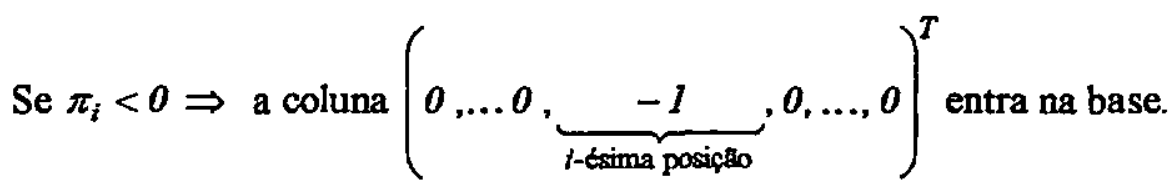


Com isto esta coluna y (padrão) representará uma variável de folga para o problema e terá custo nulo. Este fato garante que esta coluna sempre entrará na base, pois seu custo relativo terá o valor de $\pi_{i}<0$, fazendo com que o passo onde a otimalidade da solução corrente é verificada (passo 2.4 do algoritmo simplex do capitulo 3 ) resulte em falso. Reescrevendo esta afirmação de outra maneira, temos que o custo relativo da coluna y é dado por:

$\mathbf{c}_{j}-\pi^{T} \mathbf{a}_{j}=0-\left(\pi_{1}, \ldots, \pi_{i}, \ldots, \pi_{m}\right)^{T}\left(\begin{array}{l}0 \\ \vdots \\ -1 \\ \vdots \\ 0\end{array}\right)=\pi_{i}<0 \Rightarrow$ PARE = FALSE

e, portanto, não será necessário verificarmos se o custo relativo é não-negativo, podendo passar direto para o cálculo da direção simplex.

- Com relação ao número máximo de iterações para o Método Simplex consideramos sendo igual a $30 * m$.

- Como visto no capítulo 4 (seção 4.2.2), os problemas podem ser rodados para diferentes valores de $\gamma$, de acordo com a equação (4.14). Em nossas simulações consideramos inicialmente $\gamma=1$, conforme sugestão de Gramani (1997). Em seguida, com o intuito de verificação, realizamos testes também para $\gamma=0,5$. Entretanto, esta alteração não resultou em grandes diferenças, como veremos na seção 5.1 .

- Durante a realização das simulações encontramos exemplos onde ocorreram o aparecimento de ciclagem, ou seja, a partir de um certo número de iterações o Método Simplex retornava a uma solução já obtida anteriormente. Para evitar estes casos, acrescentamos uma perturbação aleatória gerada uniformemente no intervalo $\left[0,10^{-5}\right]$ à solução corrente, antes do cálculo do tamanho do passo. Os resultados obtidos com esta modificação serão apresentados e analisados no Anexo B deste trabalho. 


\section{(v) Qualidade da solução}

Como já comentado anteriormente, procuramos durante as simulações observar além da otimalidade da solução obtida heuristicamente, qual a possibilidade do problema bidimensional 2-estágios não-exato possuir a propriedade MIRUP. Entretanto, não tínhamos acesso ao valor da solução ótima do problema (4.2) para utilizarmos as relações em (3.12) e (3.13). Para resolver este problema e, levando em consideração o fato de que o valor definido em (3.12) define um ótimo ponto de referência, utilizamos seu valor para observação, ou seja, verificamos o quanto a solução obtida heuristicamente $f\left(x^{H}\right)$ difere do limitante inferior. Isto pode ser reescrito da seguinte forma:

Se $f\left(z^{H}\right)=\lceil f(\widetilde{\mathbf{x}})\rceil \quad \Rightarrow$ afirmamos que a solução obtida heuristicamente é ótima e o problema em questão possui a propriedade IRUP.

Se $f\left(\mathbf{x}^{H}\right)=\lceil f(\widetilde{\mathbf{x}})\rceil+1 \Rightarrow$ não podemos afirmar que $f\left(\mathrm{x}^{H}\right)$ não fornece a solução ótima, mas estaremos dizendo que o problema satisfaz a propriedade MIRUP (observe que há um abuso de linguagem, pois a solução ótima não é conhecida).

Se $f\left(x^{H}\right)-\lceil f(\widetilde{x})\rceil>1 \Rightarrow$ nada podemos afirmar com relação à otimalidade da solução e nem com relação às propriedades. Diremos apenas que, neste caso, a validade da propriedade MIRUP está sob suspeita.

\section{Observação 5.1:}

Com esta notação, o conceito de gap de integralidade deverá ser redefinido como: gap $=f\left(x^{H}\right)-\lceil f(\widetilde{x})\rceil$. Em todos os exemplos que rodamos, o maior valor encontrado para o gap foi de 2 unidades, ou seja, a heuristica necessitou cortar, além do limitante inferior, no máximo, mais duas peças em estoque para atender a demanda. 


\subsection{Resultados}

Feitas as considerações anteriores, vejamos os resultados computacionais obtidos com as simulações. Iniciamos apresentando os resultados utilizando os exemplos pequenos através de um gráfico que denota a qualidade da solução obtida heuristicamente ao rodarmos o algoritmo para 800 exemplos utilizando cada valor de $m$. O eixo y representa quais as porcentagens de exemplos com solução ótima (IRUP), com a propriedade MIRUP e que não possuem nenhuma destas propriedades.

\section{Exemplos pequenos $(\gamma=1)$}

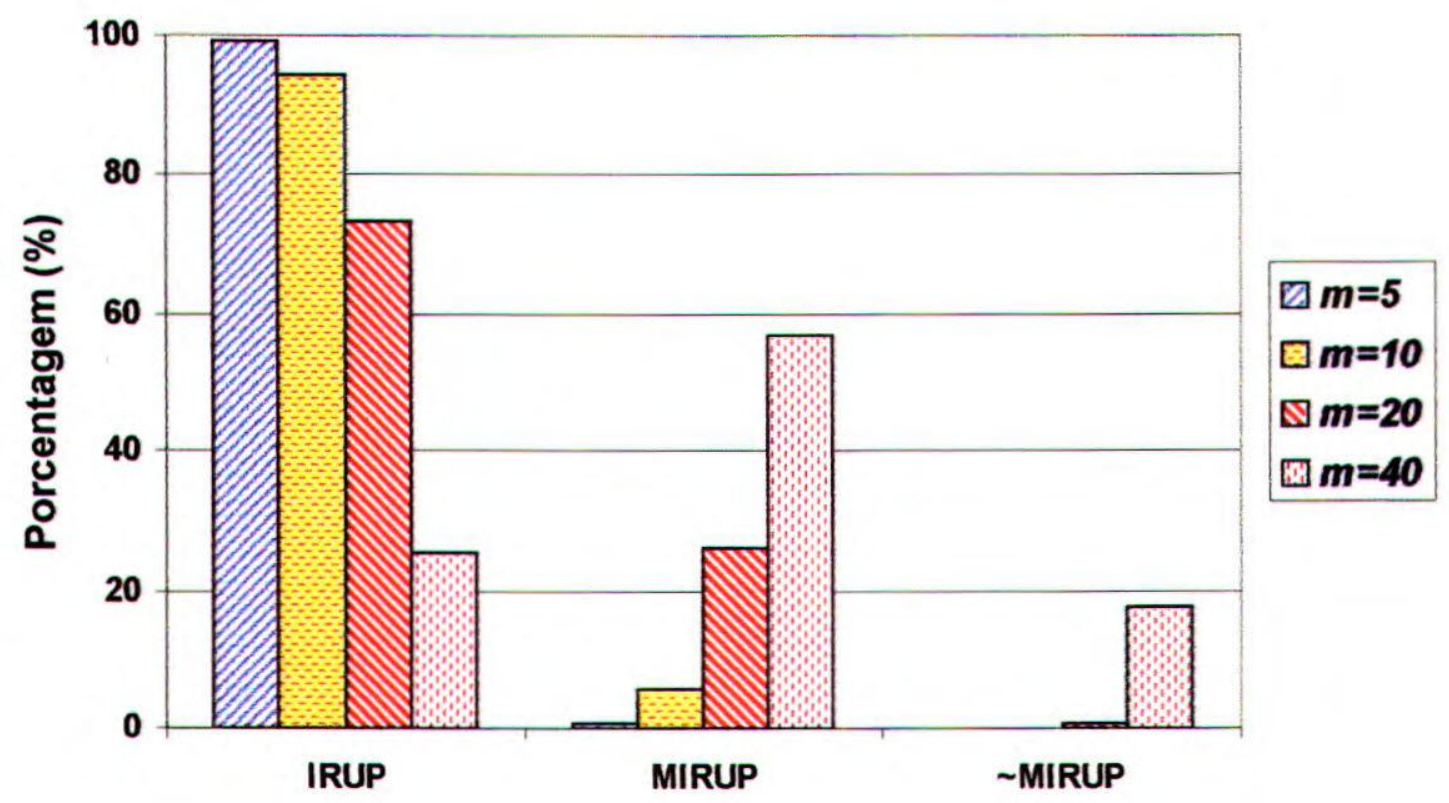

Gráfico 5.1 Qualidade da solução para exemplos pequenos

onde: MIRUP representa a porcentagem de exemplos onde a propriedade MIRUP está sob suspeita.

Observe que a porcentagem de exemplos com soluções ótimas obtidas, diminui à medida que $m$ aumenta. Esta mudança no comportamento, quando aumentamos a quantidade de itens a serem produzidos, ocorreu também de forma mais acentuada com relação ao tempo gasto para executar o programa. Isto pode ser constatado na tabela a seguir: 


\begin{tabular}{|l|c|}
\hline \multicolumn{2}{|c|}{ Exemplos Pequenos } \\
\hline \multicolumn{2}{|c|}{ Tempo médio de execução (seg) } \\
\hline$m=5$ & 0,009 \\
\hline$m=10$ & 0,069 \\
\hline$m=20$ & 1,41 \\
\hline$m=40$ & 43,73 \\
\hline
\end{tabular}

Tabela 5.1 Tempo médio de execução para exemplos pequenos

Para os exemplos grandes, os resultados serão apresentados da mesma forma, ou seja, utilizaremos um gráfico para observação da qualidade da solução e uma tabela mostrando o tempo de execução.

Exemplos grandes $(\gamma=1)$

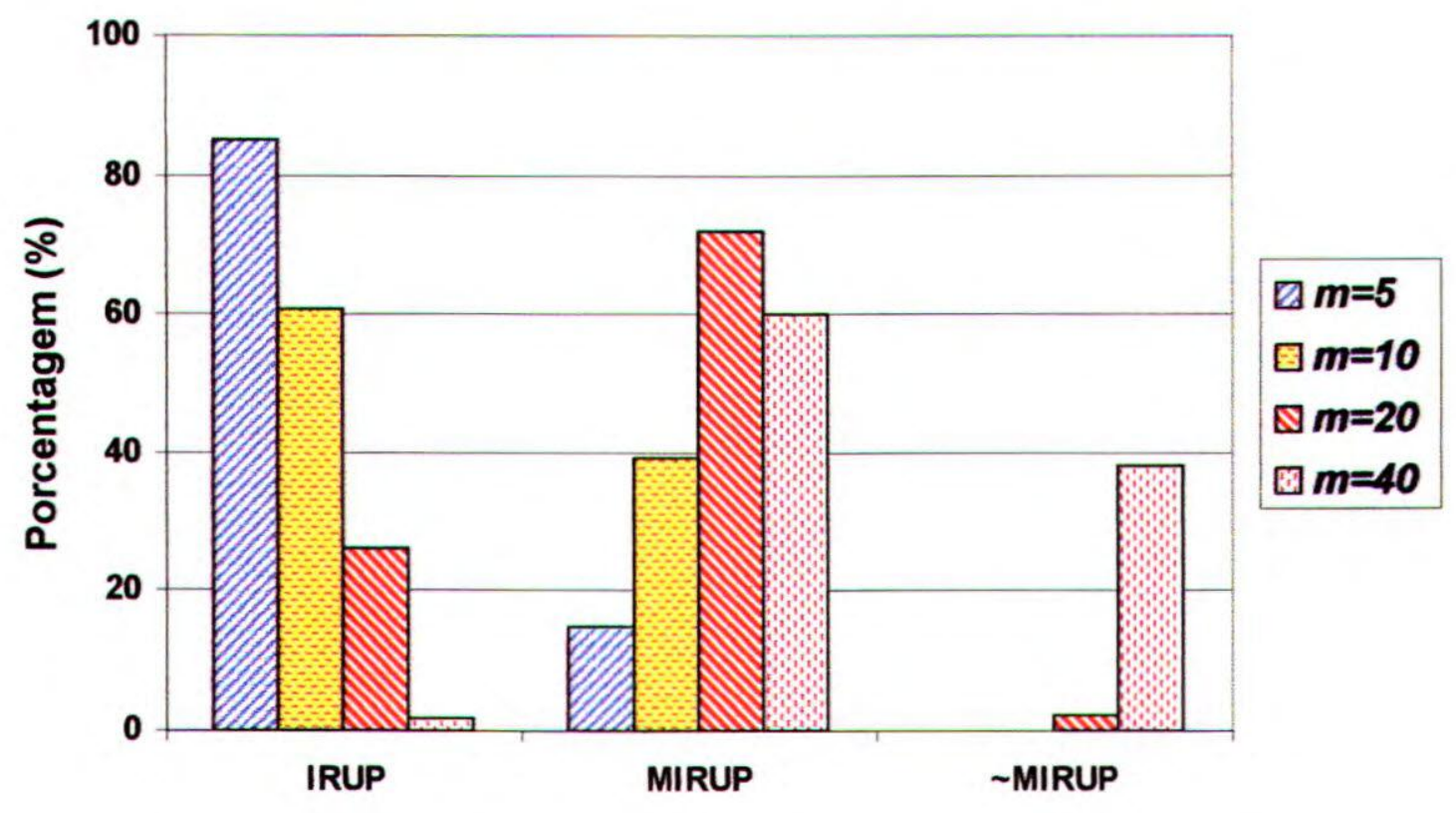

Gráfico 5.2 Qualidade da solução para exemplos grandes 


\begin{tabular}{|c|c|}
\hline \multicolumn{2}{|c|}{ Exemplos Grandes } \\
\hline \multicolumn{2}{|c|}{ Tempo médio de execução (seg) } \\
\hline$m=5$ & 0,02 \\
\hline$m=10$ & 0,28 \\
\hline$m=20$ & 6,22 \\
\hline$m=40$ & 188,37 \\
\hline
\end{tabular}

Tabela 5.2 Tempo médio de execução para exemplos grandes

Observe que o tempo computacional para os exemplos grandes cresceu consideravelmente tanto com relação ao aumento do valor de $m$ quanto se compararmos com os resultados obtidos para os exemplos pequenos. Este aumento também pode ser observado com relação à qualidade da solução, ou seja, no gráfico 5.2 vemos que a quantidade de soluções ótimas é bem menor do que para os exemplos pequenos. Entretanto, observando os padroes utilizados para resolução do problema, observamos que soluções melhores, ou seja, com um melhor aproveitamento das peças em estoque, ocorrem com maior frequência para exemplos grandes do que para os pequenos. Isto é esperado já que nestes exemplos os itens são de dimensões menores aumentando as possibilidades de combinação (por esta razão são chamados exemplos grandes, ou seja, o número de padrões de cortes é muito maior).

Devido aos resultados acima, vimos a necessidade de realizar modificações no método heurístico para tentar melhorar a qualidade das soluç̃̃es obtidas. Para apresentarmos neste trabalho, consideramos um outro valor para $\gamma(\gamma=0,5)$, o que acarreta numa combinação diferente das faixas para a construção dos padrões. Entretanto, como mostraremos abaixo, de uma forma geral, os resultados não mostraram diferenças relevantes com relação aos obtidos com $\gamma=1$. Mas, como será mostrado no Anexo A, para casos particulares, esta modificação pode até mesmo resultar em uma solução ótima para um problema onde somente era verificada a propriedade MIRUP.

Não apresentaremos a tabela com o tempo computacional por não haver muita diferença com relação ao tempo obtido com $\gamma=1$. Vejamos assim os resultados com relação à qualidade da solução, sendo que as simulações não foram feitas para $m=40$ : 
Exemplos pequenos: $(\gamma=0,5)$

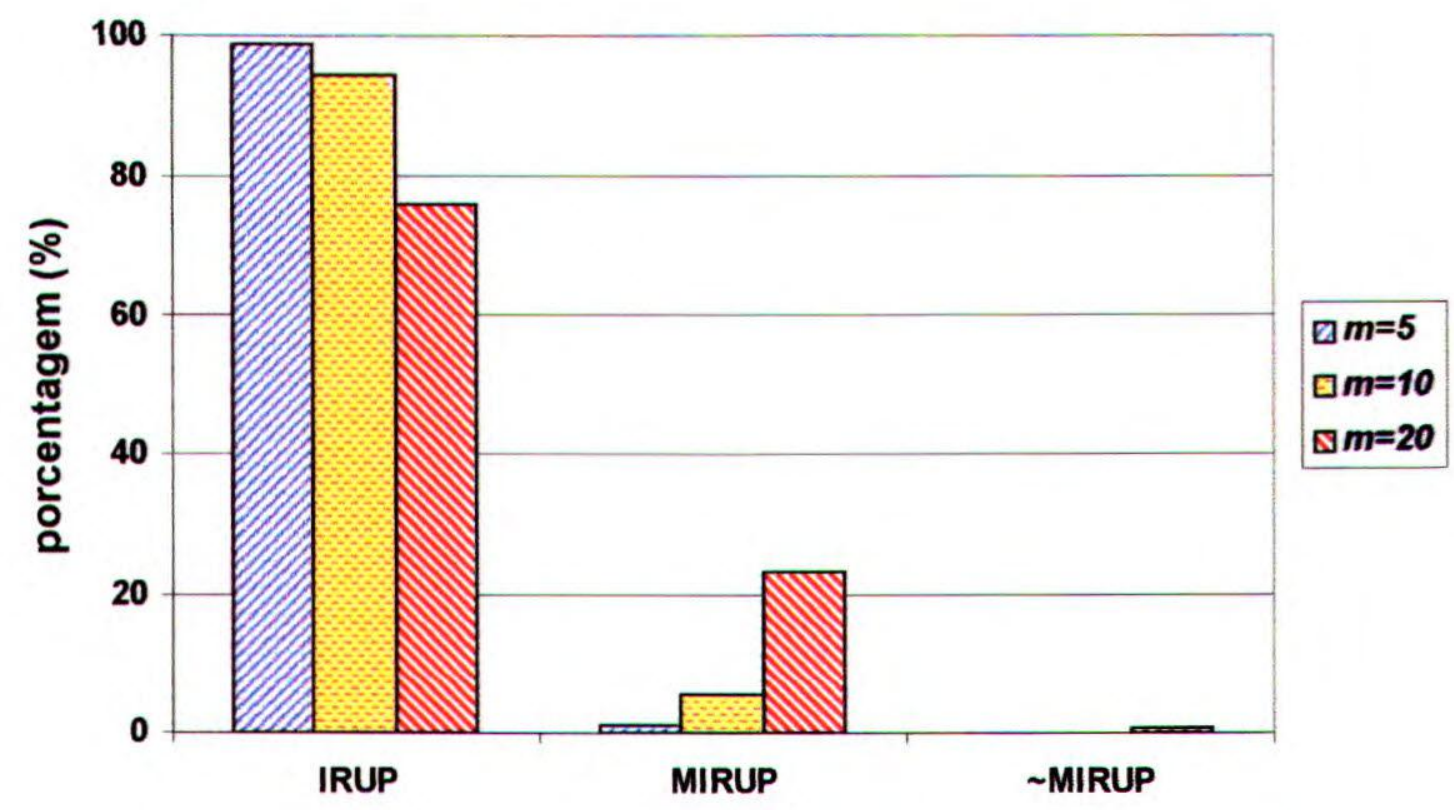

Gráfico 5.3 Qualidade da solução para problemas pequenos com $\gamma=0,5$

Exemplos grandes $(\gamma=0,5)$

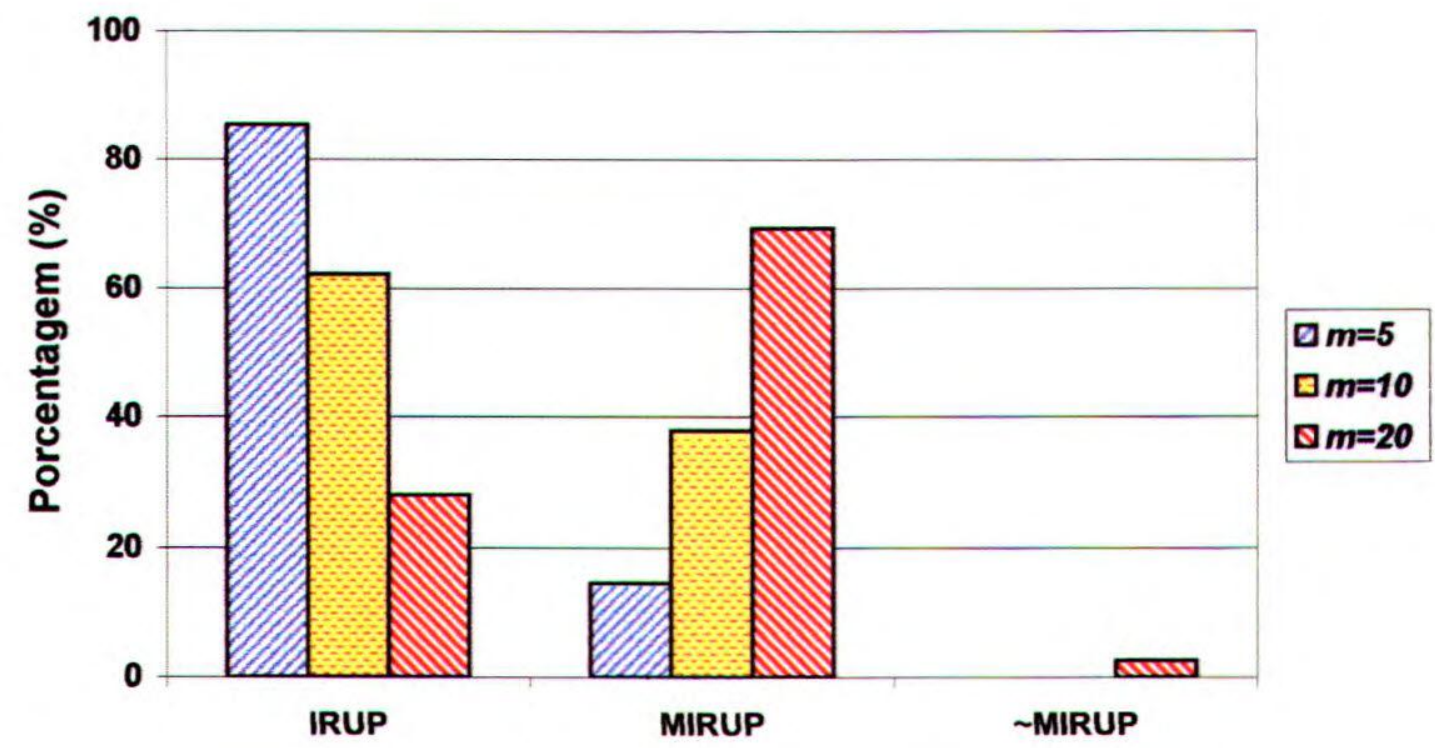

Gráfico 5.4 Qualidade da solução para exemplos grandes com $\gamma=0,5$ 


\section{Capítulo 6}

\section{Conclusōes e Propostas Futuras}

Neste trabalho foi apresentada uma breve revisão bibliográfica relacionada com o tema do projeto. Em seguida, revisamos alguns métodos heurísticos para o problema de corte de estoque inteiro unidimensional baseado em Wäscher e Gau (1996).

Com base no objetivo principal deste projeto, tratamos então do problema de corte de estoque inteiro bidimensional, onde apresentamos sua formulação e um método heurístico para sua resolução, sendo este uma extensão de um dos métodos de melhor resultado para o caso unidimensional. $\mathbf{O}$ fato de alguns conceitos não serem válidos para o problema bidimensional dificultaram esta extensão, sendo necessária a procura de conceitos equivalentes.

Uma outra dificuldade encontrada foi com relação à geração dos padrões de corte, mais precisamente, com relação à resolução do Problema da Mochila, que para o caso bidimensional não é um problema de fácil resolução. Para superar esta dificuldade, consideramos restrições do tipo 2-estágios não-exato para o problema e utilizamos o método de Decomposição/Irrestrita para resolver a mochila irrestrita e o método de Decomposiçāo/Restrita quando tivemos que resolver a mochila restrita. Estes métodos foram apresentados no capitulo 4.

Feitas estas considerações, implementamos o método heurístico e realizamos testes computacionais com o intuito de avaliarmos seu desempenho computacional e, verificar se a propriedade MIRUP poderia ser conjecturada também para o problema bidimensional. Apesar de terem sido encontrados exemplos cujas soluções heurísticas pareciam não satisfazer esta propriedade, há fortes indicações dela ser válida também para o problema bidimensional. Os resultados dos testes estão apresentados no capitulo 5 . 
Como proposta para trabalhos posteriores, sugerimos as seguintes:

- Modificações no modelo 4.2, acrescentando outras restrições ao problema. Outra opção seria considerar outras funções objetivos, como por exemplo, as já mencioriadas na seção 3.1 , quando tratávamos do problema unidimensional;

- Resolver o problema sem acrescentar restrições 2-estágios não-exato ou ainda, considerando outros tipos de restrições;

- Implementações de novos métodos heurísticos, utilizando os conceitos apresentados neste trabalho, realizando comparações com os obtidos pelo método aqui estudado; 


\section{ANEXo A}

\section{Alguns exemplos resolvidos em detalhes}

Apresentamos aqui alguns exemplares utilizando o método implementado seguindo o algoritmo da seção 4.4. Esta apresentação será feita da seguinte maneira: inicialmente fornecemos os dados do problema, ou seja, comprimento e largura da peça em estoque e, comprimento, largura e demanda de cada item. Em seguida, colocamos os resultados obtidos da relaxação do problema original, das relaxações do problema residual e da utilização do método decomposição/restrita, quando necessário. Para cada um destes resultados, são mostrados os padrões com suas respectivas freqüências já arredondadas (que estarão apresentados abaixo de cada padrão), seguido da quantidade total de padrões utilizada com o arredondamento. A demanda que ainda faltar ser atendida é apresentada depois de realizado cada passo. Finalizamos, fazendo uma breve análise do resultado obtido, ou seja, fornecemos a quantidade mínima de padrões necessária para resolver o problema e a quantidade obtida pela heurística. Se estas forem iguais, concluímos que a solução é ótima e, portanto, possui a propriedade IRUP. Se a diferença entre elas (gap de integralidade) for de uma unidade, dizemos que o exemplo satisfaz a propriedade MIRUP. Caso a diferença seja maior, dizemos que o problema não possui nenhuma das propriedades. Esta análise está baseada nas relações definidas no item (v) do capítulo 5 que se refere à qualidade da solução. Como já observado anteriormente, é importante deixar claro que, nos dois últimos casos, nada podemos afirmar quanto a não-otimalidade da solução obtida heuristicamente.

Utilizando a parte gráfica, serão apresentados a seguir, somente exemplos com $m=5$ e 10 devido à dificuldade no armazenamento da matriz com todos os padrões gerados durante as iterações do método de Geração de Colunas. Este armazenamento é necessário para que ocorra a 
reconstituição dos padrões finais. Com isto não serão mostrados exemplos onde o valor do gap seja maior que um, já que em problemas deste porte, não observamos a ocorrência desta situação, como pode ser observado nos resultados computacionais do capítulo 5 .

Considere então os seguintes exemplos:

Exemplo 1: (Exemplo grande) $m=5$

Neste primeiro exemplo, mostramos a solução do exemplo 4.1 proposto na seção 4.5 , cujos dados serão repetidos abaixo:

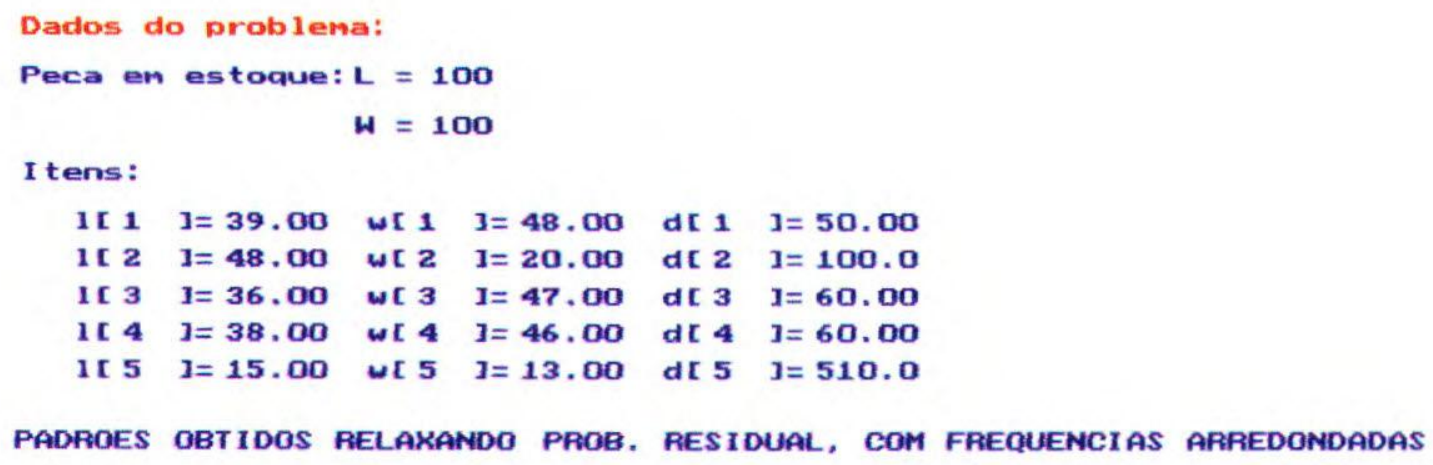

PADROES OBTIDOS RELAKANDO PROB. RESIDUAL, COM FREQUENCIAS ARREDONDADAS

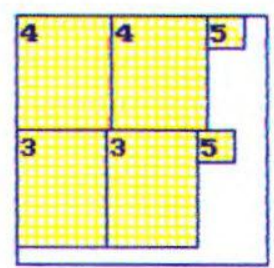

1

Quantidade de padroes utilizados: 1

Demanda Residua 1:

$(2,0,0,0,12)$

PADROES OBTIDOS RELAXANDO PROB. ORIGINAL COM FREQUENCIAS ARREDONDADAS
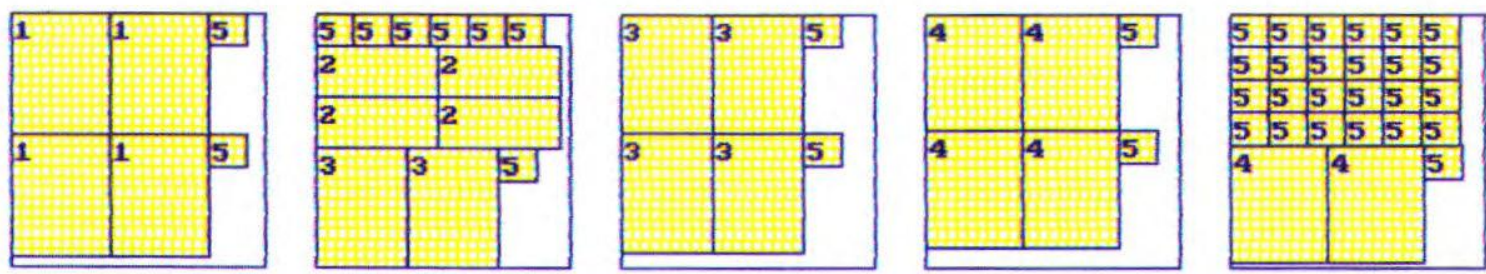

9

Quantidade de padroes utilizados: 59

Demanda Residua 1:

$(2,0,2,2,14)$ 
PADAOES UTILIZANDO DECOMPOSICAO RESTAITA

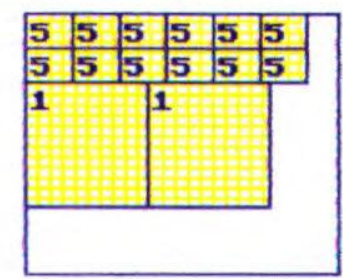

Numero de padroes obtidas: 1

ANALISE DOS RESULTADOS

Quantidade minima de padroes que deveria ser utilizada: 61

Quantidade de padroes obtidos pela heuristica: 61

Meste exemplo, vale a propriedade Inup e a solucao e otina:

Exemplo 2: (Exemplo pequeno) $m=5$

Dados do problema:

Peca en estoque: $L=100$

$$
\mathbf{W}=100
$$

I tens :

$\begin{array}{llllll}1[1 & ]=25.00 & w[1 & ]=54.00 & d[1 & ]=210.0 \\ 1[2 & ]=42.00 & w[ & ]=64.00 & d[2 & ]=90.00 \\ 1[3 & ]=74.00 & w[3 & ]=38.00 & d[3 & ]=90.00 \\ 1[4 & 1=36.00 & w[4 & ]=47.00 & d[4 & ]=150.0 \\ 1[5 & =41.00 & w[5 & 1=57.00 & d[5 & ]=120.0\end{array}$

PADROES OBTIDOS RELAXANDO PROB. ORIGINAL COM FREQUENCIAS ARAEDNDADAS

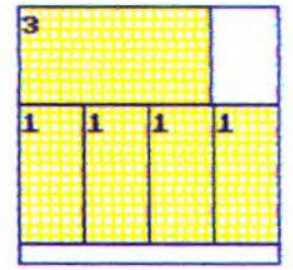

52

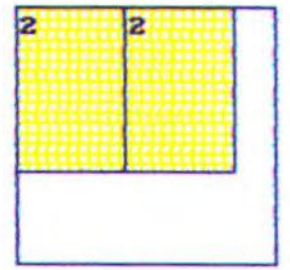

45

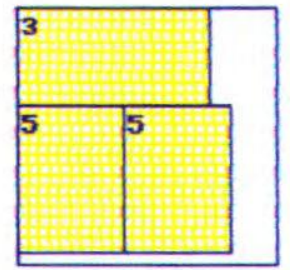

37

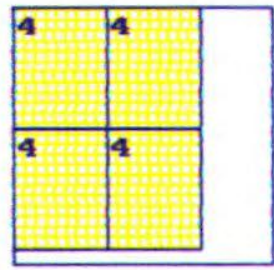

37

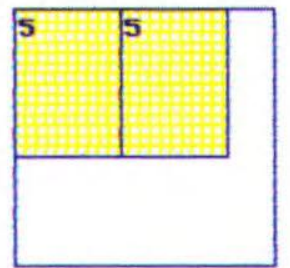

22

Quant idade de padroes utilizados: 193

Demanda Residual:

( $2,0,1,2,2)$

PADROES OBTIDOS RELAKANDO PROB. RESIDUAL, COM FREQUEMCIAS ARREDONDADAS

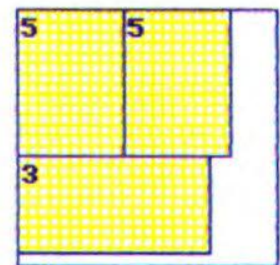

1

Quantidade de padroes utilizados: 1

Demanda Residua 1 :

$(2,0,0,2,0)$ 
PADROES UTILIZAMDO DECOMPOSICAO RESTRITA
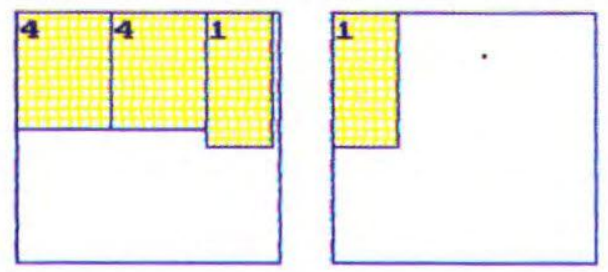

Numero de padroes obtidos: 2

ANALISE DOS RESULTADOS

Quantidade minima de padroes que deveria ser utilizada: 195

Quantidade de padroes obtidos pela heuristica: 196

Neste exemplo, vale a propriedade MIRUP:

Exemplo 3: (Exemplo grande) $m=5$

Dados do problema:

Peca em es toque: $L=100$

$$
\mathbf{W}=100
$$

Itens:

\begin{tabular}{|c|c|c|c|c|c|}
\hline 1 & ] & [ & $\mathbf{3}=$ & dr & \\
\hline 2 & $J=41.00$ & w 2 & $J=40.00$ & dI 2 & $J=60.00$ \\
\hline 63 & ]$=13.00$ & $\omega\left[\begin{array}{l}3 \\
\text { w }\end{array}\right.$ & $1=35.00$ & dr 3 & $1=220$. \\
\hline & $J=16.00$ & wt 4 & $J=46.00$ & dt & $I=140.0$ \\
\hline & $1=24.00$ & we 5 & $I=10 \cdot 00$ & dt & $1=420$. \\
\hline
\end{tabular}

PADROES OBTIDOS RELAXANDO PROB. ORIGINAL COM FREQUENCIAS ARREDONDADAS

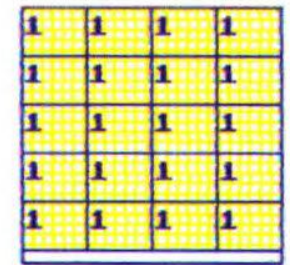

2

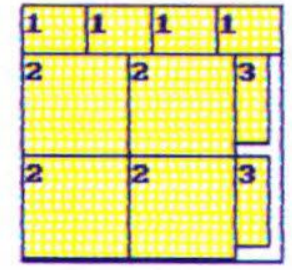

15

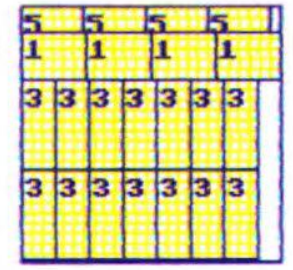

1

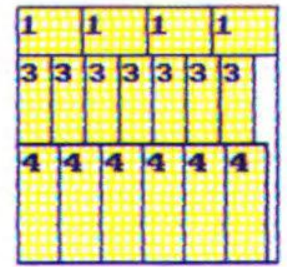

23

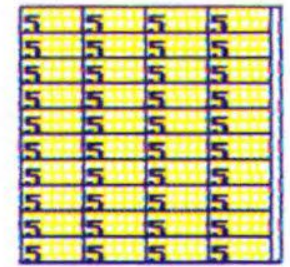

10

Quantidade de padroes utilizados: 51

Demanda Residua 1 :

$(14,0,15,2,16)$

PADROES OBTIDOS RELAXANDO PROB. RESIDUAL, COM FREQUENCIAS ARREDONDADAS

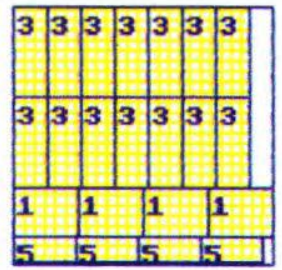

1

Quantidade de padroes utilizados: 1

Demanda Residua 1:

(10,0,1,2,12) 
PADROES UTILIZANDO DECOMPOSICAO RESTRITA
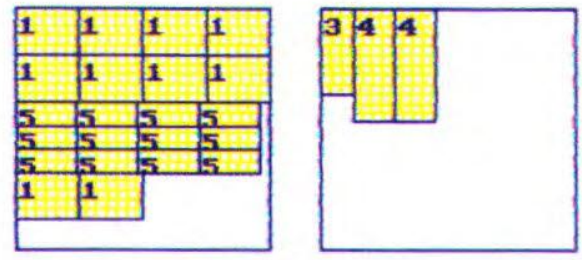

Numero de padroes obtidos: 2

ANALISE DOS RESULTADOS

Quantidade minima de padroes que deveria ser utilizada: 53

Quantidade de padroes obtidos pela heuristica: 54

Neste exemplo, vale a propriedade MIPUP?

Exemplo 4: (Exemplo grande) $m=10$

Dactos do problema:

Peca en es toque: $L=100$

$$
\mathbf{W}=100
$$

I tens:

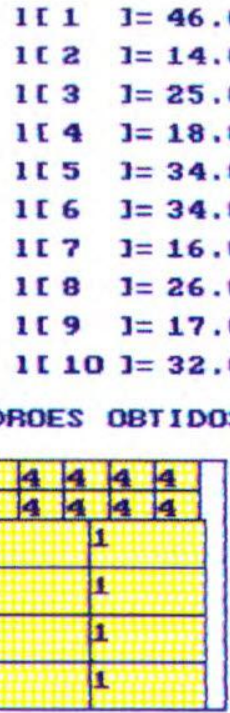

6

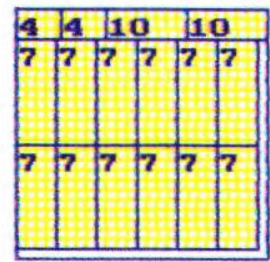

12

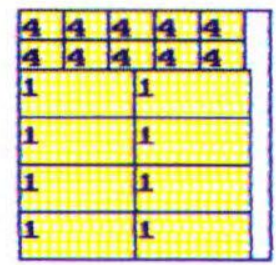

w[ 1$]=19.00$

w[ 2$]=32.00$

$\omega\left[\begin{array}{ll}3 & ]=19.00\end{array}\right.$

w[ 4$]=12,00$

$w[5]=31.00$

w[ 6$]=32.00$

w[ 7$]=42.00$

w[ 8$]=31.00$

w[ 9$]=36.00$

$w[10]=12,00$ di 1$]=110.0$

di 2 ] $=220.0$

dI $3 \quad 3=210.0$

d[ 4$]=460.0$

df 5$]=90.00$

d[ 6$]=90.00$

dr 7$]=150.0$

dr 8$]=120$. 0

dI 9$]=160.0$

d[ 10$]=260.0$

PADROES OBTIDOS RELAXANDO PROB. ORIGINAL COM FREQUENCIAS ARREDONDADAS

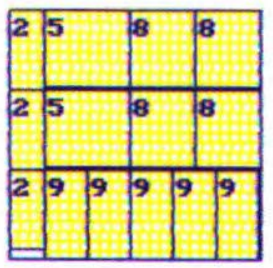

16

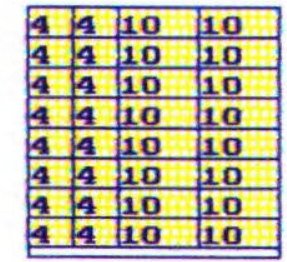

2

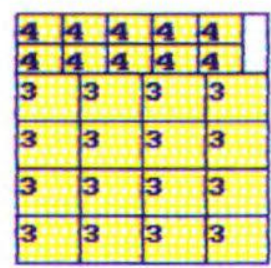

13

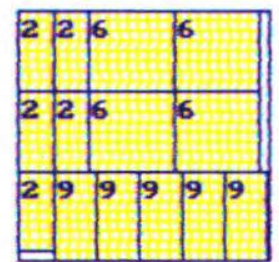

15

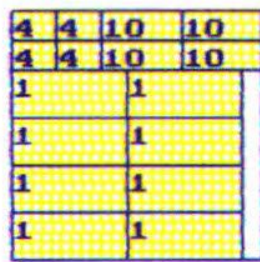

6

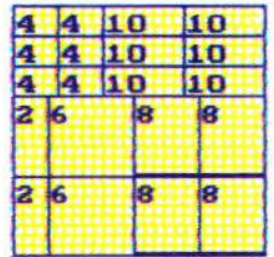

13

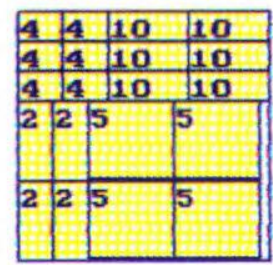

14

Quantidade de padroes utilizados: 97 Demanda Residua 1 :

$(14,15,2,28,2,4,6,4,5,18)$ 
Primeira relaxação do problema residual:

PADROES OBI IDOS RELAXAMDO PROB. RESIDUAL, COM FREQUENCI AS ARREDOMDADAS

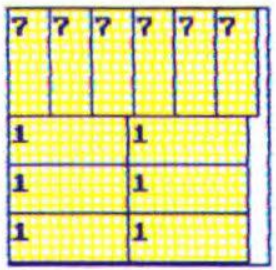

1

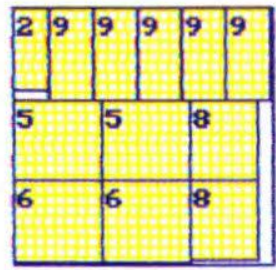

1

Demanda Residua 1 :

$(8,14,2,28,0,2,0,2,0,18)$

Segunda relaxação do problema residual:

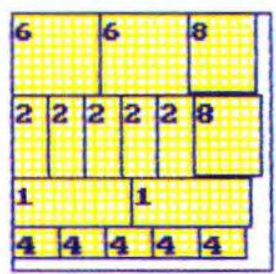

1

Quantidade de padroes ut 11 izados: 3

Demanda Residual:

$(6,9,2,23,0,0,0,0,0,18)$

Quando o problema residual é relaxado novamente e o arredondamento é feito, este resulta somente em freqüências nulas. Com isto a demanda residual será atendida da seguinte forma:

PADROES UTILIZANDO DECOMPOSICAO RESTRITA
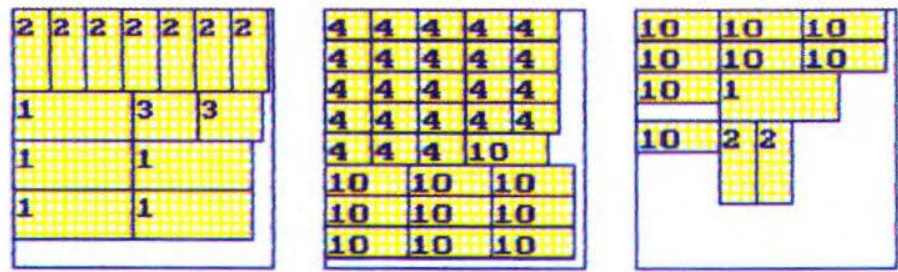

Numero de padroes obtidos: 3

ANALISE DOS RESULTADOS

Quantidade minima de padroes que deveria ser utilizada: 103

Quantidade de padroes obtidos pela heuristica: 103

Neste exemplo, vale a propriedade IRup e a solucao e otima: 
Exemplo 5: (Exemplo pequeno) $m=10$

Daclos do problema:

Peca en estoque: $L=100$

$$
\mathbf{W}=\mathbf{1 0 0}
$$

Itens:

$\begin{array}{llllll}1[1 & ]=68.00 & w[1 & ]=54.00 & d[1 & ]=60.00 \\ 1[2 & ]=33.00 & w[2 & ]=33.00 & d[2 & ]=270.0 \\ 1[3 & ]=31.00 & w[3 & ]=42.00 & d[3 & ]=210.0 \\ 1[4 & ]=39.00 & w[4 & ]=59.00 & d[4 & ]=120.0 \\ 1[5 & ]=66.00 & w[5 & ]=33.00 & d[5 & ]=120.0 \\ 1[6 & ]=63.00 & w[6 & ]=29.00 & d[6 & ]=150.0 \\ 1[7 & ]=30.00 & w[7 & ]=60.00 & d[7 & ]=150.0 \\ 1[8 & ]=74.00 & w[8 & ]=56.00 & d[8 & ]=60.00 \\ \text { If } 9]=74.00 & w[9 & ]=33.00 & d[9 & ]=120.0 \\ 1[10]=58.00 & w[10]=59.00 & d[10] & 1060.00\end{array}$

PADROES OBTIDOS RELAKAMDO PROB. ORIGINAL COM FREQUENCIAS ARREDONDADAS

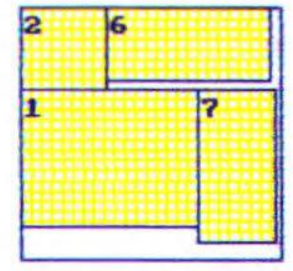

52

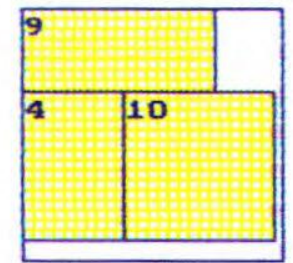

11

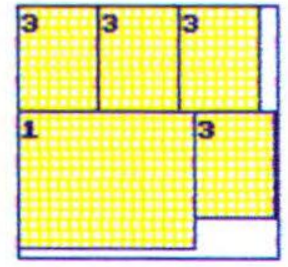

7

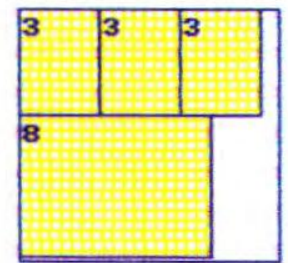

60

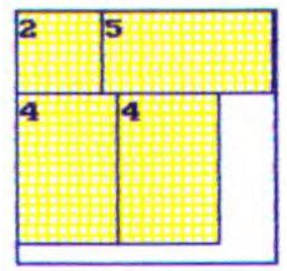

5

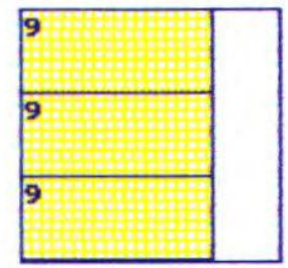

36

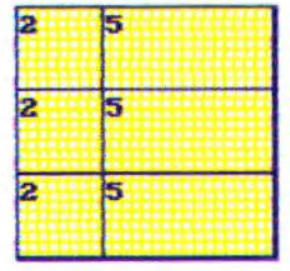

38

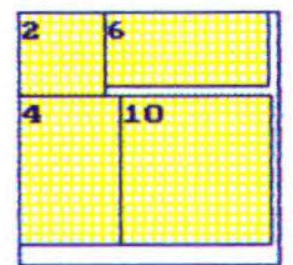

48

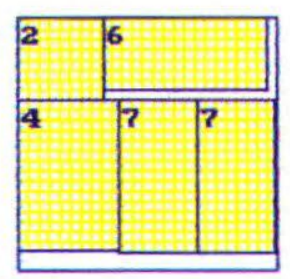

48

Quant idade de padroes utilizados: 305

Demanda Res idua 1:

$(1,3,2,3,1,2,2,0,1,1)$

PADROES UTILIZAMDO DECOMPOSICAO RESTRITA
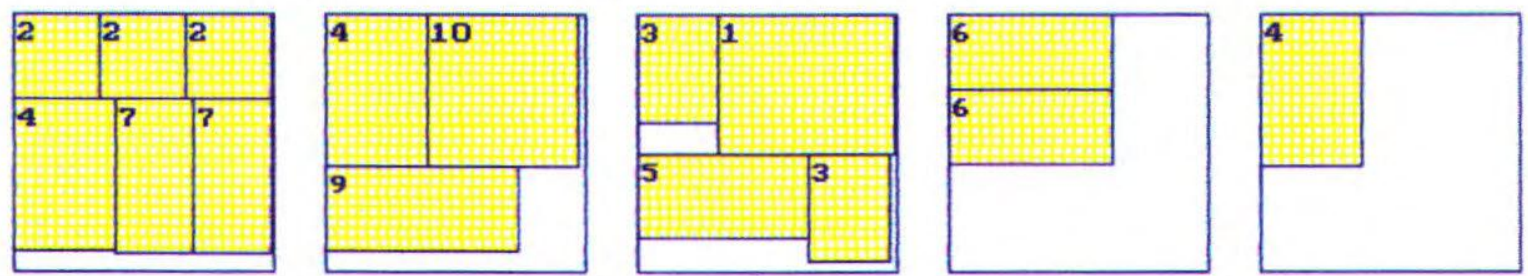

Numero de padroes obtidos: 5

ANALISE DOS, RESULTADOS

Quantidade minima de padroes que deveria ser utilizada: 309

Quantidade de padroes obtidos pela heuristica: 310

Neste exemp 1o, vale a propriedade MIRUP? 
Exemplo 6: (Exemplo grande) $m=10$

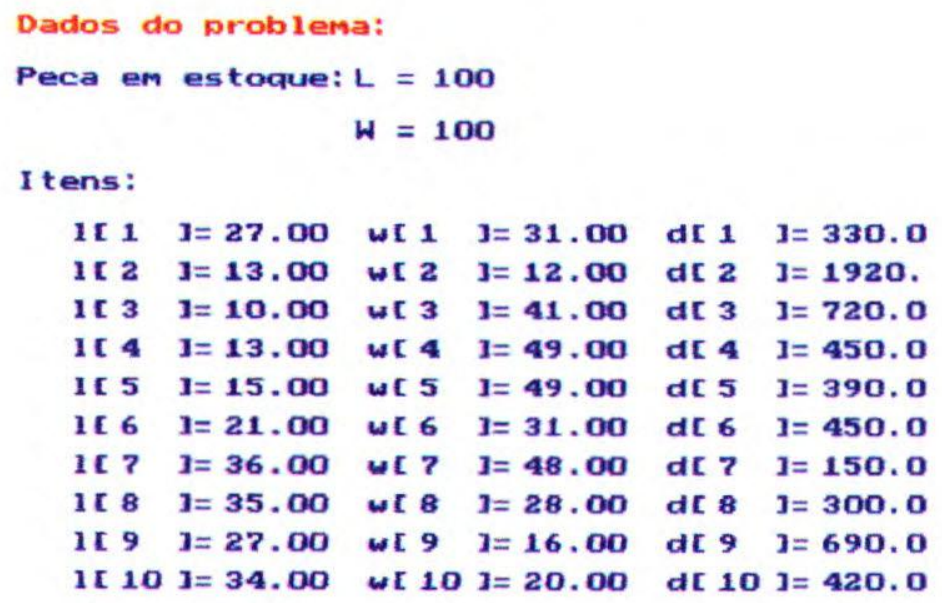

PADROES OBTIDOS RELAXANDO PROB. ORIGINAL COM FREQUENCIAS ARREDONDADAS

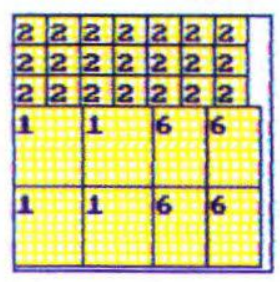

21

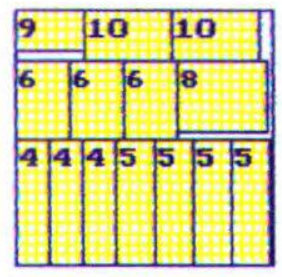

70

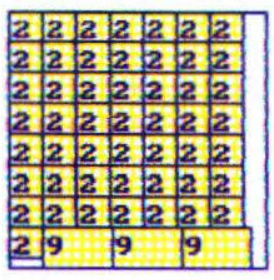

16

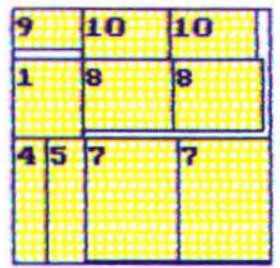

75

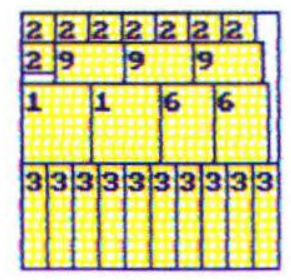

65

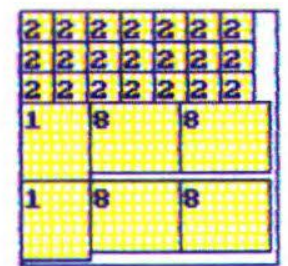

1

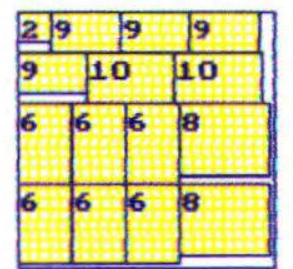

3

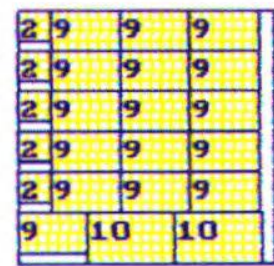

14

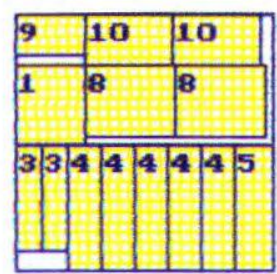

32

\begin{tabular}{|l|l|l|}
\hline 9 & 10 & 10 \\
\hline 9 & 10 & 10 \\
\hline 9 & 10 & 10 \\
\hline 9 & 10 & 10 \\
\hline 9 & 10 & 10 \\
\hline
\end{tabular}

2

Quant idade de padroes ut ilizados: 299

\section{Demanda Residual:}

$(7,65,6,5,3,8,0,6,24,12)$

Primeira relaxação do problema residual:

PADROES OBTIDOS RELAXANDO PROB. RESIDUAL, COM FREQUENCIAS ARREDONDADAS

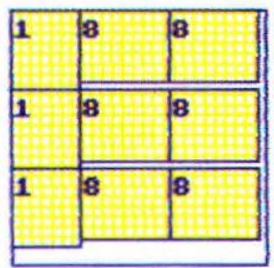

1

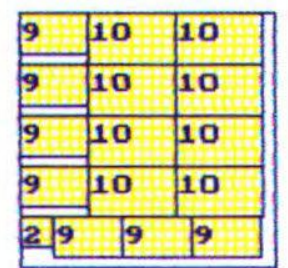

1

Demanda Res idua 1 :

$(4,646,5,3,8,0,0,17,4)$ 
Segunda relaxação do problema residual:

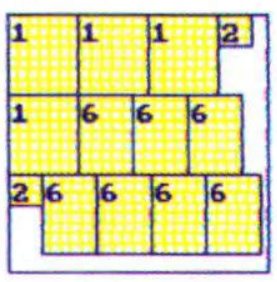

1

\begin{tabular}{|l|l|l|l|}
\hline 9 & 10 & 10 \\
\hline 9 & 10 & 10 \\
\hline 2 & 9 & 9 & 9 \\
\hline 2 & 9 & 9 & 9 \\
\hline 2 & 9 & 9 & 9 \\
\hline 2 & 2 & 2 & 2 \\
\hline
\end{tabular}

1

Demanda Residual:

$(0,52,6,5,3,1,0,0,6,0)$

Terceira relaxação do problema residual:

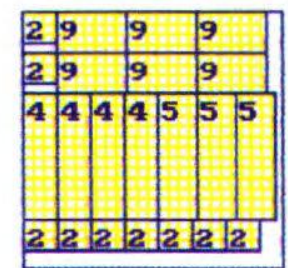

1

Quantidade de padroes utilizados: 5

Demanda Residua 1 :

( $0,43,6,1,0,1,0,0,0,0)$

Quando o problema residual é relaxado novamente e o arredondamento é feito, este resulta somente em freqüências nulas. Com isto a demanda residual será atendida da seguinte forma:

\section{PADROES UTILIZANDO DECOMPOSICAO RESTRITA}
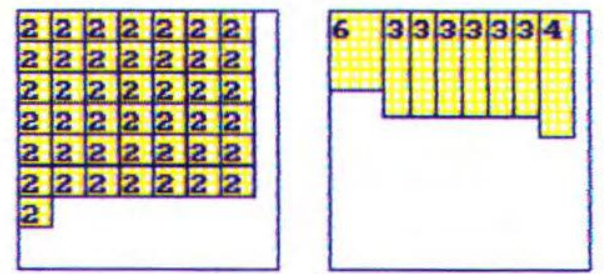

Numero de padroes obtidos: 2

ANALISE DOS RESULTADOS

Quantidade minima de padroes que deveria ser utilizada: 305

Quantidade de padroes obtidos pela heuristica: 306

Neste exemplo, vale a propriedade MIRup: 
Exemplo 7: (Exemplo grande) $m=10$

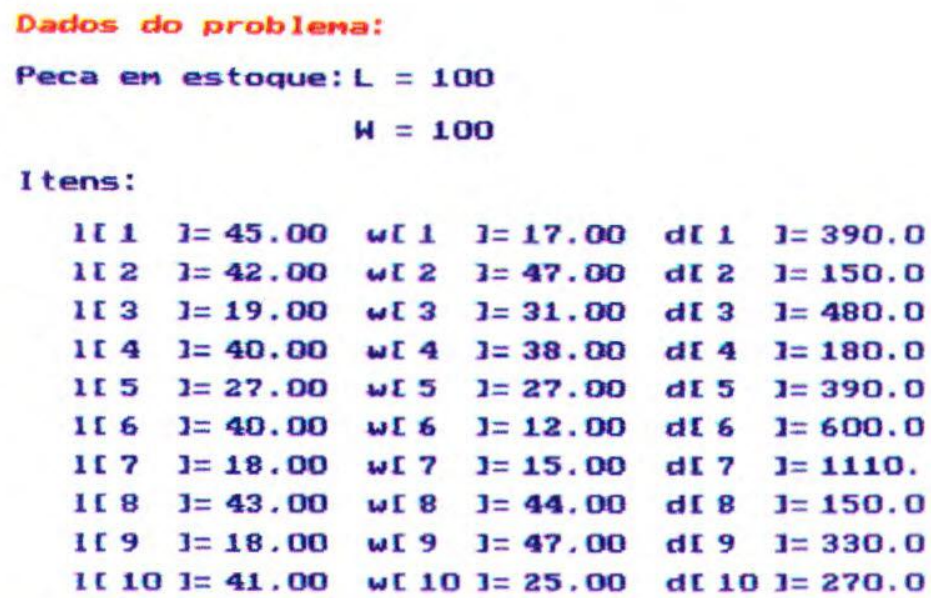

PADROES OBtIDOS RELAKAMDO PROB. ORIGINAL COM FREQUENCIAS arREDONDADAS

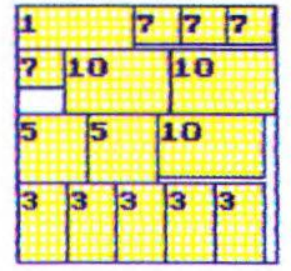

78

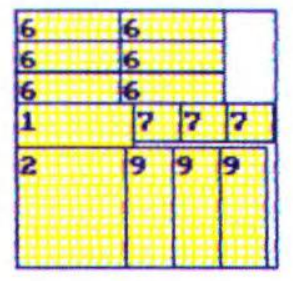

34

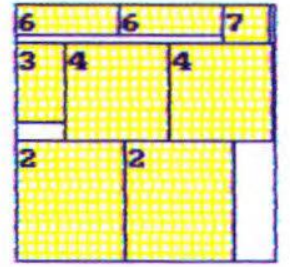

20

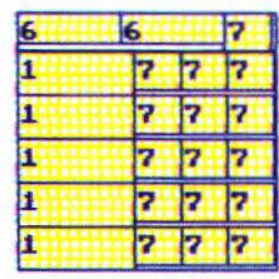

22

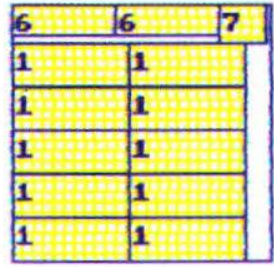

$\mathbf{5}$

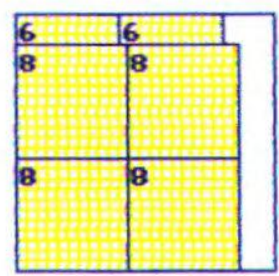

37

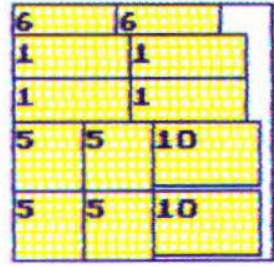

12

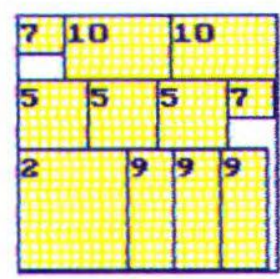

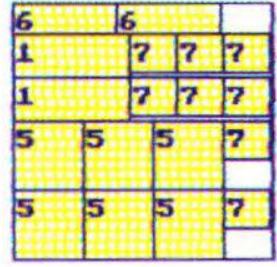

27

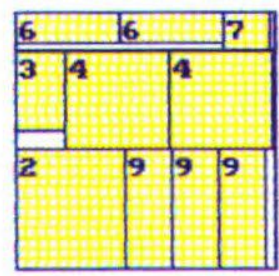

70

Quantidade de padroes utilizados: 310

Demanda Residua 1 :

$(16,1,0,0,9,10,23,2,3,2)$

Primeira relaxação do problema residual:

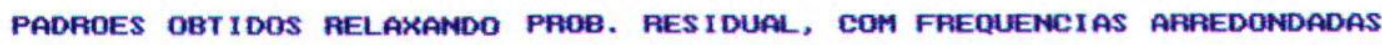

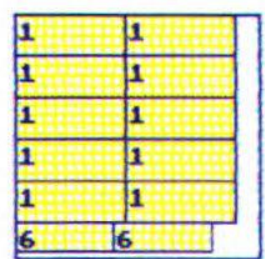

1

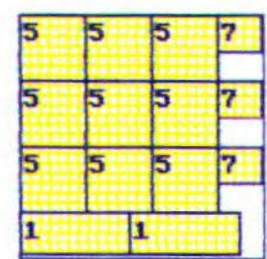

1

Demanda Residual:

$$
(4,1,0,0,0,8,20,2,3,2)
$$


Segunda relaxação do problema residual:

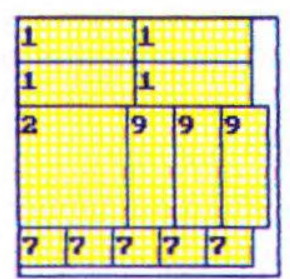

1

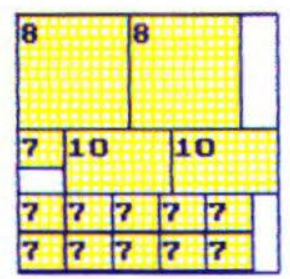

1

Quantidade de padroes utilizados:

Demanda Residua 1:

$(0,0,0,0,0,8,4,0,0,0)$

\section{PADROES UT ILIZANDO DECOMPOSICAO RESTRITA}

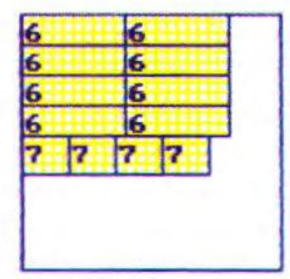

Numero de padroes obtidos: 1

ANALISE DOS RESULTADOS

Quantidade minima de padroes que deveria ser utilizada: 315

Quantidade de padroes obtidos pela heuristica: 315

Neste exemplo, vale a propriedade IRuP e a solucao e otima!

\section{Observação A.1:}

Quando apresentamos o método de resolução Decomposição/Restrita, no capitulo 4, mencionamos sobre a utilização de outros valores para a variável $\gamma$ da equação (4.14). Desta forma, no capítulo 5 mostramos os resultados computacionais também para os valores de $\gamma=0.5 \mathrm{e}$, de forma geral, vimos que não ocorreram grandes diferenças entre os resultados onde assumimos $\gamma=1$, para exemplos até $m=20$. Este fato nos levou a considerar, para todos os exemplos mostrados anteriormente, somente o valor de $\gamma=1$.

Entretanto, observamos durante nossos estudos que, para casos isolados, esta modificação acarreta em soluções diferentes, como no exemplo 5 deste anexo, cujo gap de integralidade foi igual a um, enquanto que ao considerarmos $\gamma=0.5$, obtivemos uma solução ótima e o problema passou a possuir a propriedade IRUP. Este resultado será mostrado a 
seguir, onde pode ser observado que a mudança no valor de $\gamma$ não influencia na solução obtida relaxando o problema original, pois somente quando resolvemos o problema residual, utilizamos o método Decomposição/Restrita. Os dados do problema já foram fornecidos anteriormente.

Exemplo 8: Resultado do exemplo 5 considerando $\gamma=0,5$

padroes obtidos relaxamdo prob. original com frequencias arRedondadas

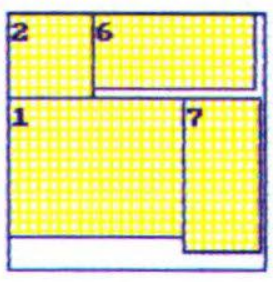

52

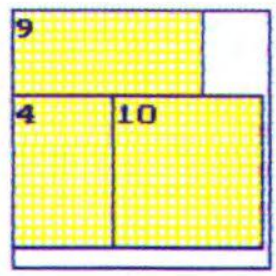

11

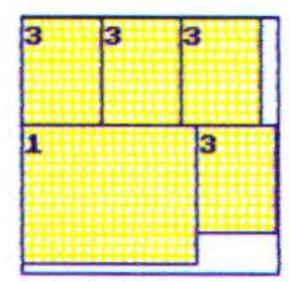

7

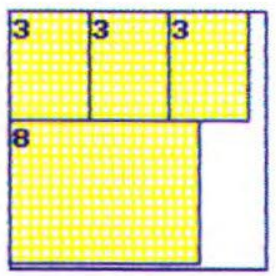

60

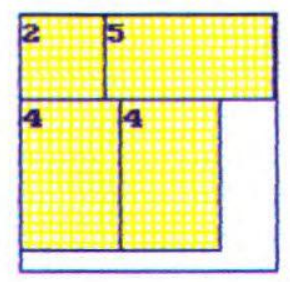

$\mathbf{5}$

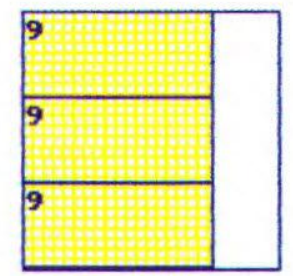

36

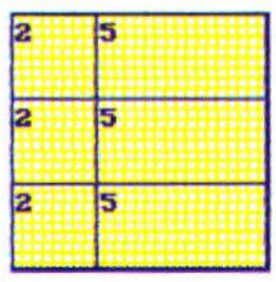

38

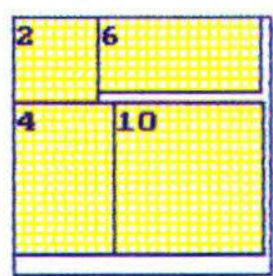

48

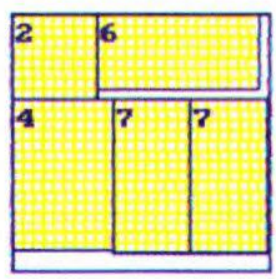

48

Quant idade de padroes utilizados: 305

Demanda Res idual:

$(1,3,2,3,1,2,2,0,1,1)$

Primeira relaxação do problema residual:

Padroes obt Idos Relaxando PRob. Residual, com frequencias arRedondadas

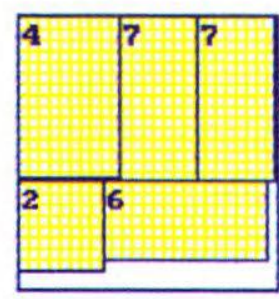

1

Demanda Residua 1 :

$(1,2,2,2,1,1,0,0,1,1)$ 
Segunda relaxação do problema residual:

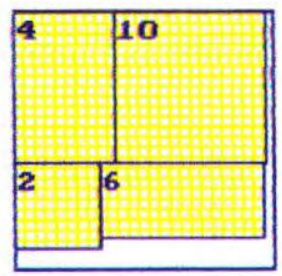

1

Denanda Residua 1:

$\langle 1,1,2,1,1,0,0,0,1,0\rangle$

Terceira relaxação do problema residual:

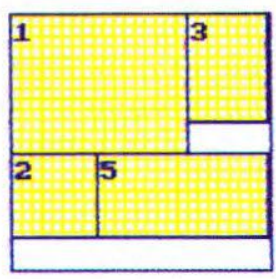

1

Quantidade de padroes utilizados: 3

Demanda Residua 1 :

$(0,0,1,1,0,0,0,0,1,0)$

PADAOES UTILIZANDO decomposicao RESTRITA

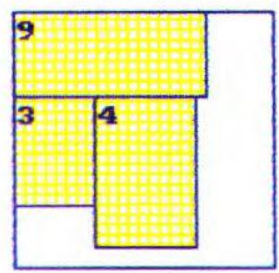

Numero de padroes obtidos: 1

ANALISE DOS RESULTADOS

Quantidade minima de padroes que deveria ser utilizada: 309

Quantidade de padroes obtidos pela heuristica: 309

Neste exemplo, vale a propriedade I RUP e a solucao e otima! 


\section{ANEXO B}

\section{Solução Degenerada com Ciclagem}

Nesțe anexo, apresentamos um exemplo cuja solução do problema original relaxado é degenerada, ou seja, quando uma ou mais componentes da solução básica $\widetilde{\mathbf{x}}$ (solução do Método Simplex) se anulam. Esta solução é chamada solução básica degenerada.

De uma forma simplificada e relacionando a definição acima com o nosso estudo, a degeneração de uma solução quando estamos resolvendo o problema 4.2, ocorre quando um número $s<m$ de padrões de corte estão sendo suficientes para atender a demanda dos itens resultando em uma freqüência nula para os demais padrões.

O aparecimento da degeneração pode resultar em alguns problemas, como por exemplo, a ciclagem que ocorre quando o Método Simplex não 'consegue' encontrar a solução ótima do problema, voltando sempre à uma partição básica já obtida em alguma iteração anterior.

Durante a realização das simulações do método, que implementamos, apareceram exemplos com ciclagem, ocorrendo a necessidade de encontrarmos uma solução para o problema. Duas regras para prevenir estes ciclos mais conhecidas na literatura são: a regra lexográfica para seleção da variável que deverá sair da base e a regra de Bland que seleciona quais variáveis deverão sair e entrar na base. Segundo Bazaraa et al. (1990), que descreve estes métodos de forma detalhada, estas regras normalmente são ignoradas na maioria dos códigos utilizados para resolução de problemas de programação linear através do Método Simplex. Isto decorre principalmente do alto custo computacional para implementar o método lexicográfico e da ineficiência computacional da regra de Bland com respeito ao tamanho do caminho simplex gerado por ela. 
Sendo assim, pensamos em resolver o problema considerando um outro caminho, que consiste em fazer uma pequena perturbação aleatória nas coordenadas do vetor $\mathbf{x}$, 'eliminandose' a degeneração, influenciando assim na escolha da variável a sair da base. Em Murty (1983) um procedimento bastante semelhante é sugerido pelo autor, onde o acréscimo seria feito no vetor de demanda $\mathbf{d}$.

Este procedimento resolveu o problema de ciclagem, entretanto, devido à perturbação ser aleatória, influenciou na resolução final do exemplo analisado. Observamos que uma nova solução para a relaxação do problema original estava sendo obtida a cada simulação. Isto é esperado e não preocupante visto que um problema pode ter múltiplas soluções. Mas, ao resolver o problema resultante para atender a demanda residual, diferentes caminhos foram tomados pelo método. Ou seja, apesar de obter um mesmo valor para a função objetivo ao final da resolução da relaxação do problema original utilizando Geração de Colunas, o método resolve de diferentes maneiras o problema residual, dependendo da demanda resultante. Isto pode acarretar em análises distintas com relação às propriedades, a cada vez que o mesmo problema é rodado.

$\mathrm{Na}$ grande maioria das vezes chegamos à conclusão de que o exemplo que será apresentado teria a propriedade MIRUP, pois estariamos gerando um padrão a mais do que a quantidade minima, entretanto, ocorreram casos em que o método obteve solução ótima e outros em que o gap foi de 2 unidades.

Para que tudo isto fique mais claro, apresentamos abaixo o problema, que é caracterizado como um problema pequeno (segundo classificação feita no capítulo 5), com $\gamma=1$. Em seguida, mostraremos alguns resultados e observações:

\section{Exemplo B.1}

\section{Dados do problema:}

- Peça em estoque: $L \times W=100 \times 100$

- Quantidade de itens: $m=20$ 
- Itens:

\begin{tabular}{|c|c|c|c|}
\hline & $l_{i}$ & $w_{i}$ & $d_{i}$ \\
\hline$i=1$ & 64,81 & 62,95 & 20 \\
\hline$i=2$ & 52,58 & 25,43 & 70 \\
\hline$i=3$ & 25,73 & 33,54 & 120 \\
\hline$i=4$ & 46,93 & 61,57 & 30 \\
\hline$i=5$ & 65,20 & 59,22 & 30 \\
\hline$i=6$ & 38,58 & 44,20 & 60 \\
\hline$i=7$ & 41,29 & 57,99 & 40 \\
\hline$i=8$ & 43,43 & 69,75 & 30 \\
\hline$i=9$ & 57,70 & 44,25 & 40 \\
\hline$i=10$ & 50,08 & 52,12 & 40 \\
\hline$i=11$ & 26,13 & 74,80 & 50 \\
\hline$i=12$ & 72,01 & 43,11 & 30 \\
\hline$i=13$ & 65,15 & 27,84 & 60 \\
\hline$i=14$ & 64,10 & 74,36 & 20 \\
\hline$i=15$ & 56,81 & 70,16 & 30 \\
\hline$i=16$ & 30,79 & 57,55 & 60 \\
\hline$i=17$ & 44,46 & 30,77 & 70 \\
\hline$i=18$ & 65,72 & 42,07 & 40 \\
\hline$i=19$ & 67,94 & 61,15 & 20 \\
\hline$i=20$ & 25,28 & 41,84 & 90 \\
\hline
\end{tabular}

Ocorreram dois casos quando rodamos várias vezes o problema acima:

Caso 1: Funções objetivos iguais, referentes às soluções diferentes (freqüência) do problema original relaxado $\Rightarrow$ resultados finais (referentes à avaliação quanto a possuir ou não as propriedades IRUP e MIRUP) iguais após aplicação do método heurístico;

Caso 2: Funções objetivos iguais, referentes às soluções diferentes (freqüência) do problema original relaxado $\Rightarrow$ resultados finais diferentes após aplicação do método heurístico. 
Para ilustrar estes casos considere os seguintes resultados obtidos depois de rodar o exemplo B.1 algumas vezes, aplicando o método heurístico:

\section{Resultado 1:}

Solução do problema relaxado $\quad\left\{\begin{array}{l}\tilde{x}_{1}^{*}=30 \\ \tilde{x}_{2}^{*}=10 \\ \tilde{x}_{3}^{*}=10 \\ \tilde{x}_{4}^{*}=10 \\ \tilde{x}_{5}^{*}=6 \\ \tilde{x}_{6}^{*}=10 \\ \tilde{x}_{7}^{*}=30 \\ \tilde{x}_{8}^{*}=6 \\ \tilde{x}_{9}^{*}=8 \\ \tilde{x}_{10}^{*}=6 \\ \tilde{x}_{11}^{*}=0 \\ \tilde{x}_{12}^{*}=7 \\ \tilde{x}_{13}^{*}=10 \\ \tilde{x}_{14}^{*}=14 \\ \tilde{x}_{15}^{*}=24 \\ \tilde{x}_{16}^{*}=10 \\ \tilde{x}_{17}^{*}=10 \\ \tilde{x}_{18}^{*}=14 \\ \tilde{x}_{19}^{*}=18 \\ \tilde{x}_{10}^{*}=13 \\ \text { Geraça de Colunas) }\end{array} \Rightarrow\left|f\left(\tilde{x}^{*}\right)\right|=246\right.$

Como a solução acima é inteira, temos que:

$\sum_{i=1}^{20}\left[\widetilde{x}_{i}^{*}\right]=246 \Rightarrow$ a solução é ótima e podemos afirmar que o exemplo B.1 possui a propriedade IRUP. 
Resultado 2: Neste resultado, observe que a solução obtida relaxando o problema original é não-degenerada.

Solução do problema relaxado
(Geração de Colunas) $\quad\left\{\begin{array}{l}\widetilde{x}_{11}^{*}=2 \\ \widetilde{x}_{12}^{*}=15 \\ \widetilde{x}_{13}^{*}=1,3 \\ \widetilde{x}_{14}^{*}=18 \\ \widetilde{x}_{15}^{*}=20 \\ \widetilde{x}_{16}^{*}=20 \\ \widetilde{x}_{17}^{*}=16 \\ \widetilde{x}_{18}^{*}=3,8 \\ \widetilde{x}_{19}^{*}=2 \\ \widetilde{x}_{20}^{*}=14\end{array}\right.$

$$
\begin{aligned}
& \tilde{x}_{1}^{*}=7 \\
& \tilde{x}_{2}^{*}=20 \\
& \tilde{x}_{3}^{*}=0,2 \\
& \tilde{x}_{4}^{*}=30 \\
& \tilde{x}_{5}^{*}=16 \\
& \widetilde{x}_{6}^{*}=1,7 \\
& \widetilde{x}_{7}^{*}=3,2 \\
& \widetilde{x}_{8}^{*}=16 \\
& \widetilde{x}_{9}^{*}=20 \\
& \widetilde{x}_{10}^{*}=19,8 \\
& \widetilde{x}_{11}^{*}=2 \\
& \widetilde{x}_{12}^{*}=15 \\
& \widetilde{x}_{13}^{*}=1,3 \\
& \widetilde{x}_{14}^{*}=18 \\
& \widetilde{x}_{15}^{*}=20 \\
& \widetilde{x}_{16}^{*}=20 \\
& \widetilde{x}_{17}^{*}=16 \\
& \widetilde{x}_{18}^{*}=3,8 \\
& \widetilde{x}_{19}^{*}=2 \\
& \widetilde{x}_{20}^{*}=14 \\
& \Rightarrow\left[f\left(\tilde{x}^{*}\right)\right]=246
\end{aligned}
$$

Somando as freqüências arredondadas para o inteiro inferior, temos: $\sum_{i=1}^{20}\left[\tilde{x}_{i}^{*}\right\rfloor=243$.

Seguindo os passos do algoritmo obtivemos mais um padrão ao resolver o problema residual relaxado e mais dois utilizando o método Decomposição/Restrita. Com isto, o método resolveu o problema utilizando 246 placas $\Rightarrow$ exemplo B.1 possui a propriedade IRUP. 


\section{Resultado 3:}

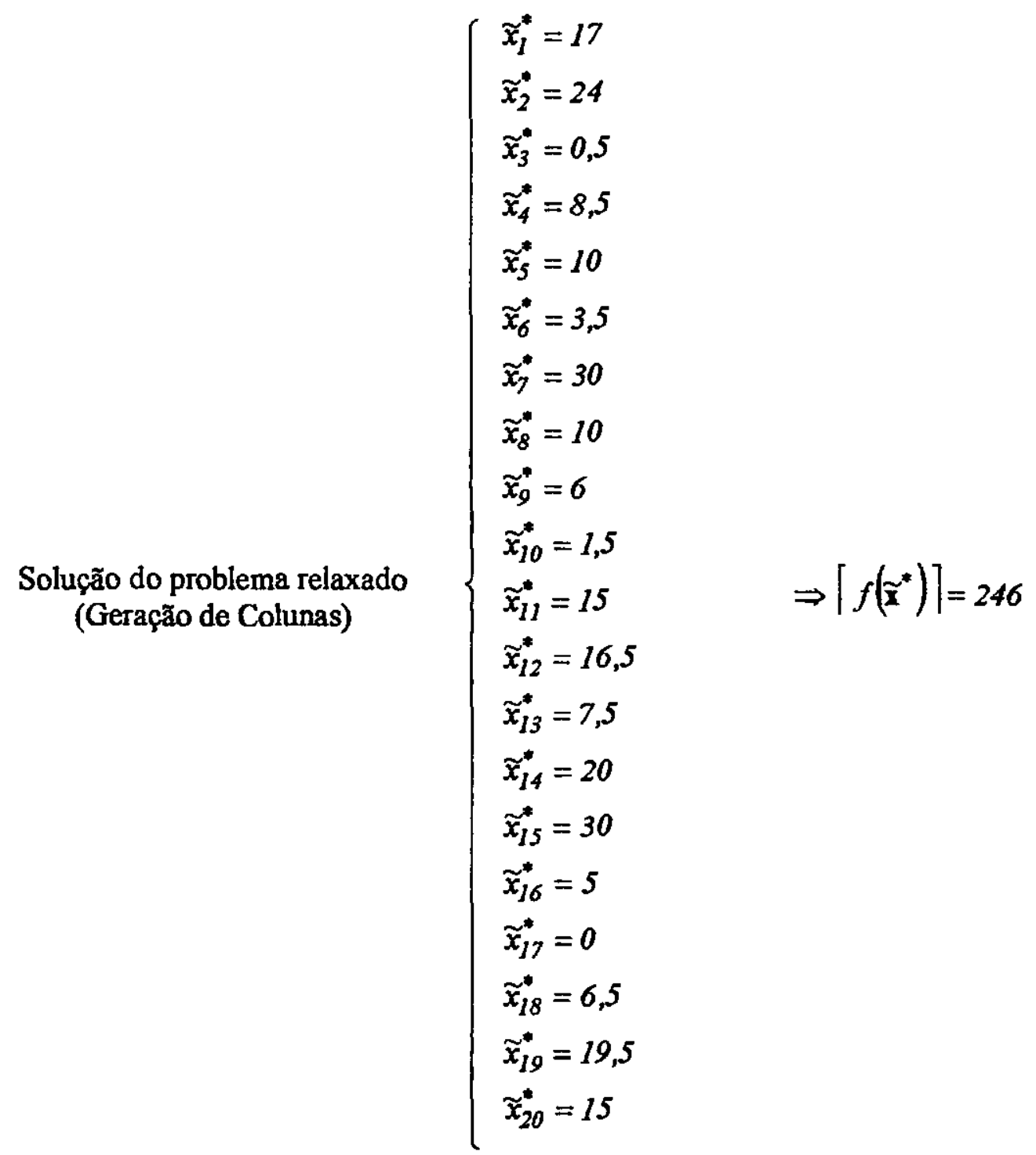

Somando as freqüências arredondadas para o inteiro inferior, temos: $\sum_{i=1}^{20}\left[\widetilde{x}_{i}^{*}\right]=242$.

Seguindo os passos do algoritmo obtivemos mais um padrăo ao resolver o problema residual relaxado e mais quatro utilizando o método Decomposição/Restrita. Com isto o método resolveu o problema utilizando 247 placas. Embora o exemplo possua a propriedade $\left[f\left(\widetilde{x}^{*}\right)\right]=f\left(x^{*}\right)$, a heuristica põe sob suspeita a propriedade MIRUP. 


\section{Resultado 4:}

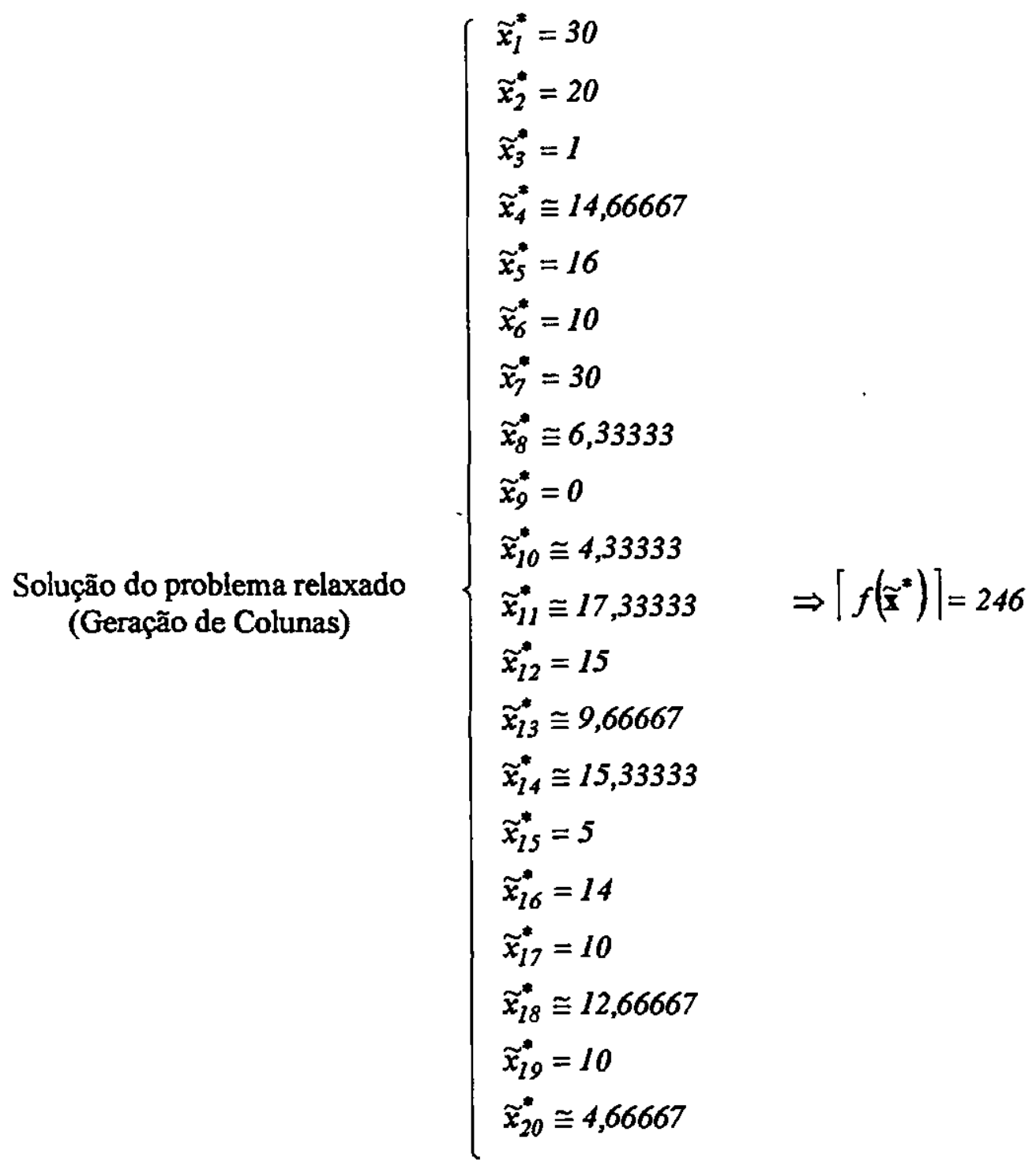

Somando as freqüências arredondadas para o inteiro inferior, temos: $\sum_{i=1}^{20}\left[\widetilde{x}_{i}^{*}\right]=242$.

Seguindo os passos do algoritmo, nenhum padrão é obtido ao resolver o problema residual relaxado enquanto que utilizando o método Decomposição/Restrita o método utiliza mais cinco padrões para resolver o problema, totalizando 247 placas $\Rightarrow$ exemplo B.1 satisfaz a propriedade MIRUP. 
Desta forma, pudemos observar que os resultados ( 1 e 2) ou (3 e 4) denotam o caso 1 enquanto que os resultados 2 e 3 caracterizam o caso 2.

Este exemplo ilustrou o fato de que com pequenas perturbações é possivel obter resultados diferentes. Com isto nos resultados apresentados no capítulo 5 , onde não foi possível a verificação da propriedade IRUP, fica evidente a possibilidade da propriedade ocorrer, caso ocorra alguma modificação no procedimento. 


\section{Referências Bibliográficas}

ARCARO, V. (1988) "Recorte de Estoque Unidimensional". Dissertação de Mestrado, Instituto de Ciências Matemáticas de São Carlos, Universidade de São Paulo - São Carlos.

ARENALES, M. e MORABITO, R. (editores) (1997), "Mini Curso: O Problema de Corte e Empacotamento e Aplicações Industriais". In: XX CNMAC - Congresso Nacional de Matemática Aplicada e Computacional, Gramado - R.S., , p. 1-23.

BEASLEY, J. E. (1985), "An Exact Two-Dimensional Non-Guilhotine Cutting Tree Search Procedure". Operations Research vol. $33, \mathrm{n}^{0} 1,49-64$.

BAZARAA, M. S. , JARVIS, J. J. e SHERALI, H. D. (1990), "Linear Programming and Network Flows". W. H. Freeman and Company, John Wiley \& Sons.

BROWN, A. R. (1971), “Optimum Packing and Depletion”. Macdonald - London and American Elsevier Inc. - New York.

CHVÁTAL, V. (1980), "Linear Programming". W. H. Freeman and Company, New York.

CHRISTOFIDES, N. e WHITLOCK, C. (1977), "An Algorithm for Two-Dimensional Cutting Problems". Operations Research, vol. 25, n 1, 30-44. 
DYCKHOFF, H. (1981) "A New Linear Programming Aproach to the Cutting Stock Problem". Operations Research vol. $29, \mathrm{n}^{\circ} 6,1092-1104$.

DYCKHOFF, H. e FINKE, U. (1992) "Cutting and Packing in Production and Distribution - A Typology and Bibliography". Physica - Verlag, Heidelberg.

GILMORE, P. C. e GOMORY, R (1961) “A Linear Programming Aproach to the Cutting-Stock Problem". Operations Research 9, 848-859.

GILMORE, P. C. e GOMORY, R. (1963) “A Linear Programming Aproach to the Cutting-Stock Problem-Part II'. Operations Research 11, 863-888.

GILMORE, P. C. e GOMORY, R (1965) “Multi-stage Cutting Stock Problems of Two and More Dimensions". Operations Research 13, 94-120.

GLMORE, P. C. e GOMORY, R. (1966) "The Theory and Computation of Knapsack Functions". Operations Research vol. 14, $\mathrm{n}^{0} 6,977-1184$.

GRAMANI, M. C. N. (1997) "Problema de Corte Bidimensional Guilhotinado e Restrito em 2- Estágios". Dissertação de Mestrado, Instituto de Ciências Matemáticas de São Carlos, Universidade de São Paulo - São Carlos.

HAESSLER, R. W. (1980) “A Note on Computacional Modifications to the Gilmore-Gomory Cutting Stock Algorithm". Operational Research vol. 28, n 4, 1001-1005.

HERZ, J.C. (1972) “Recursive Computational Procedure for Two-Dimensional Stock Cutting". IBM Journal of Research and Development vol.16, $n^{\circ} 5,462-469$.

LUENBERGER, D. (1984), "Linear and Nonlinear Programming". Addinson-Wesley Publishing Company, Reading Massachusetts. 
MURTY, K. G. (1983), "Linear Programming". John Wiley \& Sons.

MORABITO, R. (1989) “Corte de Estoque Bidimensional'. Dissertação de Mestrado, Instituto de Ciências Matemáticas de São Carlos, Universidade de São Paulo - São Carlos.

MORABITO, R. (1992) "Uma Abordagem em Grafo-E-OU para o Problema do Empacotamento: Aplicação ao Carregamento de Paletes e Contêineres". Tese de Doutorado, Escola de Engenharia de São Carlos - USP.

MORABITO, R. N. et al. (1992) "An AND/OR-Graph Approach for Two-Dimensional Cutting Problems". European Journal of Operation Research vol.58, $n^{\circ} 2,263-271$.

MORABITO, R. e ARENALES, M. (1995) "Performance of two heuristics for solving large scale two-dimensional guilhotine cutting problems'. INFOR 33, 2, 145-155.

MORABITO, R. e ARENALES, M. (1996) "Staged and Constrained Two-Dimensional Guilhotine Cutting Problems: An AND/OR-graph Aproach". European Journal of Operational Research vol. 94, $n^{0} 3,548-560$.

SCHEITHAUER, G. e TERNO, J. (1995) "The Modified integer round-up property of the onedimensional cutting stock problem". European Journal of Operational Research 84, 562-571.

SCHEITHAUER, G. e TERNO, J. (1997) "Facet-defining inequalities for the cutting stock problem". Math-NM-10, Techniche Universität, Dresden.

SCHWERIN, P. e WÄSCHER, G. (1997) "The Bin-Packing Problem: A Problem Generator and Some Numerical Experiments with FFD Packing and MTP'. International Transactions in Operational Research vol. $4, \mathrm{n}^{\circ} 5 / 6,377-389$.

STADTLER, H. (1990) "A One-dimensional Cutting Stock Problem in the Aluminium Industry and its Solutions". European Journal of Operational Research 44, 209-223. 
WÄSCHER, G. e GAU, T. (1995) "CUTGEN1: A problem generator for the Standard Onedimensional Cutting Stock Problem". European Joumal of Operational Research 84, 572-579.

WÄSCHER, G. e GAU, T. (1996) "Heuristics for the Integer One-dimensional Cutting Stock Problem: a Computational Study". OR Spektrum 18, 131-144.

WOOLSEY, R. E. D. (1972) “A Candle to Saint Jude or Four Real World Applications of Integer Programming". Interfaces 2, 20-27. 


\section{Apêndice}

\section{Métodos de Resolução da Mochila Unidimensional}

O problema (3.7) como já mencionado, é conhecido na literatura como Problema da Mochila e deve ser resolvido a cada iteração simplex para determinar a coluna a entrar na base. Este problema modela a seguinte situação: dado um conjunto de objetos de peso e valor conhecidos, deseja-se carregar uma mochila com a combinação mais valiosa destes objetos, de maneira a não exceder o peso admissível da mochila.

A estrutura de dois métodos de resolução do Problema da Mochila são apresentados na próxima seção.

\section{Ap.1. Métodos de resolução}

O Problema da Mochila pode ser resolvido por uma seqüência de decisões, que consiste em incluir uma peça por vez, dentre os $m$ tipos de peças disponiveis. Como a mochila inicialmente está vazia, o espaço disponível inicial é $L$. Ao tomarmos a decisão de colocar a peça do tipo $i$ de comprimento $l_{i}, i=1,2, \ldots, m$, restará um espaço de $L-l_{i}$ a ser preenchido. Em seguida, este espaço resultante poderá ser preenchido, escolhendo-se uma peça do tipo $j$, restando um espaço de $L-l_{i}-l_{j}$. Este processo poderá ser repetido até que o espaço resultante não seja mais suficiente para a inclusão de qualquer outra peça. Quando todas as possibilidades de inclusão forem investigadas, teremos percorrido todas as possiveis soluções do Problema da Mochila. 
Para cada decisão a ser tomada uma seqüência de decisões já terá sido tomada. Com isto se considerarmos $X$ como sendo o espaço livre na mochila, o valor ótimo da mochila de tamanho $X$ será descrito pelo seguinte problema:

$$
\begin{gathered}
G(X)=\max g\left(y_{1}, y_{2}, \cdots, y_{m}\right)=\pi_{1} y_{1}+\pi_{2} y_{2}+\cdots+\pi_{m} y_{m} \\
\text { sujeito a: } l_{1} y_{1}+l_{2} y_{2}+\cdots+l_{m} y_{m} \leq X, \\
y_{i} \geq 0 \text { e inteiro, } i=1, \ldots, m .
\end{gathered}
$$

Observe que $\mathrm{G}(\mathrm{L})$ corresponde ao Problema da Mochila original.

\section{Ap.1.1 Programação Dinâmica (Gilmore e Gomory, 1961)}

Este método propõe uma fórmula recursiva para a resolução do Problema da Mochila, utilizando uma estratégia de percorrer todas as possiveis decisões, ou seja: a solução de um nó (veja fig. 1) representando um espaço livre $X$ é determinada assim que os nós sucessores: $X-l_{1}, X-l_{2}, \ldots, X-l_{m}$ estiverem resolvidos, isto é, se são conhecidos os valores de $G\left(X-l_{1}\right), G\left(X-l_{2}\right), \ldots, G\left(X-l_{m}\right)$, será possível determinar $G(X)$. A figura 1 ilustra esta forma de percorrer as soluções. A decisão tomada de incluir a peça $k$ deve ser guardada. Logo, podemos escrever:

$$
\begin{aligned}
& G(X)=\tilde{\pi}_{k}+G\left(X-l_{k}\right)=\max \left\{\pi_{i}+G\left(X-l_{i}\right), i=1, \ldots, m\right\} \\
& \text { decisão }(X)=k, \\
& X=l_{0}, l_{0}+1, \ldots, L \\
& \text { onde: } \\
& \qquad l_{0}=\min \left\{l_{i}, i=1, \ldots, m\right\} \\
& \qquad G(x)=0, \quad X<l_{0}
\end{aligned}
$$


Observe que esta fórmula recursiva exige que todos os estados do problema sejam resolvidos.

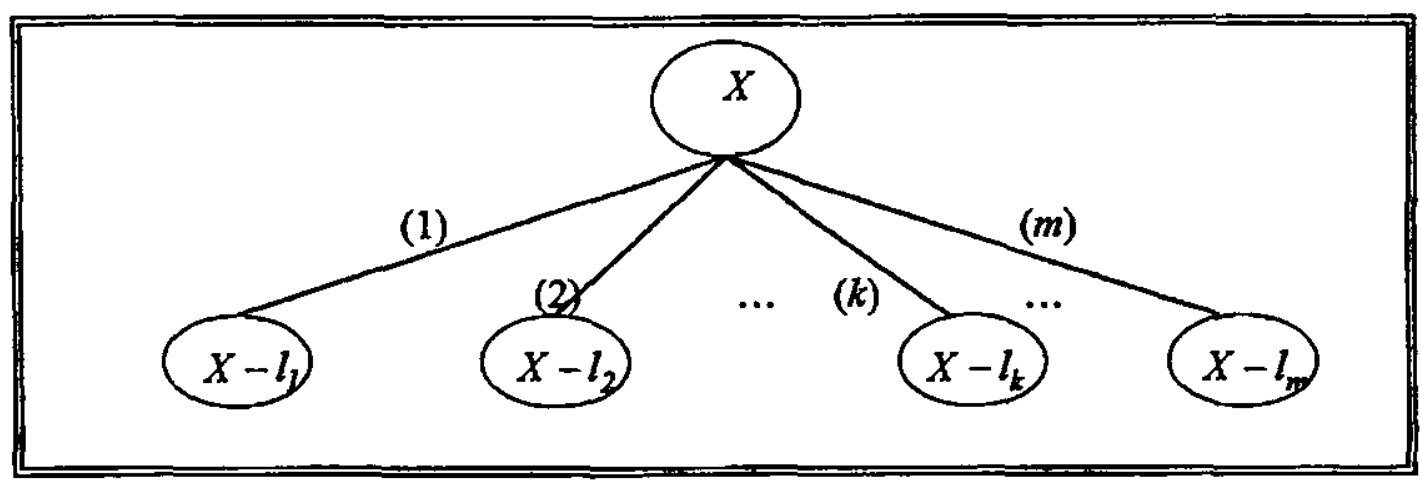

Figura Ap.1: Maneira como o método de Programação Dinâmica percorre as possíveis soluçōes do Problema da Mochila

\section{Ap. 1.2 Método de Enumeraçåo Implícita (Branch and Bound)}

\section{(Gilmore e Gomory, 1963)}

O método de enumeração implícita, implementado utilizando busca em profundidade primeiro, consiste em enumerar implicitamente todas as soluções do Problema da Mochila, ou seja, descartar soluções, com o uso de limitantes do problema, sem perder a otimalidade. Este método é importante, pois gerar explicitamente todas as possiveis soluções para o Problema da Mochila, para exemplos de tamanhos moderados, se torna um trabalho quase que impossível de ser resolvido computacionalmente.

O método de enumeração implícita para resolução do Problema da Mochila Irrestrito segue o seguinte algoritmo:

\section{Algoritmo}

Passo 1 : $\{$ Defina o problema segundo as variáveis mais valiosas\} 
Passo 2 : (Determine a solução inicial, utilizando busca em profundidade primeiro\}

Determine a solução $\mathbf{y}=\left(y_{1}, y_{2}, \ldots, y_{m}\right)$, tal que:

$$
\begin{aligned}
& y_{1}=\left\lfloor\frac{L}{l_{l}}\right\rfloor \\
& y_{k+1}=\left\lfloor\frac{L-\sum_{i=1}^{k} l_{i} y_{i}}{l_{k+1}}\right\rfloor, k=1, \ldots, m-1 .
\end{aligned}
$$

Passo 3: \{Avalie a solução corrente e armazene a mais valiosa \}

Determine: $g(\mathbf{y})=\sum_{i=1}^{m} \pi_{i} y_{i}$

Se $\underline{G}<g(y)$ (considerando inicialmente $\underline{G}=0$ ); então faça:

$$
\underline{G}=g(\mathbf{y})
$$

e guarde a solução correspondente:

$$
\underline{\mathbf{y}}=\mathbf{y}
$$

Passo 4: \{Teste a otimalidade e calcule o limitante superior\}

Determine $k$ o maior índice tal que: $y_{k} \neq 0$.

Se $\mathbf{y}=0$ então PARE, a melhor solução guardada em $\underline{y}$ é uma solução ótima.

Senāo, calcule: (se $k=m$, considere $\pi_{m+1}=0$ e $l_{m+1}=1$ )

$$
\bar{G}=\pi_{1} y_{1}+\pi_{2} y_{2}+\ldots+\pi_{k}\left(y_{k}-1\right)+\frac{\pi_{k+1}}{l_{k+1}}\left(L-l_{1} y_{1}-l_{2} y_{2}-\ldots-l_{k}\left(y_{k}-1\right)\right)
$$

Passo 5 : \{Backtracking\}

5.1 Retorno longo\}

Se $\bar{G} \leq \underline{G}$ faça $y_{k}=0$ e volte ao passo 4 . 
5.2 Retorno ao nó precedente e nova busca em profundidade\}

Se $\bar{G}>\underline{G}$ então faça $y_{k} \leftarrow y_{k}-1$ e defina a nova solução $y$ :

$$
y_{j+1}=\left\lfloor\frac{L-\sum_{i=l}^{j} l_{i}}{l_{j+1}}\right\rfloor, j=k, \cdots, m-1 .
$$

volte ao passo 3 .

Para resolver o Problema da Mochila Restrito, torna-se necessário considerar algumas modificaçס̃es no algoritmo acima, as quais serão citadas abaixo:

\section{Modificação 1:}

Uma primeira modificação deverá ser feita no passo 2, pois a solução inicial, para o caso irrestrito, é determinada alocando-se inicialmente na mochila o item mais valioso tantas vezes quanto couber e, a partir daí, verificando se ainda é possível alocar algum dos outros itens. Para o caso restrito, a solução inicial será determinada alocando na mochila o mínimo entre o que cabe do item $i$ e a sua demanda, ou seja:

$$
y_{i}=\min \left\{\left\lfloor\frac{X}{l_{i}}\right\rfloor, d_{i}\right\} \text { onde: } X=\text { espaço restante da mochila. Inicialmente, } X=L .
$$

Esta condição deverá ser considerada também no passo 5.2, quando uma nova solução y é determinada.

\section{Modificação 2:}

A segunda modificação deverá ocorrer no cálculo do limitante superior, no passo 4, pois as seguintes relações devem ser consideradas:

Seja: $\bar{L}=L-l_{l} y_{1}-\ldots-l_{k}\left(y_{k}-1\right)$; 
Determine $j$ tal que:

$$
\sum_{i=k+1}^{j-1} l_{i} d_{i} \leq \bar{L}
$$

$$
\sum_{i=1+1}^{j} l_{i} d_{i}>\bar{L}
$$

Agora, a solução do problema da mochila contínua restrita é:

$$
\begin{aligned}
& y_{i}=d_{i} \quad i=k+1, \ldots, j-1 \\
& y_{j}=\frac{\bar{L}-\sum_{i=k+1}^{j-1} l_{i} y_{i}}{l_{j}}
\end{aligned}
$$

Isto faz com que o limitante superior seja definido como:

$$
\bar{G}=\pi_{l} y_{1}+\ldots+\pi_{k}\left(y_{k}-1\right)+\pi_{k+1} y_{k+1}+\ldots+\pi_{j} y_{j}
$$

